\section{Global Proceedings Repository \\ American Research Foundation}

ISSN 2476-017X

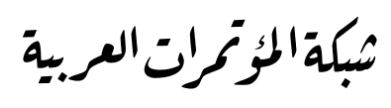

http://arab.kmshare.net/

Available online at http://proceedings.sriweb.org

Contemporary International Scientific Forum

for Educational, Social, Human, Administrative and Natural Sciences

"Present Vs Future Outlook"

الملتقى العلمي الدولي المعاصرللعلوم التربوية والاجتماعية والانسانية والادارية والطبيعية

"نظرة بين الحاضر والمستقبل"

30 - 31 31 3يسمبر 2019 - اسطنبول-تركيا

http://kmshare.net/isc2019/

\title{
أستخدم تقنية البلوكتشين في حفظ حقوق الملكية الفكرية
}

أ/عبد الله الحسن محمد السفري

جامعة الملك عبد العزيز

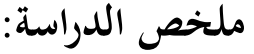

تناولت الدراسة موضوع استخدام تقنية البلوكتشين في حفظ حقوق الملكية الفكرية، وقد هدفت إلى التعرف على مقومات وأبعاد هذه التقنية في مجال حفظ حقوق الملكية الفكرية، وكذلك معرفة مدى تأثيرها في بعض المجالات الرئيسية المستخدمة في حفظ حقوق الملكية الفكرية، ومن ثم معرفة القيود والمعوقات الهيكلية لها في بجال حقوق الطبع والنشر للملكية الفكرية، ومناقشة الفرص والتحديات التي تواجه المؤسسات عند تطبيقها، واستخدمت الدراسة المنهج الوثائقي النظري، وتم جمع المعلومات من الكتب والمراجع والدراسات ذات العلاقة، وخلصت الدراسة من حيث التبع والاستقراء والمقارنة بين أراء المختصين إلى عدد من النتائج من أهمها: اهما تعتبر من احدث التقنيات واهمها، التي بدا استخدامها في بجال الملكية الفكرية ، حيث بدأت العديد من القطاعات تستكشف إمكانيات تلك التقنيات مع ظهور استخدامات ذكية جديدة، واهما تقنياً لها امكانيات كبيرة في هذا الجانب ـ ان تطبيقها في حفظ حقوق الملكية الفكرية من شانه ابراز استخدام نظام مكاتب الملكية الفكرية تكنولوجيا والبحث عن السجلات الموزعة في إنشاء سجلات ذكية للملكية الفكرية مثل تسجيل براءة 


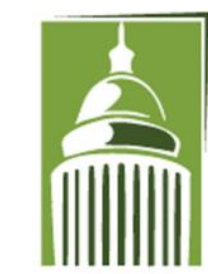

AR F
Global Proceedings Repository

American Research Foundation

ISSN 2476-017X

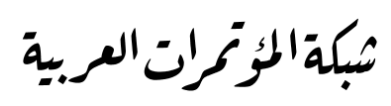

http://arab.kmshare.net/

Available online at http://proceedings.sriweb.org

الاختراع او الاسم التجاري او العلامة التجارية المحددة وهي عملياً أفضل من ادارة هذه السجلات تقليدياً، وأن من أهم مميزات استخدام تطبيقات البلوكتشين في حفظ حقوق الملكية الفكرية إن دفاتر الأستاذ الموزعة مفتوح المصدر يساهم بشكل فعال في تقليل الكلفة مقارنة بقواعد البيانات التقليدية. وتبين أن هناك عدد من المعوقات والتحديات التي تواجه تطبيقها في حفظ حقوق الملكية الفكرية ومن أهما البطء في معالجة المعلومات والبينات الوصفية بشكل كفئ وطريقة استدعاءها، حيث يتعذر احيانا معالجة المشكلات التقنية بالسرعة المطلوبة، وأيضا التبني الواسع للشبكة والتذبذب في أسعار العملات المشفرة وي كثير من الأحيان لا تتوافق مع الأطر القانونية في كثير من أشكالها وتصبح عدوة للسلطات.

\section{الإطار المنهجي للدراسة}

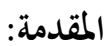

يعيش العالم اليوم في عصر ثورة المعلومات والاتصالات، واصبحت السرعة في اداء الخدمات هي السمة المميزة، وذهبت الكثير من الدول بعيدا وذلك بتطبيقها الخدمات الحكومية الالكترونية عبر مواقع تنشئها خصيصا، وفى المملكة العربية السعودية بدأت الدولة شيئا فشيئا ولوج نطاق الخدمات الالكترونية والسعي لتعميمها على كافة خدماتما المقدمة ومن ضمنها تكنلوجيا المعلومات عبر استخداماتما المختلفة، كما فعلت ذلك العديد من الدول حول العالم، ومن ضمن تكنلوجيا المعلومات المستخدمة ما يسمي بتقنية سلسة الكتل، وفي السياق فقد عرفت هذه الخدمات بخدمات الحكومة الالكترونية ومفهوما باها "قدرة القطاعات الحكومية المختلفة على توفير الخدمات الحكومية التقليدية للمواطنين وانجاز المعاملات عبر شبكة الانترنت بسرعة ودقة متناهية وبتكاليف وجهود أقل"(1)، وبالتالي فان استخدام تقنية البلوكتشين يتم عبر تقنيات الانترنت المختلفة.

وفي ذات السياق تعتبر تكنولوجيا المعلومات بأدواتا المتقدمة ذات أهمية كبيرة لمتطلبات العصر الحالي, حيث تعتبر مكمل حقيقي لعملية الحوكمة الالكترونية التي انتشرت في العالم، حيث انه لم يؤثر أي شيء على الحياة البشرية منذ الثورة الصناعية كما أثرت عليها تكنولوجيا المعلومات، حتى أصبحت لا غنى عنها في حياة الناس والمؤسسات والبلدان, ويشهد العالم تحولات تكنولوجية سريعة وتطورات متلاحقة في بجال الحواسيب والبرجيات ووسائل الاتصال, مما جعل الكم الهائل

1. الزهرانى، راشد بن سعيد، (2009م-1430هـ)، التعاملات الاككترونية الحكومية في المملكة العربية السعودية، مكتبة

الملك فهر الوطنية، الرياض، المملكة العربية السعودية. 


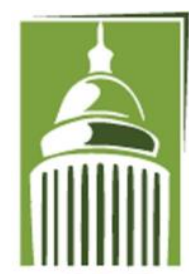

AR F
Global Proceedings Repository

American Research Foundation

ISSN 2476-017X

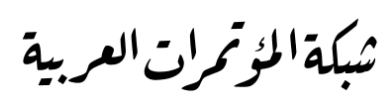

http://arab.kmshare.net/

Available online at http://proceedings.sriweb.org

من المعلومات تنمو وتتحرك بسهولة بين دول العالم، حيث اصبحت تكنولوجيا المعلومات أداة مهمة في مؤسسات الأعمال الحديثة ويتطلب من المؤسسات من جميع الأنواع والأحجام مواكبة هذا التقدم التقني الهائل إذا كان هدفها هو البقاء في بيئة تنافسية. في ذات السياق ونظراً للتطور الهائل والمتسارع الذي يشهده قطاع تكنولوجيا الاتصالات وتقنية المعلومات والتي باتت تلعب دوراً حيوياً ومباشر في شتى مناحي الحياة الاقتصادية والتنموية والاجتماعية والثقافية والتعليمية وغيرها من خلال مختلف الاستخدامات لتطبيقاما التي تشمل كذلك الجوانب الإدارية والخدمية وكل ما يتصل بشؤون الحياة فقد كان لزاماً على الحكومات في العالم التفكير في مواكبة التطور للاستفادة من كل هذه الإمكانات المتاحة في تطوير أدائها الحكومي على أكثر من صعيد(1)، وفي ذلك فقد دخل العالم حقبة متقدمة دون حدود تُلعب فيها تكنولوجيا المعلومات دور ركائز هذا التقدم، الذي أصبح سمة ميزة لهذا العصر ومع ثورة الإنترنت والمعلومات والذي جعل الانترنت جزءا من حياة البشر الذي ادى المى جعل العالم كقرية صغيرة يتفاعل فيها الاشخاص كما لو كانوا في بلد واحد.

ومع التقدم الكبير في مجال تكنولوجيا المعلومات ادى ذلك الى ظهور ما يسمى بالبلوك تشين (Block chain) حيث تعد هي الأحدث في سلسلة التقنيات الرقمية وذلك بسبب طبيعتها اللامركزية والأفقية الموزعة والمفتوحة المصدر، ومن المتوقع أن تتسبب في تغييرات جوهرية واسعة النطاق في كيفية تنظيم العلاقات الاجتماعية والاقتصادية والسياسية الحالية حيث ان تقنية البلوكتشين تعتبر احد الابتكارات القائمة على المصدر المفتوح والتي حدثت ثورة في الطريقة التي يتم هها تنفيذ المعاملات بين الأفراد والشركات وحتى الآلات، فهي تعد نموذج تنظيم جديد. وهنالك العديد من التعريفات لسلسة الكتل والتي تطرق لها الباحثين وقد عرفت باها "تقنية رقمية بتمع بين آليات التشفير وإدارة البيانات والشبكات والحوافز لدعم التحقق من المعاملات وتنفيذها وتسجيلها بين الأطراف، دفتر الأستاذ لتقنية البلوكتشين عبارة عن قائمة (سلسلة) للمجموعات من (الكتل) المعاملات، الأطراف التي تقترح المعاملة تقوم بإضافتها

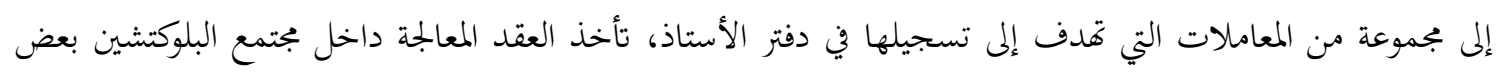
هذه المعاملات، والتحقق من سلامتها، وتسجيلها في كتل جديدة على دفتر الأستاذ، ويتم نسخ محتويات دفتر الأستاذ عبر العديد من عقد المعالجة الموزعة جغرافيا (2) .

1. المبيضين، صفوان(2011)، الحكومة الإكترونية النماذج والتطبيقات والتجارب الدولية. عمان: دار

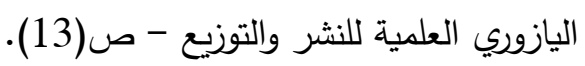

1. Daniel Conte de Leon, Antonius Q, and other. (2017).” Blockchain: properties and misconceptions", Asia Pacific Journal of Innovation and Entrepreneurship, Vol. 


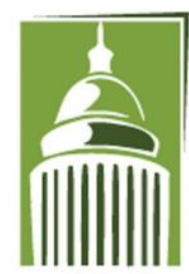

AR F
Global Proceedings Repository

American Research Foundation

ISSN 2476-017X

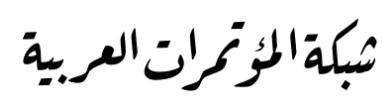

http://arab.kmshare.net/

Available online at http://proceedings.sriweb.org

اذن المدف من تقنية البلوكتشين هو خلق بيئة لامركية حيث لا يوجد طرف ثالث يتحكم في المعاملات والبيانات، فان تقنية البلوكتشين هو حل قاعدة البيانات الموزعة التي تحافظ على قائمة متزايدة باستمرار من سجلات البيانات التي يؤكدها عقد المشاركة فيها. فهو الحل اللامركزي الذي لا يتطلب أي طرف ثالث في الوسط. يتم مشاركة المعلومات حول كل معاملة مكتملة في البلوكتشين وهي متاحة لجميع العقد، وهذه الخاصية بجعل النظام أكثر شفافية من المعاملات المركزية التي تتضمن طرفًا ثالثًا، بالإضافة إلى ذلك، تكون جميع الاطراف في البلوكتشين بجهولة المصدر، مما يجعلها أكثر أمانًا للجهة المانحة لتأكيد المعاملات.

وفي سياق اخر متصل بموضوع هذه الدراسة والمتعلق بالملكية الفكرية ومنظمتها التي تتبع للأمم المتحدة والتي سميت بمنظمة الملكية الفكرية والتي تعني بحفظ حقوق المالكين لبراءات الاختراع او الافكار والثقافات المختلفة فقد "تم إصدار مجموعة جديدة من القوانين تسمى قوانين حقوق الملكية الفكرية لتوفير الحماية للمالكين تحت أسماء مختلفة مثل براءات الاختراع والتصاميم وحقوق النشر والعلامات التجارية المى غير ذلك فقد تم الاعتراف بحقوق الملكية الفكرية وموافقتها بشكل أساسي في جميع أنحاء العالم ويرجع ذلك للأسباب التالية توفير الحوافز والاعتراف الواجب للمخترعين, وضمان مكافأة مادية للملكية الفكرية, وضمان توافر المنتجات الأصلية وعند تدخل التكنولوجيا اصبح من الصعب التغلب على حفظ الافكار الى ان ظهرت تقنيات تقوم بحفظها على الوجه المطلوب ومنها تقنية البلوكتشين"(2). حيث تعد بدورها أكبر سجل رقمي موزع ومفتوح يسمح بنقل أصل الملكية من طرف إلى آخر في الوقت نفسه دون الحاجة إلى وسيط، مع تحقيق درجة عالية من الأمان لعملية التحويل في مواجهة محاولات الغش أو التلاعب وتشارك المعلومات بين جميع الافراد حول العالم وهذا يساعد في حفظ الملكية الفكرية حيث ان الملكية الفكرية تلعب دورا أساسيا في الحياة اليومية فإِها تعبر عن الحقوق الناشئة عن أي نشاط أو جهد فكري مما يؤدي إلى ابتكار في اي مجال من المجالات سواء كان ذلك صناعيا او علميا او غيرها من المجالات وأصبحت من مفردات العصر الحديث وعادة ما تسن الدول القوانين

11 No. 3. pp. 286-300. APJIE 11,3. Available at: https://doi.org/10.1108/APJIE12-2017-034 Permanent link to this document:

2. Hassan, S and P De Filippi The Expansion of Algorithmic Governance: From Code Is Law to Law Is Code, Field Actions Science Reports: The Journal of Field Actions Special, issue 17.(2017) 


\section{Global Proceedings Repository \\ American Research Foundation}

ISSN 2476-017X

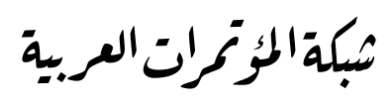

http://arab.kmshare.net/

Available online at http://proceedings.sriweb.org

والتشريعات لحماية الملكية الفكرية، وكذلك تبرم الدول الاتفاقيات الدولية لتنظيم وحماية هذه الحقوق المتعلقة بالملكية الفكرية

$$
\text { مشكلة الدوراسة: مشإلى التنمية وتشجيع التجارة المشروعة(1). }
$$

تنبع مشكلة الدراسة الحالية من اهمية حفظ حقوق الملكية الفكرية للأشخاص والكيانات المختلفة والتي تتولاها منظمة الملكية الفكرية العالمية التابعة للأمم المتحدة، حيث ان حقوق الملكية الفكرية هي أداة قوية لحماية المؤلفات، والوقت والمال والجها الذي يستثمه المخترع او المؤلف لحفظ ثمرة جهدة، وتكمن مشكلة الدراسة في الإجابة على التساؤل الرئيسي: ما هو أثر استخدام تقنية البلوكتشين في حفظ حقوق الملكية الفكرية؟ أهداف الدراسة: هذه الدراسة تمدف الى ما يلي:

1. التعرف على مقومات وأبعاد تقنية البلوكتشين التي تساعدها في حفظ حقوق الملكية الفكرية. 2. معرفة مدى تأثير تقنيةالبلوكتشين في بعض المجالات الرئيسية المستخدمة في حفظ حقوق الملكية الفكرية. 3. معرفة القيود والمعوقات الهيكلية لتقنية البلوكتشين في مجال حقوق الطبع والنشر ضمن الملكية الفكرية. 4. التعرف على الفرص والتحديات على التطبيقات التي تعمل على البلوكتشين من خلال بعض الخصائص الرئيسية ل ل مذه التقنية. 5. معرفة المشكلات التي تواجه المؤسسات عند تطبيق تقنية البلوكتشين لحفظ الملكية الفكرية. من خلال تساؤل الدراسة الرئيس تندرج تحته عدة تساؤلات وهي كالاتي: 1. ماهية ومقومات وأبعاد تقنية البلوكتشين التي تساعد في حفظ حقوق الملكية الفكرية؟ 2. ما مدى تأثير تقنية البلوكتشين في بعض المجالات الرئيسية المستخدمة في حفظ حقوق الملكية الفكرية؟ 3. ماهي القيود والمعوقات الميكلية لتقنية البلوكتشين في مجال حقوق الطبع والنشر ضمن الملكية الفكرية؟

1. كباشي، هنادي كمال ، حماية حقوق الملكية الفكرية ، مجلة العدل ، وزارة العدل ، مجلد 19،العدد 50، 2017، ص

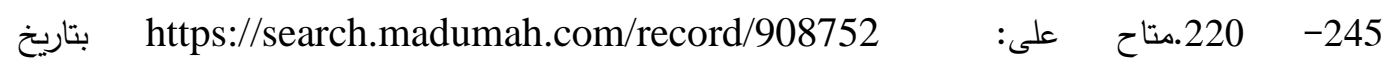




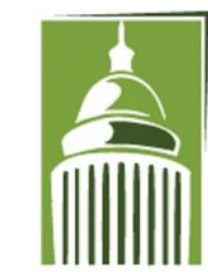

A R F
Global Proceedings Repository

American Research Foundation

ISSN 2476-017X

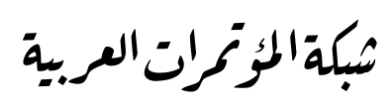

http://arab.kmshare.net/

Available online at http://proceedings.sriweb.org

4. ماهي الفرص والتحديات على التطبيقات التي تعمل على تقنية البلوكتشين من خلال بعض الخصائص الرئيسية

هذه التقنية؟

5. ما هي المشكلات التي تواجه المؤسسات عند تطبيق تقنية البلوكتشين لحفظ الملكية الفكرية؟

أهمية الدراسة:

تنبع أهمية الدراسة من أهمية بربجة تقنية البلوكتشين والتي تؤثر بشكل بكبير على حفظ الملكية الفكرية للأفراد والكيانات والجماعات المختلفة، حيث يتضح جليا اهتمام الحكومات والمنظمات في الدول المؤثرة في العالم تبنيها لتقنية البلوكتشين حيث أصبح الجميع في سباق مع الزمن للاستفادة من ما تقدمة من حلول، ولقد قدمت دعما قوياً، وكذألك وفرت حلول الأمن والثقة وقللت من تكاليف الحماية ووفرت شفافية أعلى والغت دور الوسيط، على الرغم من ان هذه التقنية فتية ولم تنضج بعد الا اهما تعد طفرة تتشعب منها حلول لمشكلات قديمة، ومن هنا تتضح أهمية هذه الدراسة في سعيها الى تحليل وشرح ابعاد تقنية تسهم وبشكل فاعل في الحفاظ على الملكية الفكرية وأهمية البلوكتشين ودوره المتوقع في حفظ الملكية الفكرية للأفراد والكيانات المختلفة، ومن هذا المنطلق تفرز الدراسة الحالية اهميتين هما: علمية (نظرية) وأهمية عملية (تطبيقية) كما يلي:

1. الأهمية العلمية (النظرية): وتتمثل في تقديم فائدة علمية أكاديمية بما يتوقع أن تضيفه نتائجها لمزيد من الاهتمام بإدارة المعلومات، وزيادة في أدبيات البحث العلمي، ويوجد لهذه الدراسة أهمية أخرى من الناحية العلمية أيضا تتمثل في الوصول إلى إطار نظري لبناء أساس متين لإدارة المعلومات والتعرف على البرامج الخدمية مثل برنامج تقنية البلوكتشين، ومما يزيد من

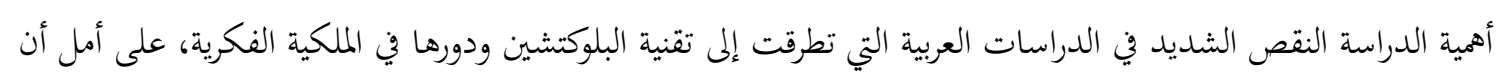
تسهم هذه الدراسة في سد الفجوة في المواضيع المشاهمة، لما قد تشكله نتائج هذه الدراسة من حافز قوي للباحثين للقيام بدراسات أخرى مكملة لهذه الدراسة.

2. الأهمية العملية (التطبيقية): حيث إنه من المتوقع أن تساعد نتائج هذه الدراسة المهتمين والمعنيين بالأمر للتزود ببعض النتائج والتوصيات التي قد تثرى رؤاهم مما يساعدهم لاتخاذ القرارات المناسبة كما تكمن اهميتها المتوقعة في ابراز بعض التوصيات

$$
\text { العملية التي قد تساعد ذوي الاختصاص في عملهم. }
$$

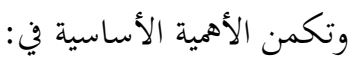

$$
\text { 1. أن موضوع الدراسة يعتبر بحد ذاته من المواضيع التي تستحق الدراسة. }
$$


Global Proceedings Repository

American Research Foundation

ISSN 2476-017X

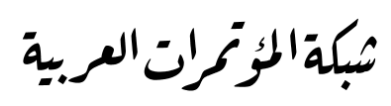

http://arab.kmshare.net/

Available online at http://proceedings.sriweb.org

$$
\text { 2. أثراء المحتوى العربي. }
$$

3. أن حقوق الملكية الفكرية تشكل هاجس لدى الكثير من المؤلفين والمبتكرين والشعراء وغيره.

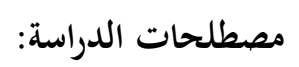

- تقنية البلوكتشين: هي تقنية حديثة تسهم في حفظ الحقوق والملكيات. وقد تم ابتكار "تقنية البلوكتشين block chain

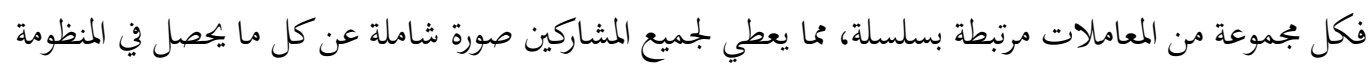

بأكملها. (1)

- - الملكية الفكرية: هي كل تلك الحقائق التي ترد على اشياء معنوية من ناتج الفكر، مثل حق

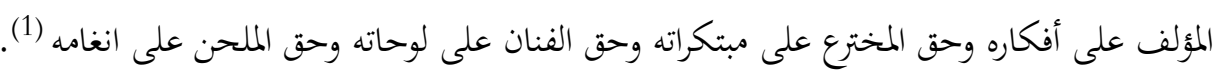
منهج الدراسة: إن أي دراسة تحتاج إلى منهج يكون الوسيلة التي تحدد للباحث مجالات البحث كي تسهل له عملية الإجابة عن

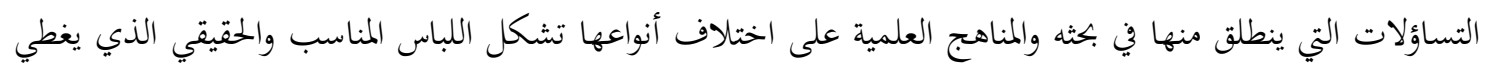

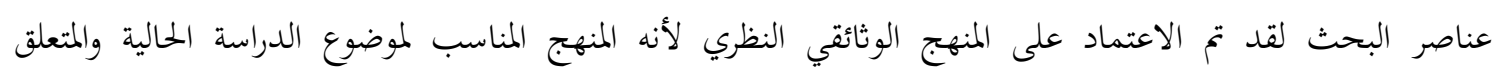
باستخدامات تقنية البلوكتشين وأثرها على الملكية الفكرية من خلال تحليل الدئل الدراسات والكتابات نظريا.

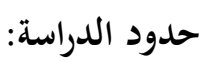

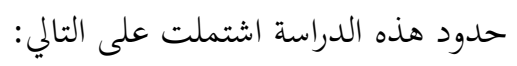

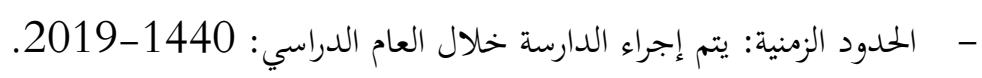
- - الحدود الموضوعية: تقنية البلوكتشين وأثرها على الملكية الفكرية.

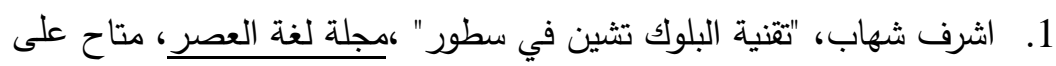
2018/11/17) بتاريخ http://ahram.org.eg/news/87647.aspx

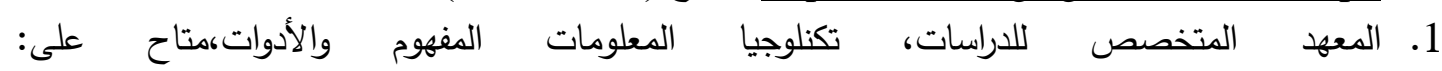
http://qu.edu.iq/el/plagingfile.php/87045/mod-resuoce-content/0 2. قاسم، حشت، (2007م)، مذل لدراسة المكتبات وعلم المعلومات، الطبعه الثانية، القاهرة: دار غريب، ص 6. 


\section{Global Proceedings Repository \\ American Research Foundation}

ISSN 2476-017X

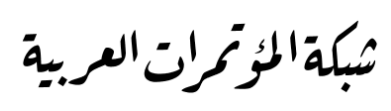

http://arab.kmshare.net/

Available online at http://proceedings.sriweb.org

\section{الإطار النظري/ النطبيقي للدراسة}

في هذا الفصل الثاني والذي يهوي على الإطار النظري للدراسة والحديث فيه من خلال ثلاث مباحث اولمم ماهيه تقنية

البلوكتشين وخصائصها ومميزاتا، ثم المبحث الثاني يتحدث عن الجوانب التي يمكن تطبيقها في حفظ حقوق الملكية الفكرية، أما المبحث الثالث للدراسة يشمل التحديات والمعوقات التي تواجهها ، ومما لاشك فيه ان تكنلوجيا المعلومات والمعرفة اصبح الحصول عليها وامتلاكها الشغل الشاغل للكثير من الجهات، حيث زاد الاهتمام بها والاعتماد عليها في الكثير من القطاعات الانتاجية او الخدمية، وبتطور وسائل الاتصال والمعلوماتية ودخول شبكات الانترنت ضمن منظومة متكاملة اصبح العالم كله يعتمد على تكنلوجيا المعلومات، ووسائل الاتصالات، وشبكات الانترنت، لتكمل بعضها في منظومه هي اقل ما توصف باغها نموذج التقدم والتطور. وأدت الزيادة الهائلة في كمية تكنلوجيا المعلومات المتوافرة المى خلق ضرورة ملحة لوضع نظم متكاملة لهذه التكنلوجيا تستعمل فيها أساليب جديدة وحديثة قادرة على التعامل مع أحدث الأجهزة التقنية الحديثة القادرة على معالجة البيانات وخزن واسترجاع حجم هائل من المعلومات"(1). وعليه فقد تنبهت الدول المتقدمة المى أهمية امتلاك مواقع الكترونية تسعى مهى من خلالما الم تقديم الخدمات المختلفة للمستفيدين الكترونيا وبشكل يحقق لما النجاح ويقلل من كلف الوقت والجهه المبذول فضلا عن تحفيض الكلف المادية للمعاملات بالنسبة للحكومات والمواطنين على حد سواء ومنها تقنية البلوكتشين. لقد تبنت معظم الحكومات ضمن استراتيجياتا وأهدافها مفهوم الحكومة الالكترونية كواحدة من أهم الوسائل والأدوات التي تسهم في تحقيق النجاح والفاعلية في أدائها لأعماها وبذلت في سبيل ذلك جهودا عديدة وجبارة فضلا عن تحمل موازناها لكلف مادية عالية لتوفير البنية التحتية الملائمة. ظهرت في السنوات الأخيرة مفاهيم جديدة فرضت علينا نتيجة للتقدم والتطور التكنولوجي، مثل مفهومي البيانات والمعلومات، وهذه المفاهيم هي التي أضفت صبغة جديدة على مفهوم

1. الثلبي، فراس سليمان والخوالدة، رياض عبد الله. ( د ت) دور الحكومة الالكترونية في تعزيز الفاعلية التظيمية دراسة حالة وزارة المالية الاردنية، دراسة مقدمه الى كلية عمان الجامعية، عمان: جامعه البلقاء 


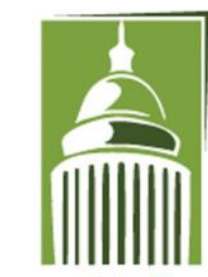

AR F
Global Proceedings Repository

American Research Foundation

ISSN 2476-017X

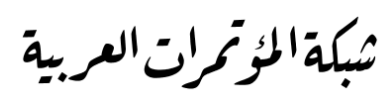

http://arab.kmshare.net/

Available online at http://proceedings.sriweb.org

المعرفة ومفهوم المعرفة ليس بالأمر الجديد بالطبع فالمعرفة رافقت الإنسان منذ أن تفتح وعيه وارتقت معه وبالتالي هي تعتمد على المعلومات ويمكننا التعرف على المعلومات وانظمتها باعتبار ان نظام تقنية البلوكتشين يعتمد على تلك المعلومات ومن بعدها يعتمد على شبكة الانترنت وانظمة وتقنية المعلوماتية.

\section{المعاهدات الدولية المهتمة بمجال الملكية الفكرية:}

تحدد (نديم ،11 • ب إ) المعاهدات والمبادرات الدولية المهتمة بمجال الملكية الفكرية: تعد قوانين حق المؤلف أحد الركائز التي قامت عليها النهضــة الحضــارية والثقافية الحالية. ذلك اها اقرت حقوق لكل مؤلف على مصــفة ورتبت حماية لها، وانطلقا من أهمية الإبداع والابتكار وحمايته على الصـعيد الدولي متمثلا في إبرام اتفاقية " بيرن " لحماية المصـنفات الأدبية والفنية في بـ18م، ومازال التطور التشريعي على المستوى المحلي والإقليمي والعالمي مستمرا. الا ان أحدث هذه الاتفاقيات هي اتفاقية الجوانب المتصلة بالتجارة من حقوق الملكية الفكرية (تربس) والتي تم ابرامها عام ؟9 9 ام، واهتمت بحماية المصــنفات الرقمية مثل برامج الحاســـوب وقواعد المعلومات. يرجع تاريخ حقوق الملكية

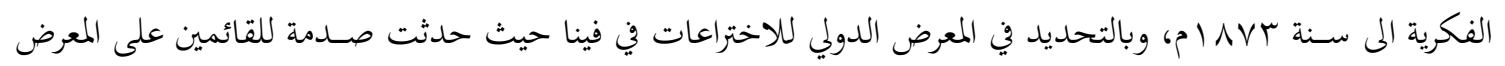
وللجمهور عندما امتنع عدد كبير من المخترعين الأجانب المشـــاركة، وذلك خشـــية من ان تتعرض أفكارهم للنهب والاسـتغلال التجاري في دول أخرى، لقد أظهرت هذه المقاطعة الحاجة الماسـة الى توفير الحماية الدولية لبراءات الاختراع والملكية الفكرية بوجه عام.

الامر الذي نتج عنة انبثاق اول معاهدة دولية مهمة ترمي المى منح مواطني بلد معين حق حماية أعمالمم الفكرية في

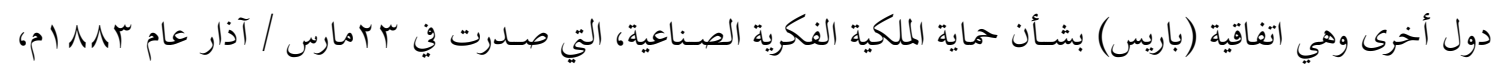
ودخلت حيز التنفيذ في العالم التالي، وكانت هذه الاتفاقية بجرد البداية التي توالت بعدها الاتفاقيات على المســتوى الدولي من اجل حماية الملكية الفكرية في شتى صورها (المصنفات الأدبية والفنية... الخ). وفي عام 1/1 ام دخل مفهوم حق المؤلف الى السـاحة الدولية بفضـل اتفاقية "برن" بشـأن حماية المصـفات الأدبية والفنية. وتتولى إدارة المعاهدتين منظمة دولية مكلفة بأدرتا، بإقرار من كل الدول الأعضـاء في الأمم المتحدة بداء من 17 ديسمبر/كانون الأول ع ا9 ام، وهي المنظمة العالمية للملكية الفكرية الويبو (Wipo).

ثم فوجئت الدول الأعضاء في مفاوضات اتفاقيات ( ألجأت ) بورقة مقدمة من الشركات العملاقة متعددة الجنسيات الى سـكرتارية" ألجأت " في جنيف في يونيو 911 ام ، بخصوص تضمين اتفاقية ألجأت اتفاقية خاصسة بما يسمى وايبو ( 


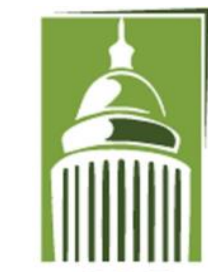

AR F
Global Proceedings Repository

American Research Foundation

ISSN 2476-017X

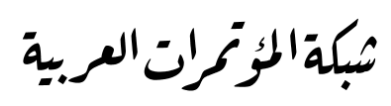

http://arab.kmshare.net/

Available online at http://proceedings.sriweb.org

حقوق الملكية الفكرية المرتبطة بالتجارة ) والجدير بالذكر ان ذلك قد تم من وراء منظمة الوايبوس Wipo وبالفعل صـدرت اتفاقيات ( ألجأت ) متضـمنة اتفاقية للحقوق الملكية الفكرية المرتبطة بالتجارة ، والتي يطلق عليها اختصـار اتفاقية تريبس ( (Trips بالأعمال التي يتم تداولا عبر الانترنت وضمان إدارة المعلومات المتناقلة عبر تلك الرسائل. مراحل التطور في سن التشريعات لمعالجة حقوق الملكية الفكرية:

يتبين ان هناك ضـرورة ملحة لسـن تشـريعات وقوانين جديدة لتواكب التطور السريع للإنترنت وبالتالي حفظ حقوق التأليف والنشر. في عام 991 امُّان عام مواجهه التحديات الجلديدة سواء أكان مالكي المعلومات ام مستهلكيها حيث ان قوانين حقوق التأليف التقليدية لا تغطي جوانب استخدامات الإنترنت والحصـول على المعلومات من المصـادر الرقمية والحفاظ على حق المبدعين في إبداعاقم من خلال الأنظمة والقوانين الجديدة مثل قانون الألفية الرقمية DMCA. ومعاهدات الملكية الفكرية Wipo لحفظ حقوق النشر والتأليف. واتضح ان قانون حقوق التأليف يتناسب مع الأعمال التقليدية كالكتب والمواد المطبوعة واما بالنسبة للأعمال الرقمية والحســابات فهو غير كاف، حيث يتم انتهاك حقوق المؤلف في كثير من الاســتخدامات على الإنترنت. من خلال اسـتعراض التشـريعات الوطنية الخاصـة بحقوق التأليف وتوجهاتها الحلديثة في العصـر الرقمي في المملكة العربية السـعودية، يلاحظ تميزها في حماية حقوق الملكية الفكرية عن غيرة من قوانين الدول العربية بصــياغة منفردة بتعلك واحداً من أكثر الأنظمة والقوانين التصاقا بمسالة الهوية الإسلامية التي تميز الأنظمة السعودية. لقد صـدر اول نظام للمطبوعات بالمرسوم

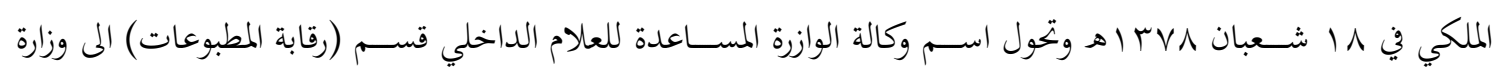
المساعدة للإعلام الداخلي، وينقسم الإعلام الداخلي تنظيميا الى: - (2) أ- المديرية العامة للمطبوعات. وتتولى مهمه رقابة كافة أوعية المعلومات الإعلامية وتطبيق نظام المطبوعات والنشـــــــائحة التنفيذ وإصــــار التراخيص الإعلامية لممارسة الأنشطة الإعلامية المختلفة. ب- الإدارة العامة لحقوق المؤلف. 


\section{Global Proceedings Repository \\ American Research Foundation}

ISSN 2476-017X

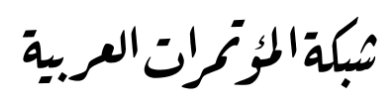

http://arab.kmshare.net/

Available online at http://proceedings.sriweb.org

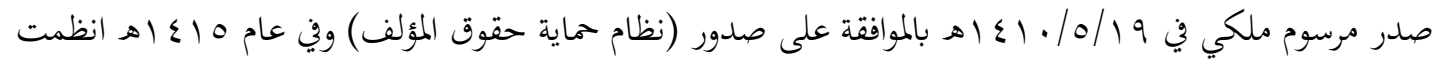
المملكة الى الاتفاقية العالمية لحقوق المؤلف. كما عملت الوزارة على الاهتمام بحماية حقوق التأليف ورفع مستوى الإدارة الى إدارة عامة.

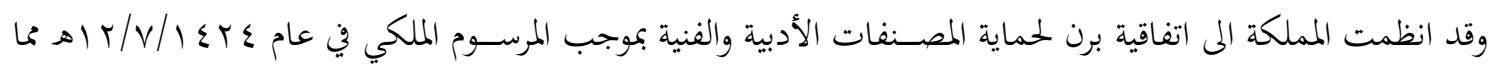
عاف من مسؤوليات ومهمات هذه الإدارة في مكافحة أعمال القرصنة على المصنفات الفكرية: كما أصسـبحت الإدارة معنية بتنفيذ اتفاقية الجوانب التجارية المتصــلة بالملكية الفكرية تريبس Trips وهي احدى اتفاقيات منظمة التجارة العالمية بعد انضمام المملكة للمنظمة في فاية عام ب بـ اهـ. في المملكة العربية السعودية ثلاث جهات مختلفة لحماية الحقوق الفكرية تم ضمها جميعا الى الميئة السعودية للملكية الفكرية وهي كالاتي: 1- إ حقوق المؤلف والناشر وتتتبع وزارة الإعلام r- ( بقوق العلامات التجارية تتبع وزارة التجارة r- حقوق المخترعات والمبتكرات تتبع مدي الملك عبد العزيز للعلوم والتقنية.1

وفي 1438/06/26هـ أنشئت الهيئة السعودية للملكية الفكرية بموجب قرار وزاري رقم 410.وتعد بوابة واحدة لتسهيل تسـجيل حقوق الملكية الفكرية وإصـــار التراخيص ومنح وثائق الحماية وانفاذها وتوفير المعلومات المتعلقة بحقوق الملكية الفكرية واتاحتها للجمهور، وكذلك تمثيل المملكة في المنظمات الدولية والإقليمية ذات العلاقة بحقوق الملكية الفكريه.0 المبحث الاول/ تقنية البلوكتشين: نشأة تقنية البلوكتشين: هي التقنية والهيكل الأساسي لعملة البتكوين، العملة المشفرة التي أحدثت ضجيج في جميع الأوساط سوى كانت السياسية والاقتصادية والاجتماعية وكذلك الأكاديمية منذ تاريخ نشر الورقة البيضاء من قبل المخترع الغامض لها الذي اطلق على نفسة اسم سأتوشى ناكموتو في عام (2008م) الى الوقت الحالي، ان فكرة وجود نظام الأموال الرقمية المستقلة عن سلطة

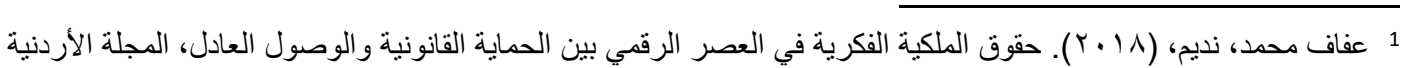

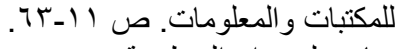
متاح على: دار المنظومة. 


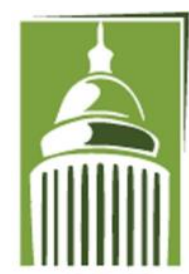

AR F
Global Proceedings Repository

American Research Foundation

ISSN 2476-017X

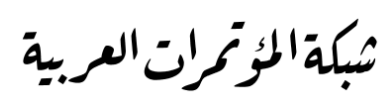

http://arab.kmshare.net/

Available online at http://proceedings.sriweb.org

الدولة هو هدف استراتيجي لمجموعة من الأشخاص او منظمة يطلقون على أنفسهم (المشفرون الانريك') او (علماء الإنترنت)، لقد كانت تتم مناقشة كيف تعمل العملة المشفرة بتكوين من منظور مالي فقط، الا ان الايدولوجية او الفرضية الهيكلية لهذه التقنية لها جذور سياسية قديمة ولما بعد فلسفي اقرب ماتكون المى الليبروتارية ويصفها مناهضيها فوضوية لاسلطوية يسارية متطرفة "راديكالية"(1).

في عام (1990م) تم طرح مخطط العملة المشفرة على قائمة بريد (Cypherpunks) وهي قائمة بريد لمجموعة غير رسمية تمدف الى تحقيق الخصوصية من خلال الاستخدام الاستباقي للتشفير، يتبنا الانريك بشكل عام فرضية ان التشفير فن، وعلم تشفير المعلومات يمكن استخدامه لإحداث تغيير سياسي واجتماعي إيجابي وبالتالي يمكن ان تؤدي الى اليوتوبيا. يقول (Tim May) وهو احد مؤسسي القائمة البريدية (Cypherpunk)، لقد استخدمت القائمة لتعزيز (تشفير الانريك او الاسلطوية) باستخدام التشفير لتسهيل الطلب التعاقدي الخاص، وتعزيز الحرية الفردية، وتفكيك الدولة القومية، وعلى حسب قولة كانت الحكومات وتواصل قمع التشفير الشعبي(2). وبعد ذلك أوضح بيان المشفرون الانريك في عام (1988م) التالي: " ستحاول الدولة إبطاء او وقف انتشار هذه التكنولوجيا متحججه بمخاوف على الأمن القومي او استخدام التكنولوجيا من قبل بتحار المخدرات والمتهربين من الضرائب، وكذلك مخاوف من تفكيك المجتمع، وبطبيعة الحال كثير من هذه المخاوف ستكون صحيحة وسوف يسمح التشفير الانريكي بتداول الأسرار الوطنية بحرية "ويعد موقع ويكالكس انتصار للانريك وخير دليل "وتسمح بتداول المواد غير المشروعة والمسروقة، وذلك لأنه اذا وجد سوق محوسب مجهول سيكون جذاب للأعمال غير المشروعة من ابتزاز واغتيالات وتحرب عن الضرائب، سوف ينشط استخدام شبكة المشفرون (Crypto Net) من قبل عناصر إجرامية ولكن هذا لن يوقف

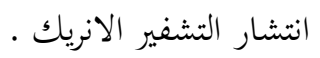

حين ظهرت رسالة (Tim May) الى المجتمع الانريكي او وطن مستخدمين الانترنت بداء عليهم القلق واتضح بالفعل ان الحكومات الإقليمية ستحاول تقييد الحريات على حدود الالكترونية الجديدة وتحويلها المى إدارة للمراقبة (3). واعتبر مجتمع الانريكي ان المقاومة من خلال التشفير ضرورية حتى يتمكنو من الهروب من التهديد الذي يلوح في الأفق من جانب

1. See Wei Dai, supra note 14; Wei Dai, BITCOINWIKI, https://perma.cc/NLE2YM3Q (last visited Oct. 22, 2017); Wei Dai, THE BOOK OF BITCOIN, https://perma.cc/A935-B8RF (last visited APRIL. 22, 2019

1. See Wei Dai, supra note 14; Wei Dai, BITCOINWIKI, N,https://perma.cc/A935-B8RF

2. See Wei Dai, op.cit. 


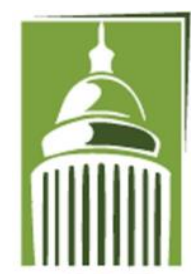

AR F
Global Proceedings Repository

American Research Foundation

ISSN 2476-017X

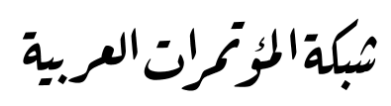

http://arab.kmshare.net/

Available online at http://proceedings.sriweb.org

الحكومة. في V نوفمبر 1998 قام شخص يطلق على نفسه (Wei Dai) بإرسال رسالة الى (Cypherpunk) والتي تتعلق ببرتوكول جديد لتشفير الشبكة لكنة تضمن أيضا رابط لمقال قصير على موقع الويب الخاص به، والذي بداء فيه بقول: انا مفتون بالتشفير الانريكي ل Tim May))الذي على عكس فرضية المجتمعات المرتبطة تقليديا بكلمة الفوضى في الفوضى المشفرة لأيتم تدمير الحكومة مؤقتا ولكنة يمضرها بشكل دائم ويجعلها غير ضرورية دائما. بداية من هذا المنظور الايدولوجي او الفلسفي عزز Wei Dai الرؤية المشبوه من خلال وضع تقنية من شائنها ان تخلق نظاما لتبادل القيم المالية يطلق علية (B-Many) حيث تضمن ان جميع المعاملات تم التحقق منها من قبل شبكة لامركزية تحمل دفتر الحساب او الأستاذ الموثوق والأمن دايما، ولن يرمز دفتر الحساب المى القيمة المُفظ بها في شكل اخر ولكنة سيشكل تلك القيمة بالفعل، وكذلك سيتم انشاء أموال جديدة بشكل أساسي. لم تنجح هذه التقنية لأسباب لن نتطرق لها الان (1). بعد عشر سنوات، في عام (2008م) ارسل شخص او منظمة اطلق على نفسة سأتوشى ناكموتو الى عدة قوائم بريدية ورقة بيضاء مكونه من (9) صفحات تصف تطبيق Wei Dai) مع إضافة مزيد من التعديلات والتفاصيل على السمات الأساسية لاقتراحه الخاص بالمال واطلق على هذا التطبيق اسم بتكوين نظام النقد نظير الى نظير ونشر على موقع الويب وتستشهد حاشية الورقة الأولى الخاصة به برسالة (Wai Dai) لعام (1998م)، ان كل من سأتوشى ناكموتو شخصيات غامضة، حيث أشار ملف تعريف المستخدم الأصلي الى اهم عاشوا في اليابان، ومع ذلك كان (Wai Dai) عنوان بريدهم الالكتروني من مزود بريد بجاني في المانيا. على الرغم من المحاولات العديدة للكشف عن شخصية سأتوشى ناكموتو الا أنه يبدو اهما ستظل لغزا.

في عام (2009م) تم إطلاق اول عمله رقمية وسماها بتكوين عملة التكوين بالإضافة الى العديد من عملات البتكوين المبكرة (2). مما يجعله مرشحا محتمل في تقييمات أثرياء العالم في التبادل الأخير. لعدة سنوات كان هناك اهتمام كبير في بتكوين من قبل المنظمات الاعلام والحكومات والمقالات الأكاديمية في العلوم المالية والاقتصادية وعلم الاجتماع والقانون وكان تركيزها الأكبر على التحديات التي تمثلها العملة المشفرة على السياسة الوطنية والسياسة الضريبية وكيفية السيطرة على لي لئل هذه العملات. لعل من أبرز الأحداث التي ساعدت في التبني الكبير للعملة المشفرة بتكوين يرجع الى الأزمة العالمية لعام

1. Gervais Daniel, João Pedro,\& Quintais Balázs Bodó. (2018), "Blockchain and smart contracts: the missing link in copyright licensing?", Vol. 26, Issue 4.

2. Nakamoto,S.(2008),"Bitcoin:a peer-to-peer electronic cash system “,available at: https://bitcoin.org/bitcoin .pdf 


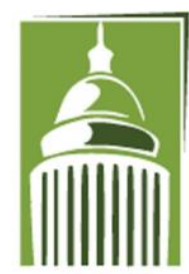

AR F
Global Proceedings Repository

American Research Foundation

ISSN 2476-017X

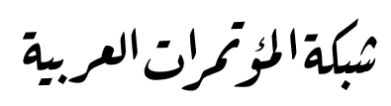

http://arab.kmshare.net/

Available online at http://proceedings.sriweb.org

(2008م) (أزمة الرهن العقاري) على الرغم من ان جذورها تسبق الأزمة بفترة طويلة. الا انه تردد صدى الاهتمام بها بعد المناقشات التي دارت حول طبيعة الأموال والبنوك التي تسبت في الأزمة على الرغم من تنوعها السياسي. في عام (2015م) ظهرت العقود الذكية من خلال تطبيق (Ethereum) بداء صانعو السياسة والاقتصاديون والأكاديميون والقانونيون في ملاحظة الإمكانات الهائلة التي تمتلكها تقنية البلوكتشين المبنية على عملة البتكوين، واتضح اها أكثر اثارة للاهتمام من خلال الخصائص المكونة لدفتر الأستاذ الموزع وكيفية توفير الشفافية وتنفيذ المعاملات مع عدم وجود طرف ثالث او وسطاء موثوق بكم ومن هنا بداءات النظرة تتحول وتفصل وتفرق بين عملة بتكوين وتقنية تقنية البلوكتشين. وكما أشار تقرير المملكة المتحدة حول استخدامات تقنية البلوكتشين في مذكرات الحكومة " اها تقنية يمكن ان تساعد الحكومات على جمع الضرائب وإصدار جوازات السفر وتسجيل الأراضي والملكيات وضمان سلامة سجلات وخدمات الحكومة عموما وتسجيل سندات الملكية او غيرها "(1). تم استخدام نظام البلوك تشن لأول مرة في عام (2008م)، أي منذ أكر من عشر سنوات، وذلك باعتباره المنصة الرئيسية لعملة البتكوين الافتراضية، والتي استمدت قوقا من ثقة المتعاملون فيها، على الأقل حتى الآن، بفضل ذلك النظام، ويخلط كثر من الناس بين البتكوين والبلوك تشن، ويعتبروها كياناً واحداً، على الرغم من عدم صحة هذا، فالبلوك تشن هو العمود الفقري لعملة البتكوين، وهو ما يميزها عن غيرها من العمليات الافتراضية الأخرى، ومثلا تم استخدامه في تحويل العمات الافتراضية، يمكن أيضاً استخدامه في العديد من التطبيقات الأخرى، مثل تسجيل الممتلكات وتوثيق المعاملات وأعمال الوساطة(2). مفهوم تقنية البلوكتشين: يعرفها (BIKRAMADITAYA) واخرون من منظور وظيفي(الاعمال) ومنظور فني (تقني) كما يلي (3):

1. Jake Goldenfein and Dan Hunter, (2017). Blockchains, Orphan Works, and the Public Domain, Columbia Journal of Law \& the Arts, Vol. 41, No. 1, 2017, P. p43. Posted: 11 Dec 2017, Available At: https://ssrn.com/abstract=3083153 .

2. An Introduction to Bitcoin and Blockchain Technology, KAYE Scholar, February 2016, accessible at: http://bit.ly/2o- IoDnV

3. Bikramaditya SinghalGautam DhamejaPriyansu Sekhar Panda,(2018).Beginning Blockchain A Beginner's Guide to Building Blockchain,, Apress Media LLC , California , Berkeley, CA,PAGE 


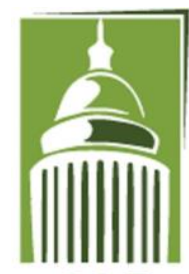

AR F
Global Proceedings Repository

American Research Foundation

ISSN 2476-017X

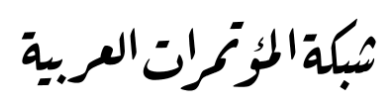

http://arab.kmshare.net/

Available online at http://proceedings.sriweb.org

1. تقنية البلوكتشين هي نظام من سجلات المعاملات ذات القيمة (وليس المال فقط) يتم التبادل فيه بطريقة نظير الى نظير، مما يعني انه لا توجد حاجة الى وسيط كالبنوك او أطرف ثالث موثوق بها، وما يميزها اها تمنع الازدواجية في الدفع. مع ملاحظة ان المعاملة والتسوية او الوعاء ليست كيانات مختلفة في إعداد تقنية البلوكتشين، حيث المعاملة متماثلة مع التسوية، مثال على ذلك: إذا قام أحدهم بدفع · إ ريال فانة لا يملكها بعد ذلك، يتم نقلها جسديا الى المستلم لما. 2.

تقنية البلوكتشين هي نظام نظير الى نظير من المعاملات ذات القيمة مع عدم وجود طرف ثالث. هي نظام مشترك لامركزي، ودفتر الأستاذ مفتوح المصدر ويتم نسخه عبر عدد كبير من العقد. ملاحظة توجد أنواع حديثة من دفتر الأستاذ الخاص سنتحدث عن ذلك لاحقا. قاعدة بيانات دفتر الأستاذ هي قاعدة بيانات الحاقية فقط، ما يعني انه لأيمكن الإضافة اليها او تغيرها حيث ما

$$
\text { يدخل من كتل هو دائم. }
$$

لا توجد حاجه المى أطراف ثالثة موثوقة للخدمة كوسيط ضامن للتحقق والتامين وتسوية الصفقة، حيث توفر

$$
\text { آليات التوافق نفس دور الوسيط مع شفافية أكبر. }
$$

لقد تم تصميم (TCP/IP) لتحقيق وفتح النظام، وتم تصميم تقنية البلوكتشين لتمكين اللامركزية الحقيقية، لقد جعل سأتوشى ناكموتو اليتكوين مفتوح المصدر ما يعني انه أعطى ترخيص للجميع للتطوير مما الهم وحفز الكثير

$$
\text { من التطبيقات اللامركزية. }
$$

مفهوم تقنية البلوكتشين من منظور المعلومات:

يعرفها (كلارك) بانها عبارة عن سجل مفتوح للمعاملات يمكن استخدامه لتسجيل المعاملات وتتبعها، وتستخدم شبكة نظير المى نظير في تبادل ذلك السجل والتحقق من سلامته، والغرض منها ضمان شفافية السجل وموثوقيته، اذ تتيح لمختلف الأطراف في المعاملة التأكد مما سيدون في السجل مسبقاً ومن عدم قدرة أي طرف على تغيير ذلك المضمون بعد تسجيله، وترسل كل معاملة او (كتلة) الى جميع المشاركين في الشبكة (أي حاسوب كل مشارك) عن طريق حل معادلة رياضية معقدة، 


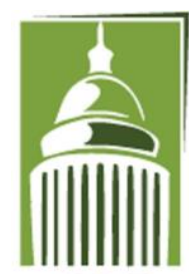

AR F
Global Proceedings Repository

American Research Foundation

ISSN 2476-017X

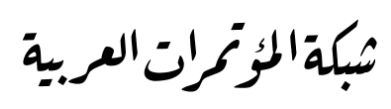

http://arab.kmshare.net/

Available online at http://proceedings.sriweb.org

وبمجرد التحقق من الكتلة، تضاف الى السجل او السلسلة، يكمن الابتكار الحقيقي لتكنولوجيا دفتر الأستاذ الموزع في اها تضمن سلامة السجل بإخضاعه لرقابة جماعية لا تتطلب وجود سلطة مركزية، (1). مفهوم تقنية البلوكتشين من منظور قانولي:

في ابسط وصف له هو دفتر حساب موزع او قاعدة بيانات الحاقية فقط، والتي يكون لكل مستخدم نسخة موثقة ومحدثة باستمرار، يمكن لأي شخص لدية حق الوصول الى دفتر الأستاذ ان يصل الى نفس محفوظات المعاملات الكاملة والقدرة على التحقق من صحة جميع السجلات والمشاركة في آليات الإجماع، حيث تضمن هذه الآليات أنه لأيمكن إضافة إدخالات جديدة الى دفتر الأستاذ الموزع الا اذا كانت متوافقة مع السجلات السابقة، ويمكن استخدام دفتر الأستاذ لتتبع الرموز المميزة التي تتنمي الى حسابات محددة او محافظ وعمليات نقل هذه الرموز بين الحسابات حيث تمكن هذه الحالة ضمان ان المعاملات متسقة مع مرور الوقت ولا يتم انفاق الرموز مرتين. اعتماد على التصميم التكنولوجي الفعلي، يمكن ان يكون صاحب الحساب (بجهول/اسم مستعار) فرديا او كيان قانوين او عقدا ذكيا (رمز البرنامج) او أي مجموعه أخرى. الرمز يمكن ان يمثل أي شيء تقريبا، مثل وحدة من عملة مشفرة، او أصل او كيان مادي في العالم الحقيقي، او أي كيان اخر مستخرج (2) (2)

نستنتج من هذه التعاريف ثلاث نواحي مخلفة: 1. من الناحية الفنية (التقنية): فإن تقنية البلوكتشين عبارة عن قاعدة بيانات الحاقية تحافظ على دفتر الأستاذ الموزع الذي بمكن فحصه بشكل مفتوح. 2. من الناحية التجارية (الاعمال): فإن تقنية البلوكتشين هي شبكة تبادل لنقل المعاملات والقيمة والأصول بين الأقران، دون مساعدة الوسطاء.

1. بيرغيت كلارك، (2018)."تقنية البلوكتثين وقانون الملكية الفكرية: سر النجاح في زمن التثفير ؟"، مجلة الويبو.

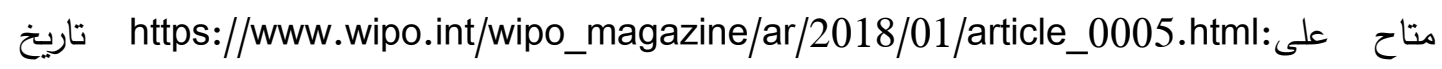
2019/03/03 الاطلاع

1. Daniel Conte de Leon, Antonius Q, and other. (2017)." Blockchain: properties and misconceptions", Asia Pacific Journal of Innovation andEntrepreneurship, Vol. 11 No. 3, 2017 pp. 286-300. APJIE 11,3. Available at: https://doi.org/10.1108/APJIE-12-2017-034 . 


\section{Global Proceedings Repository \\ American Research Foundation}

ISSN 2476-017X

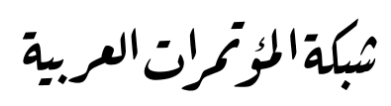

http://arab.kmshare.net/

Available online at http://proceedings.sriweb.org

3. من الناحية القانونية: فان تقنية البلوكتشين تساعد في التحقق من صحة المعاملات، لتحل محل الأطراف الثالثة

|الوسطاء.

سبب تسميتها بتقنية البلوكتشين:

هي في الواقع بنية بيانات بمعنى أها عبارة عن سلسلة من الكتل مرتبطة معًا. والكتلة يمكن أن تعني معاملة واحدة أو بكئو معاملات متعددة جمعت معا. ان وظائف التجزئة، والتي هي لبنة البناء الأساسية لهيكل بيانات تقنية البلوكتشين هي بجزئة تشفير تشير إلى كتلة البيانات، حيث يكون مؤشر التجزئة هو بجزئة كتلة البيانات نفسها، بخلاف القوائم المرتبطة التي تشير إلى الكتلة التالية حتى تتمكن من الوصول إليها، تشير مؤشرات التجزئة إلى كتلة البيانات السابقة وتوفر طريقة للتحقق من عدم تعرض البيانات للعبث، الغرض من مؤشر التجزئة هو بناء سلسلة كتل مقاومه للعبث يمكن اعتبارها مصدرًا واحدًا للحقيقة، وذلك بسب الطريقة التي تعمل بها وهي تخزين تجزئة الكتلة السابقة في رأس الكتلة الحالية، وسيتم تخزين بجزئة الكتلة الحالية في رأس الكتلة التالية. ويؤدي هذا إلى إنشاء سلسلة من الكتل، وهذا هو السبب في تسميتها بتقنية البلوكتشين على الرغم من ان سأتوشى ناكموتو ذكر كلمة كتلة وسلسلة متفرقة في الورقة البيضاء ولم يجمع بينهما الا ان تسميتها جاءت من الطريقة التي يتم فيها الهيكل البنائي لهذه التقنية. كما يمكننا أن نلاحظ، كل كتلة تشير إلى كتلتها السابقة، والمعروفة باسم (الكتلة الأم)، كل كتلة جديدة تتم إضافتها إلى السلسلة تصبح كتلة الأصل لإضافتها إلى المجموعة التالية، يتم الانتقال إلى الكتلة الأولى التي يتم إنشاؤها في تقنية البلوكتشين، والتي تسمى (كتلة التكوين)، في مثل هذا التصميم حيث يتم ربط الكتل مرة أخرى بالتجزئة، من غير العملي أن يقوم شخص ما بتغيير البيانات في أي كتلة. أن التجزئة لن تتطابق إذا تم تغيير البيانات. ان أي محاولة لتغيير محتوى رأس الكتلة أو محتوى جسم الكتلة سيؤدي الى كسر السلسلة بأكملها (1). مكونات الكتلة: تتكون الكتلة من العناصر التالية:

1. Bikramaditya SinghalGautam DhamejaPriyansu Sekhar Panda, (2018). Beginning Blockchain A Beginner's Guide to Building Blockchain,,Apress Media LLC , California , Berkeley, CA, Page36. 
Global Proceedings Repository

American Research Foundation

ISSN 2476-017X

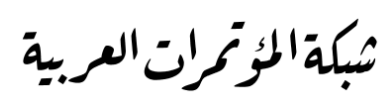

http://arab.kmshare.net/

Available online at http://proceedings.sriweb.org

1. متوى رأس الكتلة: تتكون من سلسلة من الكتل التي يتم ضمها مع منطق خاص. كل كتلة لما رأس كتلة تحتوي على المعلومات التالية: - 20 - n - بزئة الكتلة السابقة

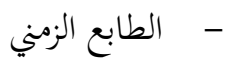

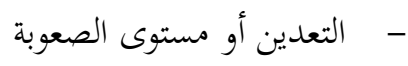

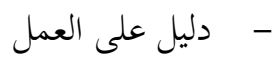
- - تجزئة الجذر لشجرة (Merkle 2. متوى جسم الكتلة: ويتكون من معاملة واحدة او بجموعة معاملات في الكتلة وبيانات أخرى. ويكمن إضافة العناصر التالية: - قائمة اختيارية من (OMMERS,OR UNCLE) في الكتلة، وتعني نصف المكافئة للمنقبين عند العثور على حلول مكررة للكتلة بسبب أوقات الكتل الأقصر في ايثيريم. العم يعني مكافأة أصغر من كتلة كاملة (وإذا تم ارسالها في وقت لاحق من الكتلة التالية تقل المكافئة وتنتهي عند الصفر بعد سبع كتل). - - موكة اختيارية هنا او هناك(1). وفي تقسيم اخر تتكون كل كتلة من ثلاث مكونات رئيسية هي (2):

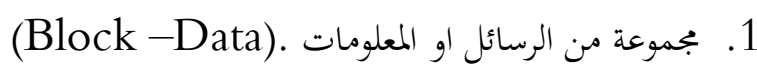

2. تسلسل التجزئة: نسخة من قيمة التجزئة للكتلة السابقة مباشرة (Chaining-Hash). 3. قيمة التجزئة المحوسبة لكتلة البيانات او الرسائل بالإضافة الى قيمة تجزئة التسلسل (Block-Hash. مكونات تقنية البلوكتشين: تتكون من ثلاثة عناصر تمثل اجزائه الاساسية وهي (3):

1. Debajani Mohanty, (2018)." Ethereum for Architects and Developers",Apress Media LLC, California, page 14-15.

2. Daniel Conte de Leon, Antonius Q, and other. (2017). Blockchain: properties and misconceptions, Asia Pacific Journal of Innovation and Entrepreneurship, Vol. 11 No. 3, 2017 pp. 286-300. APJIE 11,3. Available at: https://doi.org/10.1108/APJIE-12-2017-034 .

3. Daniel Conte de Leon, Antonius Q, and other., op.cit, pp. 286-300. 


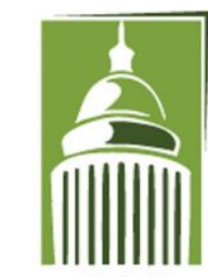

A R F
Global Proceedings Repository

American Research Foundation

ISSN 2476-017X

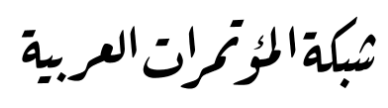

http://arab.kmshare.net/

Available online at http://proceedings.sriweb.org

1. شبكة من أجهزة الكمبيوتر : يمكن ان تتضمن كل شخص لدية جهاز كمبيوتر او مجموعة صغيرة من الكيانات المعروفة التي توافق على المشاركة. كل جهاز كمبيوتر في شبكة معينة يسمى عقدة، في الحالة المثالية تحتوي كل عقدة على نسخة من دفتر الأستاذ بالكامل، على غرار قاعدة البيانات التقليدية، وتعمل مع العقد الأخرى للحفاظ على تناسق او سلامة دفتر الأستاذ وهذا يخلق التسامح مع الخطاء لذلك إذا أخفقت عقدة واحدة لا يضيع كل شي، ما يعني عدم وجود نقطة فشل واحدة.

2. بروتكول الشبكة: يحكم بروتكول الشبكة كيفية اتصال تلك العقد مع بعضها البعض.

3. آلية التوافق (الإجماع): هي مجموعة من القواعد التي تستخدم الشبكة للتحقق من كل معاملة والاتفاق على الحالة الراهنة لتقنية البلوكتشين، بالنسبة ل بتكوين تسمى آلية التوافق إثبات العمل (POW)، حيث يقوم المشاركون في الشبكة بتشغيل خوارزميات لتأكيد التوقيع الرقمي الرفق بالكتل والتحقق من سلامة كل معاملة في الشبكة. اما آلية الإجماع في تقنية البلوكتشين الخاصة تكون الآلية لمشاركين معروفين وحددي من قبل كيان مركزي، وفي ترفي هذه الحالة لا تحتاج تقنية البلوكتشين لتأسيس الثقة لأفما موجودة بالفعل. عناصر تقنية البلوكتشين: يتكون من أربعة عناصر رئيسية تتمثل في الكتلة، والمعلومة، والهاش، وبصمة الوقت، تمثل هذه العناصر في مجملها تقنية

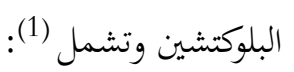

1. الكتلة: تمثل وحده بناء السلسلة وهي عباره عن مجموعة من العمليات أو المهام المرجو القيام بها أو تنفيذها داخل السلسة، ومن أمثلة الكتل تحويل أموال أو تسجيل بيانات أو متابعة حالة أو خلافه، وعادة ما تستوعب كل

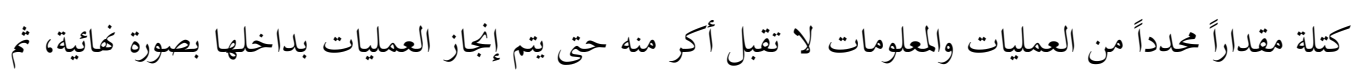
يتم إنشاء كتلة جديدة مرتبطة بها، والهدف الرئيسي هو منع إجراء معاملات وهمية داخل الكتلة تتسبب في تجميد السلسلة أو منعها من تسجيل وإفاء المعاملات.

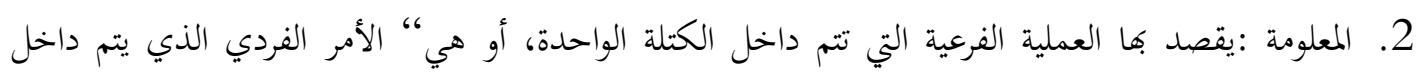
الكتلة، ويمثل مع غره من الأوامر والمعلومات الكتلة نفسها

1. خليفة، ايهاب. (2018م). البلوك تثين: الثورة التكنلوجية القادمة في عالم المال والادارة، ورقة علمية صادرة عن مركز المستقبل للأبحاث والدراسات المتقدمة، ص3. 


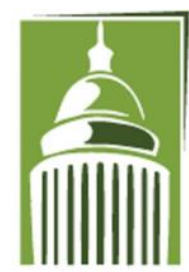

AR F
Global Proceedings Repository

American Research Foundation

ISSN 2476-017X

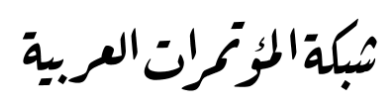

http://arab.kmshare.net/

Available online at http://proceedings.sriweb.org

3. الهاش: هو عبارة عن الحمض النووي المميز لتقنية البلوكتشين، ويرمز إليه البعض أحياناً لها بالتوقيع الرقمي فهو

$$
\text { عبارة عن كود يتم إنتاجه من خال خوارزمية داخل برنامج. }
$$

التشفير في تقنية تقنية البلوكتشين.

هي الخوارزميات التي تدعم هذه الخصائص، حيث يتم استخدام تقنيات التشفير لضمان امن الاتصالات مثل المستخدمة في تلغرام او الواتس اب. سيكون الحديث عن التشفير في بتكوين كوها التطبيق الأساسي الأكثر نجاحا في تقنية البلوكتشين، هناك مبادئ أساسية تسمى أولويات التشفير او الترميز البدائية والتي يمكن اعتبارها اللبنات الأساسية المفاهيمية لوظيفة تقنية البلوكتشين وتشمل هذه المبادئ (1):

1. وظيفة بجزئة أولية "بجزئة التشفير"(Hash): هي في الأساس دالة رياضية لإدخال البيانات من أي حجم ينتج عنها ناتج ذي حجم محدد يمكن حسابة بكفاءة في فترة زمنية محدودة تشتمل وظيفة التجزئة على العديد من الخصائص المهمة، نذكر الان خصائص مفيدة بشكل خاص في العملات المشفرة: - تكون وظيفة التجزئة مقاومة للتصادم: ما يعني ان اثنين من المدخلات المميزة او المتشابه لا تنتج نفس المخرجات، وهذا يعني في الممارسة العملية أنه يمكن استخدام وظيفة التجزئة كخلاصة للرسائل أي البيانات الوصفية للمحتوى مع اختلاف في كوغا ليست اختصار للمحتوى، وهي أداة للتحقق من ان النسخة من الرسالة متطابقة مع الأصل. - الخاصية الثانية مختبئة او غامضة مقاومة (Preimage)، مما يعني انه بالنظر الى المخرجات فقط، لا يمكن لاحد ان يستنتج قيمة المدخلات او الإدخال بمعنى من غير الممكن العثور على الإدخال. - - الخاصية الثالثة هي سهولة التعامل مع اللغز مقاومة (Preimage) ما يعني أنه يمكن تقديم دالة التجزئة في شكل لغز رياضي حيث يحاول ادخال مدخلات مختلفة لوظيفة دالة هاش معينة للحصول على ناتج ذًا قيمة محددة مسبقا؛ او بمعنى اخر يشير سهوله اللغز المى عدم وجود اختصار للحل والطريقة الوحيدة للوصول الى الحل هي اجتياز جميع الخيارات الممكنة في مساحة الإدخال.

1. Debajani , Mohanty, (2018). Ethereum for Architects and Developers, Apress Media LLC, California, page 45. 


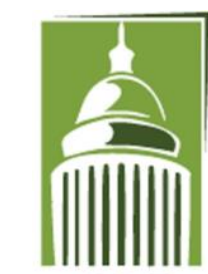

AR F
Global Proceedings Repository

American Research Foundation

ISSN 2476-017X

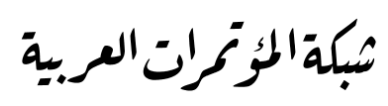

http://arab.kmshare.net/

Available online at http://proceedings.sriweb.org

- لا يعد ملائمة الألغاز شرطا ضروريا لبنية البيانات على وجه الخصوص ولكنة ضروري للعملات المشفرة. هو مؤشر

في علوم الكمبيوتر بشكل عام وفي هياكل البيانات على وجهه الخصوص وهو في الأساس إشارة حيث يتم تخزين

المعلومات، على غرار البيانات الوصفية في فهرس المكتبة.

2. التوقيع الرقمي: هي طريقة تشفير وظيفية لتوقيع الرسائل رقميا، من اجل القيام بذلك تستخدم طريقة التوقيع

الرقمي التشفير غير المتماثل ثنائي المفاتيح. هو في الأساس قفل مع زوج مفاتيح، واحد منها يفتح فقط والآخر

فقط للقفل. الان في الشكل الرقمي جعل مفتاح الفتح العام، بينما يبقى مفتاح القفل خاص وبالتالي إذا قام

شخص ما بتشفير رسالة بمفتاح خاص وقدم الإخراج الناتج "التوقيع" مع نسخة من الرسالة الأصلية، يمكن لأي

شخص لدية مفتاح عام فك تشفير التوقيع للتحقق من الرسالة قد تم توقيعها بالفعل بواسطة صاحب المفتاح

الخناص (1).

ونظرا لأن قد يكون هناك مفتاح خاص واحد فقط، يعرفه شخص واحد فتط، فان طريقة التوقيع هذه توفر هوية يمكن

التحقق منها، كما يمكن التتبع من خلالها (2)، باستخدام زوج المفاتيح ووظيفة التجزئة، من الممكن انشاء عناوين بتكوين،

وهي عبارة عن بتزئات أساسية للجزء العام من زوج المفاتيح. يتيح الجمع بين هاتين الطريقتين للتشفير البناء الأساسي للعملة المشفرة. لتوضيح ذلك بطريقة مبسطة نفترض صفقة نقدية بين احمد وخالد. أولا يستطيع احمد باستخدام زوج مفاتيح تم إنشاؤه، انشاء رسالة رقمية يقول انه يمتلك عشر عملات رقمية ويمكنه توقيعها باستخدام المفتاح الخاص. بعد ذلك من اجل إتمام الصفقة مع خالد، يضيف رسالة الى القائمة والتي يقول فيها انه يرسل الى خالد عشر عملات رقمية، يعتمد كل هذا فقط على الاتفاقية بين احمد وخالد اللذان يوافقان على التعامل معا للإتمام الصفقة. تقوم العقد/المنقبون بالتحقق من ان ما أتفق علية احمد وخالد صحيح وجميع الاشتراطات مطابقة. ومن ثم يتم تنفيذ الاتفاق المبرم بينهما كما هو موضح في

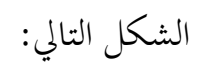

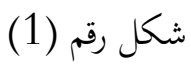

هيكل ومعالجة المعاملات باستخدام ازواج المفاتيح العامة والخاصة على تقنية البلوكتشين

1. G. Ishmaev, (2017).” Blockchain Technology as an Institution of Property, Wiley online library Met philosophy / Volume 48, Issue 5. Cited by: 3 .AVIALBAL AT: https://doi.org/10.1111/meta.12277 


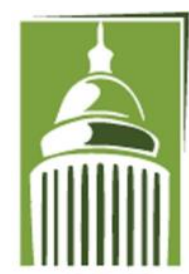

AR F

\section{Global Proceedings Repository \\ American Research Foundation}

ISSN 2476-017X
شبكة المؤتمات العربية

http://arab.kmshare.net/

Available online at http://proceedings.sriweb.org

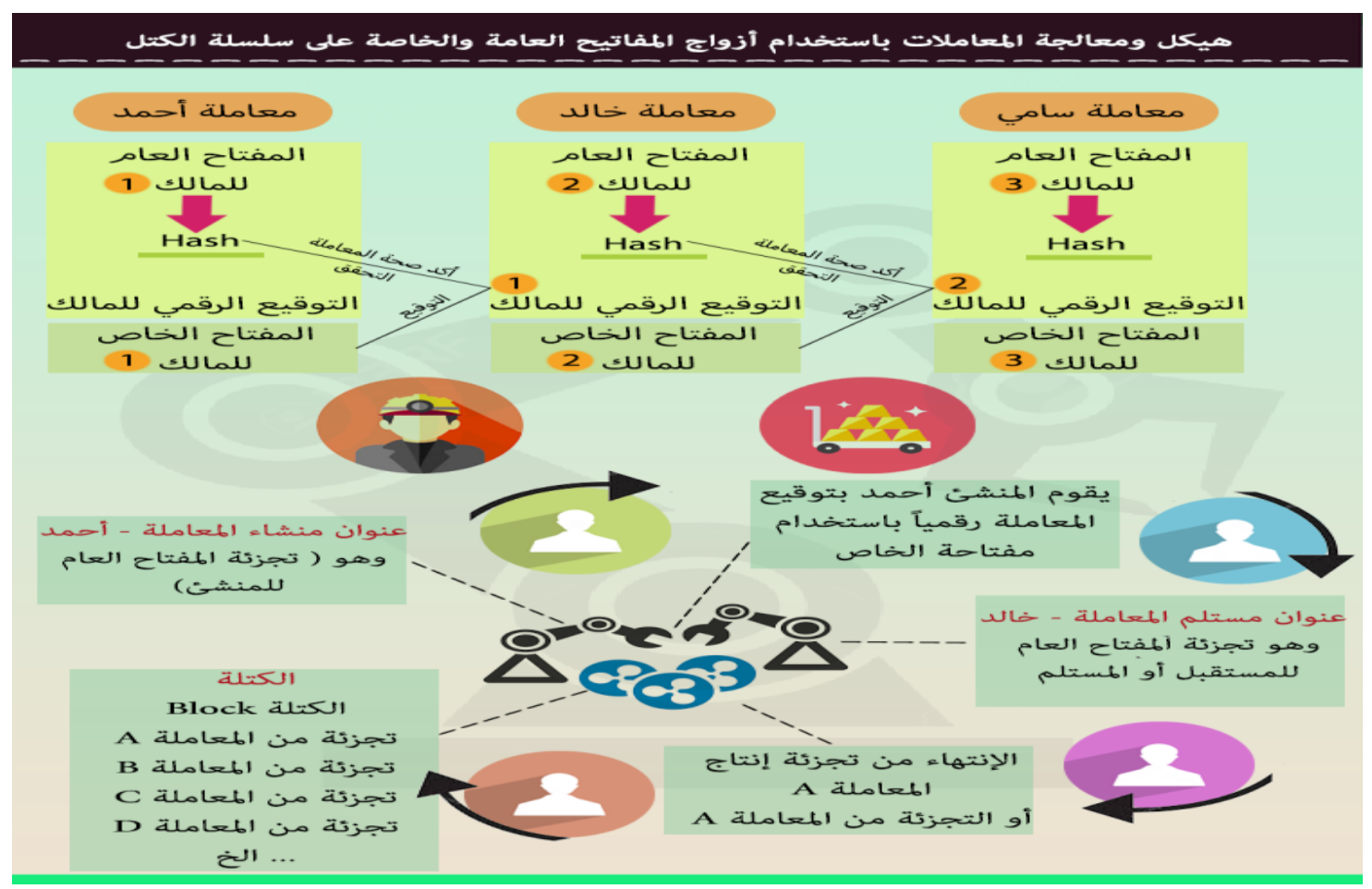

Resource: Bikramaditya Singhal Gautam Dhameja Priyansu Sekhar Panda, (2018).,Page 16

للتوضيح أكثر، أنه عندما يرسل احمد العملة المشفرة الى خالد عبر تقنية البلوكتشين، فإنه يرسل فعليًا نسخة بجزأة من

المفتاح العام، والمفتاح الخاص يكون مخفي. يستخدم هذا المفتاح الخاص لاشتقاق المفتاح العام، كل شخص في الشبكة يعرف مفتاحه الخاص، إنه يشبه المفتاح الرئيسي لصندوق الودائع الآمن الخاص بك في أحد البنوك ولا يجب مشاركته مع أي شخص، إلا إذا كنت تريد سرقة عملاتك المشفرة. يتم استخدام المفتاح الخاص لاشتقاق المفتاح العمومي حسابياً، والذي يتم تحويله بعد ذلك باستخدام دالة هاش (وظيفة التجزئة) لإنتاج العنوان الذي يمكن أن يراه الآخرون، وتتلقى العملات المشفرة التي يرسلها الآخرون إلى عنوانك. في هذه المرحلة، قد تسأل نفسك ما إذا كان المفتاح العمومي مستمدًا من مفتاح خاص، ألا يمكن لأحد أن ينشئ المفتاح الخاص المستمد من عكس المفتاح العام مما يتيح له سرقة عملات أي شخص في هذه العملية، تعمل العملات المشفرة على حل هذه المشكلة باستخدام خوارزمية رياضية معقدة لإنشاء المفاتيح 
Global Proceedings Repository

American Research Foundation

ISSN 2476-017X

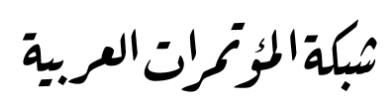

http://arab.kmshare.net/

Available online at http://proceedings.sriweb.org

العامة: الحوارزمية بتعل من السهل إنشاء مفاتيح عمومية من المفاتيح الحاصة، ولكن من الصعب "عكس" الخوارزمية لإنجاز عكس ذلك (1). تطبيقات وظائف التجزئة. لوظائف بزئة الشفير العديد من الاستخدامات المختلفة في مواقف خختلفة. فيما يلي بعض الأمثلة على ذلك: • استخدام دالات التجزئة (Hash) في التحقق من سلامة وصلاحية المعلومات.

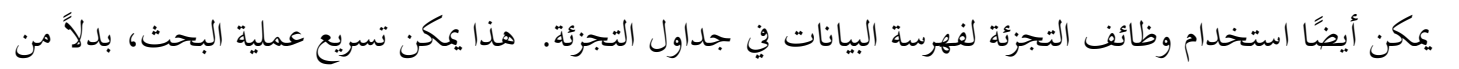

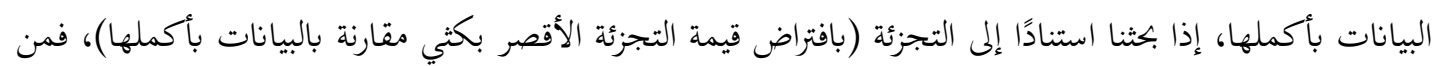

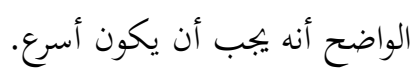

يككن استخدامها لمصادقة المستخدمين بأمان دون تخزين كلمات المرور محليًا. إذا كنت لا ترغب في تخزين كلمات المرور على الخادم، لأنه أنه إذا قام أحد الخصوم باختراق الخادم فلن يتمكن من الحصول على كلمة المرور من التجزئة المخزنة. في كل مرة يماول المستخدم تسجيل الدخول، يتم حساب تجزئة كلمة المرور المثقوبة ومطابقتها مع التجزئة المخزن.

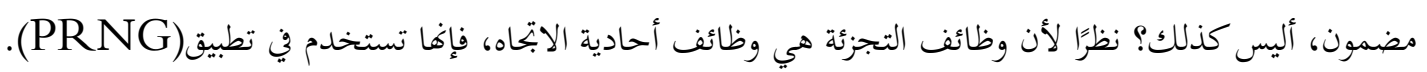

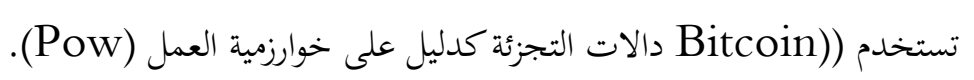

تستخدم (Bitcoin) أيضًا وظائف التجزئة لإنشاء عناوين لتحسين الأمان والخصوصية أهم تطبيقين هما التوقيعات التهات

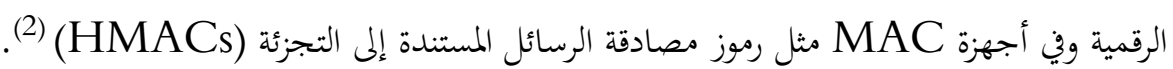
يمكن تقسيم آليات الإجماع/التوافق بشكل أساسي إلى الأنواع التالية (3): • (POW) اثبات العمل (P) • إثبات الحصة /المخاطر (POS) • (DPOS) إثبات حصة المفوض (D)

1. Debajani Mohanty,(2018). Ethereum for Architects and Developers, Apress Media LLC , California ,page 36.

1. Bikramaditya Singhal Gautam DhamejaPriyansu Sekhar Panda, (2018). Beginning Blockchain A Beginner's Guide to Building Blockchain,Apress Media LLC, California, Berkeley, CA, Page 58.

2. Debajani Mohanty,(2018). op.cit,page 56. 


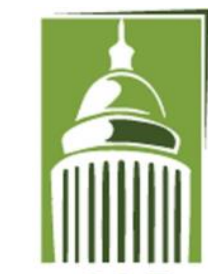

AR F
Global Proceedings Repository

American Research Foundation

ISSN 2476-017X

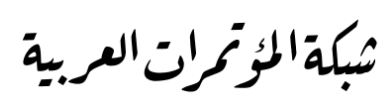

http://arab.kmshare.net/

Available online at http://proceedings.sriweb.org

$$
\text { • (POA) (إثبات السلطة (P) }
$$

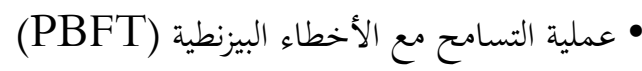

• الرسوم البيانية الحلقية الموجهة (DAGs) حاليا تم اعتماد آليات التوافق هذه على نطاق واسع بواسطة تقنية البلوكتشين مختلفة وأطر دفتر الأستاذ DLT. نموذج معين يمكن يتم اختيارهم على الآخرين وفقًا لمتطلبات أعمال المنظمة. الأداء،

$$
\text { والتدرجية، والأمن هي عوامل رئيسية قبل اختيار أي منها على الآخرين. }
$$

1. اثبات العمل(POW): انه أول آلية إجماع قدم مع بتكوين. فيه يتنافس جميع المنقبون على حل مشكلة رياضية، وييتم مكافئة الفائز في حلها. والمنقبون الاخرون يبذؤن في التحقق من صحة ذلك تصل إلى نسبة متفق عليها (51) بالمائة أو (90) بالمائة حسب التكوين)، يعمل المنقبون على قاعدة أطول سلسلة بمعنى آخر، إذا كانت هناك شوكات تم إنشاؤها بسبب اختلاف المنقبون في سلاسل جاببية مختلفة، فإن السلسلة الأطول هي الأكثر جدارة بالثقة، قريبًا سيبدأ آخرون باتباع هذه السلسلة، وسيتم التخلص من السلاسل الجانبية الأخرى (الشوكة). تصل مدة بجزئة الكتلة (10) دقائق. تستخدم من قبل: بتكوين، ايثيريم، المزايا: وقت اختبارها وآمنة، العيوب: بطيئة للغاية في قابلية التوسع، واستهاكك الطاقة المائل. 2. إثبات المخاطر(POS): إجماع نقاط البيع ليس له علاقة بالتعدين، ومع ذلك لا يزال يتحقق من صحة الكتل ويضيفها إلى تقنية البلوكتشين. تعتمد خوارزمية التوافق القائمة على الضمان هذه على الحصة الاقتصادية للمدقق في الشبكة. بمعنى آخر، يجب أن يمتلك كل مشارك في التدقيق الحصة في الشبكة عن طريق إيداع بعض الأموال في الشبكة. في اثبات المخاطر المعتمدة على تقنية البلوكتشين العامة، يتناوب العديد من المدققين على الاقتراح والتصويت على الكتلة التالية، ويعتمد وزن تصويت كل مشارك في التدقيق على حجم الإيداع. يستخدم من قبل: نموذج (Ethereum) العيوب: أكثر عرضة للهجوم لأنه لا يوجد عامل حسابي مثل (POW) للحفاظ على الشبكة آمنة.

الهدف من آليات الاجماع والتحقق من صحة المعاملة: الهدف الرئيسي لخوارزمية تقنية البلوكتشين هو التأكد من أن هيكل سلسلة البيانات يحتوي فقط على كتل صالحة، والتي تتكون بدورها من بيانات معاملات صالحة ورؤوس كتل صالحة، يتم تقييم صحة هذه البيانات على أساس بجموعتين متميزتين لقواعد التحقق من الصحة: 1. قواعد التحقق من صحة بيانات المعاملة تحدد قواعد التحقق من صحة بيانات المعاملة البيانات المطلوبة لوصف المعاملة، وتشمل هذه القواعد الصحة الرسمية والدقة الدلالية والترخيص. 


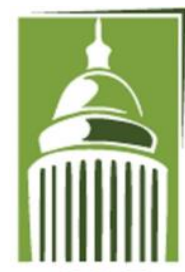

A R F

\section{Global Proceedings Repository}

American Research Foundation

ISSN 2476-017X

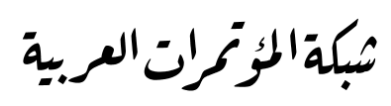

http://arab.kmshare.net/

Available online at http://proceedings.sriweb.org

2. قواعد التحقق من صحة رؤوس الكتل تركز قواعد التحقق من صحة رؤوس الكتل على الدقة الرسمية والدلالية

لرؤوس الكتل. هذه القواعد غير ملائمة لختوى بيانات المعاملة، بدلاً من ذلك، يهتمون بطريقة إضافة المعلومات

إلى بنية، يتمثل العنصر الرئيسي لرؤوس الكتل الصحيحة في التحقق من إثبات العمل أو أن اللغز لديه على

التوالي. يتم فقط معالجة الكتل التي تحتوي رؤوسها على حل صحيح من أحجية التجزئة الفردية الخاصة بها (1).

والشكل التالي يبين آليات الاجماع لسلسة الكتل:

شكل رقم (2) (1) - (2)

آليات الاجماع/التوافق على تقنية البلوكتشين

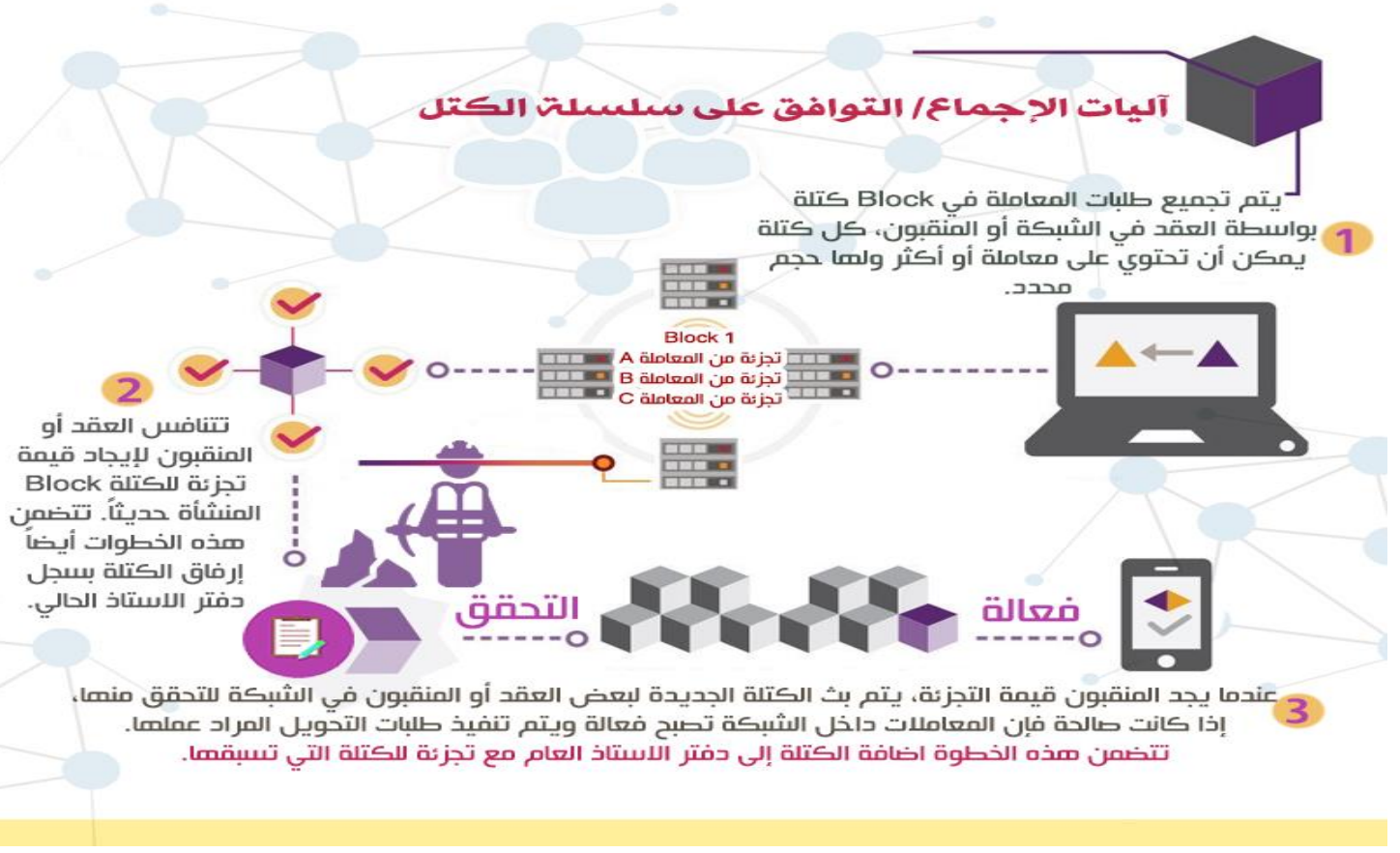

Source: Daniel Drescher, (2017, PAGE 154-160

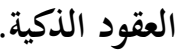

1. Daniel Drescher, (2017)."BLOCKCHAIN BASICS: A NON-TECHNICAL INTRODUCTION IN 25 STEPS, Springer Science+Business Media New York, Pages 154-160, 


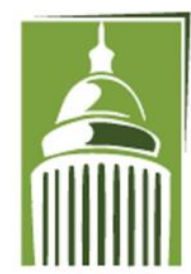

AR F
Global Proceedings Repository

American Research Foundation

ISSN 2476-017X

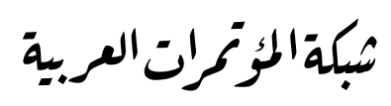

http://arab.kmshare.net/

Available online at http://proceedings.sriweb.org

هو رمز كمبيوتر يعمل على طبقة البلوكتشين ويحتوي على بجموعة من القواعد التي يتفق بموجبها الطرفان في ذلك العقد الذكي على التفاعل مع بعضهما البعض وعندما يتم استيفاء الشروط المحددة مسبقا يتم تنفيذ الاتفاقية تلقائيا، لقد تم تصميم دفتر الأستاذ في البداية لتبادل المال نظير الى نظير دون الحاجة المى وسيط وكان عددا قليل من الأدوات المدبجة التي تؤدي دور أمتّة المعاملات. جاء مشروع ايثيريم (Ethereum) الذي قدم فكرة فصل طبقة العقد من طبقة البلوكتشين حيث يتم استخدام دفتر الأستاذ نفسة بواسطة عقود ذكية تعمل على تشغيل المعاملات تلقائيا عند تحديد محدد مسبقا وتم استيفاء الشروط، تم إضافة (Turing) كامل بلغة الكمبيوتر الى التكنولوجيا، حيث تمكن هذه اللغة المستخدمين من كتابة برامج معقدة تتفاعل مع دفتر الأستاذ الموزع،، ومن اشهر اللغات المستخدمة في العقود الذكية هي (Solidity) وهي اللغة الرسمية والأكثر استخدامًا في شبكة ايثيريم، باستخدامها، تتم كتابة العقود الذكية التي يتم الاتفاق عليها بين الطرفين، هذه اشهر اللغات المستخدمة في العقود الذكية (1)، تعد العقود الذكية الجيل الثاني من دفتر الأستاذ العام وهي أجزاء من التعليمات البربجية التي تنشى المعاملات اذاتم استيفاء الشروط المشفرة فيها، على سبيل المثال اذا دفع X مبلغا من العملة المشفرة الى حساب العقد الذكي فان العقد يمنحه حق الوصول الى نسخة رقمية من العمل. وعلى نفس المنوال قد يساعد العقد الذكي في توزيع العائدات؛ مثل إذا أنتج عمل فلم وكان المشاركون ف العمل متعددين مثل مخرج العمل ومنتج العمل والممثلون والمغنون وأخرين يمكن للعقد الذكي توزيع الإتاوات الصغيرة بين المالكين وفقا للاتفاق المبرم في العقد (RML Token). كما يمكن للعقد اجراء وتنفيذ معاملات اشد تعقيدا. حيث ان هذه العقود هي جزء من التعليمات البرجية التي يتم تشغيلها على قمة شبكة تقنية البلوكتشين. قمدف العقود الذكية الى توفير امن معلومات متفوق على العقود التقليدية وتخفض تكاليف معاملات التنسيق والتنفيذ. حيث يمكن استخدامها في مجالات متعددة سوء للمعاملات الاقتصادية البسيطة مثل إرسال الموال من X -X او تسجيل أي نوع من الملكية مثل سجلات الأراضي او الملكية الفكرية او إدارة التحكم في الأصول الذكية. كما يمكن استخدامها في معاملات أكثر تعقيدا مثل إدارة مجموعة من الأشخاص الذين يتشاركون نفس الاهتمامات والاهداف. تعتبر المنظمات المستقلة اللامركزية (DAOs) مثلا على العقود الذكية الأكثر تعقيدا، كما يمكن ان تلعب دورا في توحيد شروط التراخيص لأعمال حقوق الطبع والنشر. عبر الاستخدامات والاختصاصات القضائية

1. Josep Lluis de la Rosa1, and another, (2017). A SURVEY OF BLOCKCHAIN TECHNOLOGIES FOR OPEN INNOVATION، ResearchGate. Available at:https://www.researchgate.net/profile/Lutz_Maicher/publication/321381169_A _Survey_of_Blockchain_Technologies_for_Open_Innovation/links/5a1fccd9aca $272 \mathrm{cbfbc} 325 \mathrm{cb} / \mathrm{A}-\mathrm{Survey-of-Blockchain-Technologies-for-Open-}$ Innovation.pdf?origin=publication_detail. 


\section{Global Proceedings Repository \\ American Research Foundation}

ISSN 2476-017X

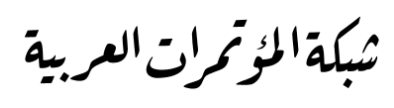

http://arab.kmshare.net/

Available online at http://proceedings.sriweb.org

$$
\begin{aligned}
& \text { المختلفة، على غرار الطريقة التي يتم بها نشر تراخيص المشاع الإبداعي على مستوى عالمي. ومع ذلك لايزال هناك تعقيدات } \\
& \text { كبيرة وقيود تحول دون تبنيها بشكل واسع ف الوقت الحالي. لا ينبغي الخلط بين العقد الذكي والعقد القانوني في الوقت } \\
& \text { الحالي (1) } \\
& \text { ويوضح الشكل عملية بيع سيارة باستخدام العقود الذكية } \\
& \text { شكل رقم (3) }
\end{aligned}
$$$$
\text { عملية بيع سيارة باستخدام العقود الذكية }
$$

1. Balazs Bodo', Daniel Gervais† and Jo ao Pedro Quintais, (2018). Blockchain and smart contracts: the missing link in copyright licensing, Oxford Source:International Journal of Law and Information Technology, VOLUM 26, 


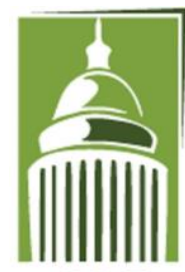

AR F

\section{Global Proceedings Repository \\ American Research Foundation}

ISSN 2476-017X

Available online at http://proceedings.sriweb.org

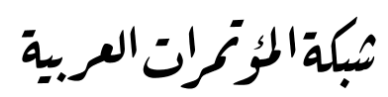

http://arab.kmshare.net/

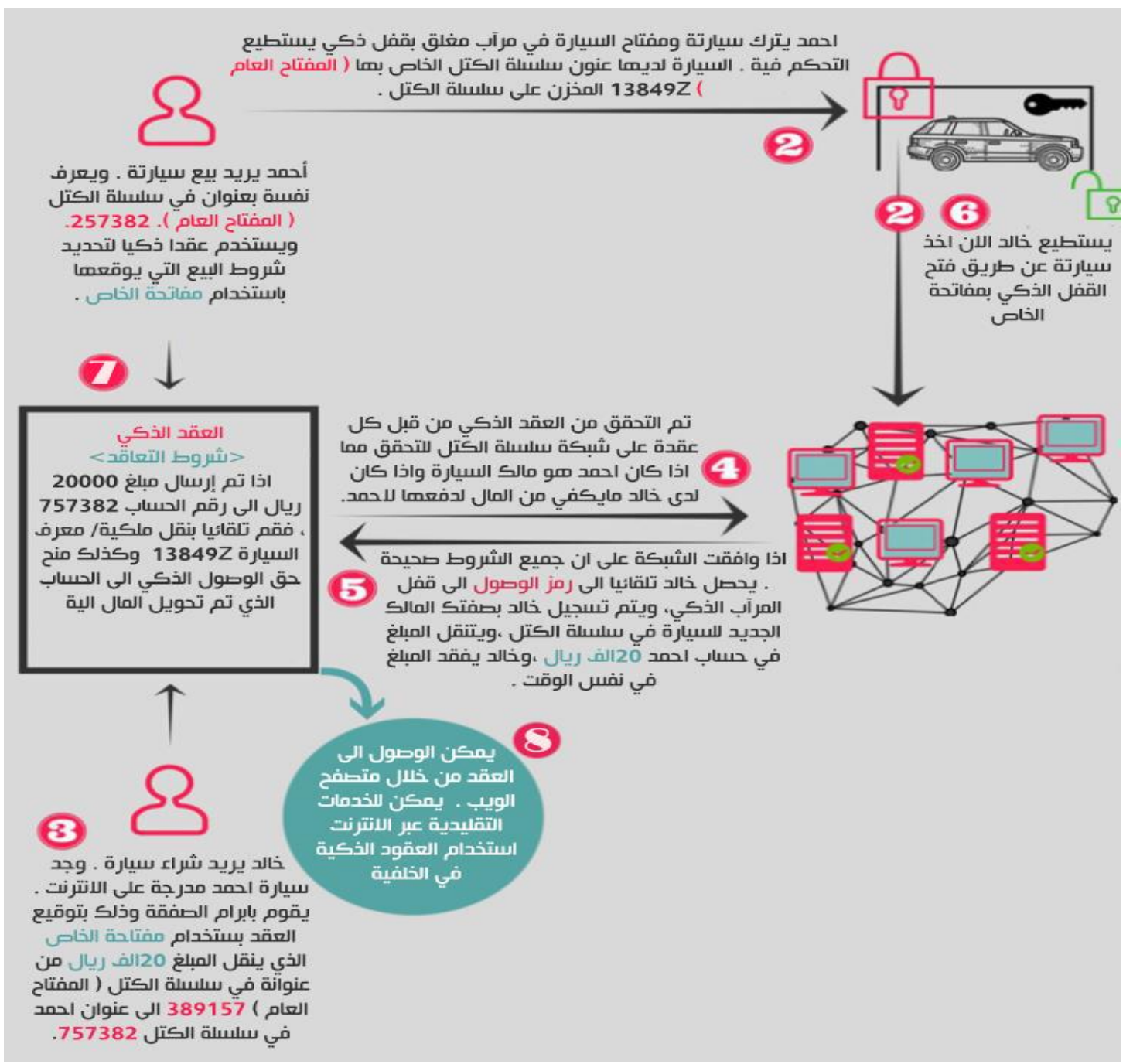

Source: Bal' azs Bodo', Daniel Gervais† and Jo ao Pedro Quintais, (2018). Pages 311 336. ISSUE 4, WINTER 2018, PAGES 311-336.November 2018 16. AVIALBE AT: http://creativecom- mons.org/licenses/by/4.0

الغاز GAS

الغاز هو الوقود الذي يشغل شبكة ايثيريم. لإغراء المزيد والمزيد من المدققين للعمل على التحقق من صحة الصفقة، يقوم مُنشئ المعاملة بتخصيص كمية معينة من الغاز للمعاملة، والتي يجب دفعها إلى عامل المناجم الذي يقوم بتعدين المعاملة بشكل أسرع. حيث تحدد حد الغاز: وهو الحد الأقصى لمقدار الغاز الذي ترغب في دفعه إلى شركة التعدين للتحقق من صحة المعاملة. كلما ارتفع السعر، زادت فرصة أن يتم تنفيذ معاملتك بشكل أسرع لأن ذلك سيجذب المزيد من المدققين 


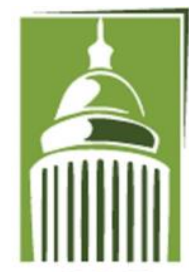

ARF
Global Proceedings Repository

American Research Foundation

ISSN 2476-017X

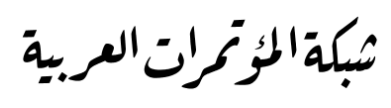

http://arab.kmshare.net/

Available online at http://proceedings.sriweb.org

لتحديد أولويات معاملتك على الآخرين. أيضا، فإن وضع مبلغ غير كافي في حد الغاز سيؤدي إلى فشل الصفقة. ان سعر الغاز: هو مقدار الأثير أو جزء الأثير الذي ترغب في إنغاقه على كل وحدة من الغاز.1

أين يتم تخزين البيانات في ايثيري؟؟ تستخدم ايثيريم في إنشاء تطبيقات لا مركزية باستخدام عقود ذكية. وهذه العقد عبارة عن مزيج من البيانات (مثل متغيرات الحالة) ووظائف لتخزين هذه البيانات إلى عنوان محدد في شبكة ايثيريم على تقنية البلوكتشين حيث يمكن استرداد البيانات واستخدامها بشكل أكبر. شبكة ايثيريم تحمل بجموعة من الحسابات. كل حساب لديه صاحب وتوازن، وهو بعض الأثير. إذا أثتبت هويتي، فيمكني نقل الأثير (وهو العملة المشفرة، أو المال في نموذج آخر) من حسابي إلى حساب آخر.

تكلفة التخزين.

كلما زادت البيانات أو زادت مساحة التخزين، زادت تكلفة المعاملة من حيث الوقود. ومع ذلك، التخزين في شبكة ايثيريم غير مقيّد بالوقت؛ إنه دفعة لمرة واحدة، وقد تكون البيانات موجودة إلى الأبد. أيضًا، قراءة البيانات من الشبكة مجانية. في الفصول اللاحقة، ستحد تكلفة كل تعليمات في عقد ذكي من مقدار التخزين الذي تستخدمه. يسمح ايثيريم بمساحة تخزين غير محدودة نظريًا، ومع ذلك يتعين عليك توفير الغاز لكل عملية قراءة / كتابة بعناية.2

\section{خصائص تقنية البلوكتشين:}

هنالك خصائص متعددة لتقنية البلوكتشين يحاول الباحث هنا التعرف على بعض من تلك الخصائص وهي (3): 1. الثبات: اها الخاصية الأساسية للحفاظ على ذرية المعاملات في تقنية البلوكتشين، بمجرد تسجيل المعاملة لأيمكن تغيرها. إذا تم بث المعاملات الى الشبكة فسيحصل الجميع تقريبا على نسخة منها، ومع مرور الوقت عندما

1

Debajani Mohanty, (2018)." Ethereum for Architects and Developers", Apress Media LLC, California, page

2

Debajani Mohanty, (2018)." Ethereum for Architects and Developers", Apress Media LLC, California, page

1. Bikramaditya Singhal Gautam DhamejaPriyansu Sekhar Panda, (2018)., Page 63. 


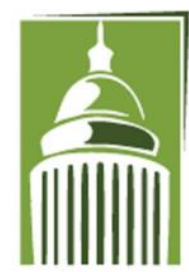

AR F
Global Proceedings Repository

American Research Foundation

ISSN 2476-017X

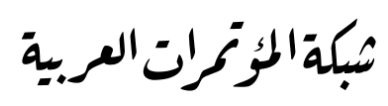

http://arab.kmshare.net/

Available online at http://proceedings.sriweb.org

تضاف كتل أكثر وأكثر الى دفتر الأستاذ تزداد قابلية الثبات وتصبح غير قابلة للتغير تماما. إذا حاول شخص ما تغير بيانات بعض الكتل في السلسلة، فانة من غير الممكن عمليا لأهما مؤمنة بشكل مشفر ومرتبطة بالكتلة التي قبلها، لذا فان أي معاملة يتم تسجيلها تبقى الى الأبد في النظام. او من الصعب العبث بها او تغيرها.

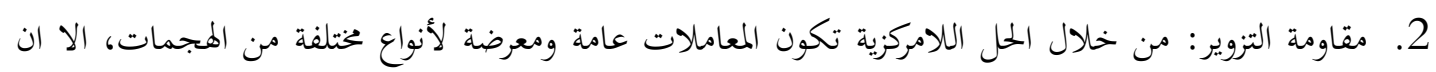
محاولات التزوير هي الأكثر وضوحا، خاصة عند التعامل مع أي شي ذًا قيمة، كما يمكن استخدام بجزئة التشفير والتوقيعات الرقمية لضمان مقاومة التزوير في النظام، أنه من غير المجدي حسابيا صياغة توقيع شخص اخر. حيث إذا قمت بأجواء معاملة وقمت بتوقيع التجزئة منة فلن يتمكن أحد من تغيير المعاملة لاحقا او يدعي أنك وقعت معاملة مختلفة، وكذلك لأيمكن ان تدعي لاحقا أنك لم توافق على الصفقة، لأنك انت الذي وقع عليها، يمنع دفتر الأستاذ الموزع التنصل. 3. ديمقراطية: يجب ان يكون أي نظام لامركزي من نظير المى نظير دمقراطيا وفقا للتصميم (قد لا يكون قابلا للتطبيق بشكل كامل في تقنية البلوكتشين الخاصة)، كما يجب ان لا يكون هناك أي كيان في النظام أكثر قوة من الكيانات الأخرى، يجب ان يتمتع كل مشارك بحقوق متساوية في أي موقف، ويتم اتخاذ القرارات عندما تتواصل الأغلبية

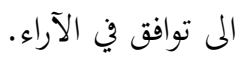
4. مقاومة الانفاق المزدوج: ان الإنفاق المزدوج شائع في الهجمات النقدية وغير النقدية. تكون محاولات الإنفاق المزدوج في العملة المشفر عندما يحاول شخص إنفاق نفس المبلغ على عدة أشخاص، مثال لديك . . ا ريال في حسابك وتدفع • وريال الى طرفين او أكثر تعتبر هذه العملية نوع من أنواع الإنفاق المزدوج. لمن مثل هذه العملية نجد في العملات المشفرة مثل بتكوين لا توجد فكرة رصيد إغلاق، ان الإدخال في المعاملة (عندما تدفع لشخص ما) هو ناتج معاملة أخرى حيث تلقيت على الأقل المبلغ الذي تدفعه من خلال هذه المعاملة.

\section{فوائد تقنية تقنية البلوكتشين:}

لسلسة الكتل فوائد من استخدامها وهي بلا شك ذات إثر واضح وكبير خاصة على حقوق الملكية الفكرية، وهذه

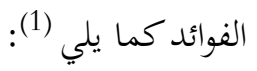
1. ل الميكن تغيير البيانات الموجودة في دفتر الأستاذ.

1. Debajani Mohanty, (2018). Ethereum for Architects and Developers, page 89. 


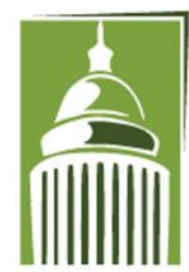

AR F
Global Proceedings Repository

American Research Foundation

ISSN 2476-017X

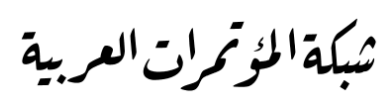

http://arab.kmshare.net/

Available online at http://proceedings.sriweb.org

2. إها قاعدة بيانات آمنة للغاية تستخدم المفاتيح العامة والخاصة للمعاملات. 3. ق قاعدة البيانات متاحة للجميع ويمكن للجميع لتحقق من صحة وإضافة المعاملات.

4. بما أن شبكة البلوكتشين غير مركزية، فلا يوجد وقت توقف في الشبكة، وبالتالي يمكن إضافة المعاملات في أي

$$
\text { وقت ومن أي مكان. }
$$

5. يمكن أن تكون عامَة أو خاصَة وفقًا لاحتياجات الفرد أو العمل التجاري وبالتالي فهي مرنة.

6. دفتر الأستاذ مفتوح للتدقيق في أي وقت.

أنواع تقنية تقنية البلوكتشين:

لتقنية البلوكتشين انواع عديدة تحاول هذه الدراسة التعرف على بعض من هذه الانواع على النحو التالي (1):

1. تقنية البلوكتشين العامة: هي مفتوحة المصدر، وبدون إذن؛ ما يعني أنه يمكن لأي شخص المشاركة بدون إذن،

كما يمكن لأي شخص تنزيل الشفرة وبداء تشغيل عقدة عامة على اجهزتم والتحقق من صحة المعاملات في الشبكة، وبالتالي المشاركة في عملية الإجماع وهي عملية يتم تحديد ما يتم أضافته الى السلسلة وما هي الحالة الراهنة لسلامة الكتلة، ويمكن لأي شخص في العالم ان يرسل المعاملات عبر الشبكة ويتوقع ان يراها ضمن تقنية البلوكتشين اذا كانت المعاملة صالحة، ويمكن لأي شخص قراءة المعاملة على مستكشف كتلة الجمهور، كما ان المعاملات شفافة، ولكنها بجهولة؛ أي ان صاحب المعاملة يمكن ان يكون اسم مستعار ـ ومن الأمثلة على العامة:

(Bitcoin, Ethereum, Dodgecah Litecoin, Dash, Monaro)

$$
\text { - - القدرة على تعطيل نماذج الاعمال الحالية من خلال عدم التدخل. }
$$

- - لا تكاليف على البنية التحتية: لا حاجة للحفاظ على للخوادم او مسؤولية صيانة النظام، كما يقلل من تكاليف

$$
\text { إنشاء وتشغيل النظام النظام المركزي. }
$$

2. تقنية البلوكتشين الفيديرالية او المتحدة (Federated): تعمل تقنية البلوكتشين الموحدة تحت قيادة مجموعة على عكس العامة، لا تسمح لأي شخص ليس لدية الحق في الوصول الى شبكتها بالمشاركة في عملية التحقق من المعاملات. تكون أسرع (اعلى قابلية للتوسع) وتوفر المزيد من الخصوصية للمعاملات. يتم التحكم في عملية التوافق بواسطة بجموعة من العقد المحددة مسبقا. على سبيل المثال تحاد 10 مؤسسة تعمل على تقنية البلوكتشين

2. Shermin Voshmgir, And Valentin Kalinov,(2017),"BlockchainA Beginners Guide".BlockchainHub. Version 1.0 Available at https://blockchainhub.net/ 


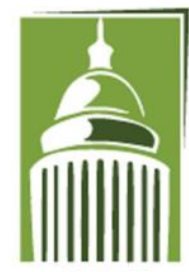

AR F
Global Proceedings Repository

American Research Foundation

ISSN 2476-017X

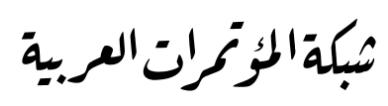

http://arab.kmshare.net/

Available online at http://proceedings.sriweb.org

كل منها يشغل عقدة ويجب ان يوقع • ا منها على كل كتلة لكي تكون الكتلة صالحة، قد يكون الحق في قراءة تقنية البلوكتشين عام، او يقتصر على المشاركين. ومن الأمثلة على الفيدرالي:(cord، B3Ilinsurance) ، R3lbanks، EWflenergy - ميلل من تكاليف المعاملات والبيانات الزائدة عن الحاجة ويستبدل النظم القديمة ويبسط معالجة المستندات والتخلص من آليات الامتثال شبة اليدوية. - - بهذا المعنى يمكن اعتبارك مكافئًا ل (SAR) في التسعينات: يقلل من التكاليف ولاكن لا يعطل. قد يجادل الكثيرون بان تقنية البلوكتشين الفدرالية او الخاصة قد تعاني من مصير الشبكات الداخلية في التسعينات عندما قامت الشركات الخاصة ببناء شبكاها المحلية او الخاصة او شبكات WAN بدلا من استخدام الانترنت العام وجميع الخدمات، ولكنها عاف عليها الزمن خاصة مع ظهور (SAAS Software As A Service) (Web2) (هي بربيات تعمل خلف جدار ناري في شبكة محلية او حاسوب شخصي وهي تقدم كخدمة

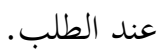

3. تقنية البلوكتشين الخاصة: يتم الاحتفاظ بأذونات الكتابة مركزيا لمؤسسة واحدة، قد تكون أذونات القراءة عامة او مقيدة الى حد تعسفي، وتشمل أمثلة تطبيقات إدارة قواعد البيانات والتدقيق وما الى ذلك، والتي تكون داخلية لشركة واحدة. وبالتالي قد لأتكون قابلية القراءة العامة ضرورية في كثير من الحالات على الإطلاق، في حالات أخرى تكون قدرة التدقيق العام مطلوبة. تعتبر طريقك للاستفادة من تقنيات تقنية البلوكتشين من خلال انشاء مجموعات مشاركين يمكنهم التحقق من المعاملات الداخلية. هذا يضعك في خطر الاختراقات الأمنية مثلما هو الحال في النظام المركزي على عكس العام المضمون من قبل آليات الحوافز لنظرية اللعبة. ومع ذلك فأها لديها حالات استخدام، خاصة عندما يتعلق الامر بقابلية التطوير والامتثال للدولة لقواعد خصوصية البيانات والقضايا التنظيمية الأخرى، حيث لديها مزايا أمنية معينة، وعيوب أمنية أخرى. ومن الأمثلة على الخاصة: (MONAX،Hyperledger, Multichain) - ميلل من تكاليف المعاملات والبيانات الزائدة عن الحاجة ويستبدل النظم القديمة، ويبسط معالجة المستندات

$$
\text { والتخلص من آليات الامتثال شبة اليدوية. }
$$

- ميكن اعتباره مكافئة ل SAP حيث يقلل من التكاليف ولأكنة لا يؤدي الى تعطيلها. تدرس الشركات تقنية البلوكتشين والمزيد حول تحسين نظامها الحالي وعملية توفير التكلفة او حماية البيانات (مثل تبسيط العملية) او 


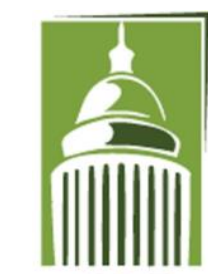

AR F
Global Proceedings Repository

American Research Foundation

ISSN 2476-017X

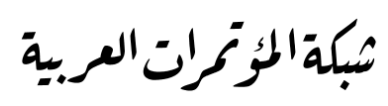

http://arab.kmshare.net/

Available online at http://proceedings.sriweb.org

انشاء أنواع جديدة من الخدمات (مثل قاعدة بيانات مع حماية اقوى للنزاهة). توجد معسكرات مختلفة تقوم ببناء اطر عمل تقنية البلوكتشين للمؤسسة الخاصة، والأكثر شيوعا الان هو(Hyperledger Fabric) وهي جزاء من مشاريع (The Linux Foundatichain) التي تستضيفها (Ther) مع ملاحظة ان جميعها للأشخاص المصرح لهم، مما يعني أنه يمكن فقط للأشخاص المسموح لهم المشاركة في تشغيل واستخدام تقنية البلوكتشين، جميع العقد مملوكة ويتم صيانتها من قبل المؤسسة وبالتالي يتم تحديد التدابير الأمنية من قبلهم، مثال تقرر المؤسسة عدد العقد التي تعمل على التوافق، وأين يتم توزيع العقد جغرافيا، هذا يحدد مستوى المتانة ضد الهجمات، لا يرى المستخدمون أي قيم إضافية ل تقنية البلوكتشين مالك ينعكس ذلك من خلال تخفيض التكلفة على المستخدم والمرونة في تنفيذ احتياجات المستخدم، ما لفائدة اذا كان البنك يقوم بتبسيط نظام الواجهة الخلفية الخاصة به بتقنية تقنية البلوكتشين مالم ينعكس على المستفيد بتخفيض التكلفة.

$$
\text { أسباب تبني تقنية البلوكتشين: }
$$

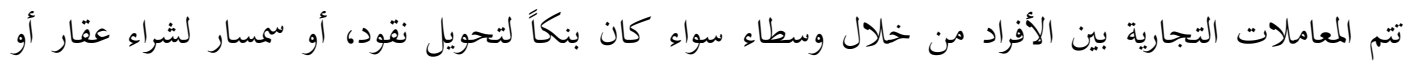

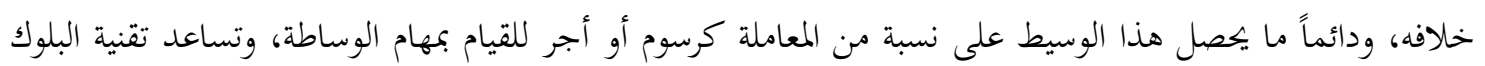

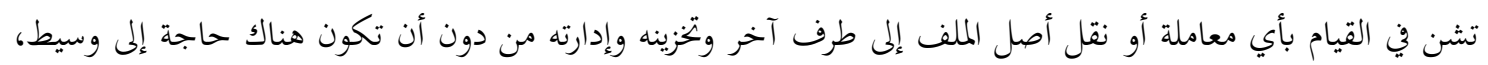

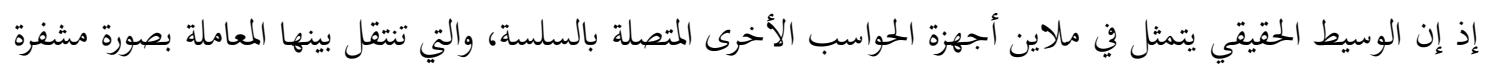

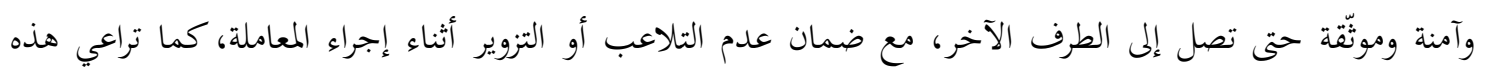

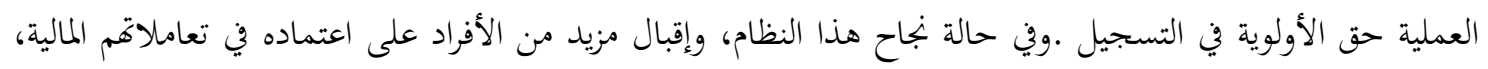

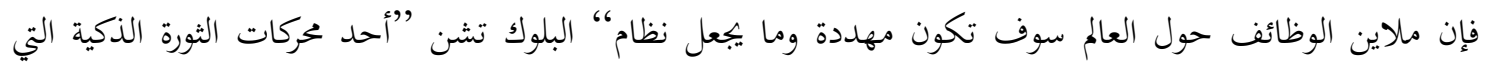

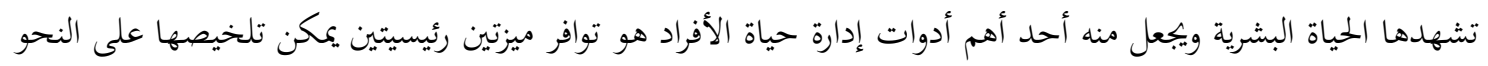

1. نقل أصل الملفات: يتمثل الهدف الرئيسي من البلوك تشن في نقل أصل الشيء إلى الطرف الآخر عبر

الإنترنت، فما يحدث دائماً هو نقل نسخة من الملف، وليس نقل الملف الأصلي، بمعنى عند إرسال إيميل أو

ملف عبر الإنترنت فما يحدث هو إرسال نسخة من الملف أو المعلومات الموجودة عن الطرف الأول إلى الطرف

الثاني، مع إمكانية الطرف الأول بالاحتفاظ بالأصل، وهو ما لا يمكن أن يحدث عند محاولة نقل أصل الشيء

1. Don Tapscott,(2018). How the blockchain is changing money and Business, TED Summit, June 2016, accessible at: http:// bit.ly/2bp4XiI (Last accessed: February 5. 


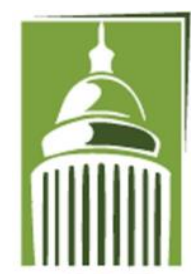

AR F
Global Proceedings Repository

American Research Foundation

ISSN 2476-017X

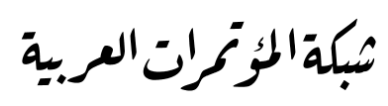

http://arab.kmshare.net/

Available online at http://proceedings.sriweb.org

مثل الأموال، فما يمكن أن تقوم بإرسال مبلغ مائة دولار لأحد الأفراد ثم تحتفظ به مرة أخرى لنفسك، وكذلك الأمر ينطبق على التصويت في العملية الانتخابية، والحصول على حقوق الملكية الفكرية وبراءات الاختراع، أو شراء الملفات الأصلية كالأغاني والأفلام الأصلية التي يتم شراؤها والاستحواذ عليها بصورة غائية بما يعني أنه لا ينبغي لطرف آخر الاحتفاظ بها.

2. حماية المعاملة من التلاعب :تتميز البلوك تشن بخاصية مهمة، وهي التأكد من عدم الغش أو التدليس أثناء تنفيذ المعاملات التي يتم إجراؤها عبر تقنية البلوكتشين، وعدم التلاعب بالمعاملات بعد إتمامها، وينطبق ذلك على العديد من الأنشطة اليومية، مثل عمليات نقل الأموال والطرود والشحنات والحاويات وعمليات تسجيل العقود والممتلكات وشحن البضائع والتأكد من خط سر المركبات والمواصلات وإجراء المعاملات الحكومية، حيث تمنع (البلوك تشن) من التلاعب بالمعاملات بصورة تسبب الإضرار بروات الدولة أو الإخال بمبدأ تكافؤ الفرص، وهو ما يساعد في القضاء على الفساد بصورة كبيرة، حيث يضمن نظام البلوك تشن عدم التلاعب هما وعدم التعديل عليها أو حذفها لاحقاً، وهو ما يساعد في خلق الثقة بن المستخدمين بصورة كبيرة. تطبيقات تقنية البلوكتشين:

تتعدد استخدامات البلوك تشن في عدة مجالات مختلفة، إذ لا يقتصر دوره فقط على تحويل الأموال، سواء كانت افتراضية أو تقليدية، ويمكن وتوضيح ذلك في عدة نقاط رئيسية على النحو التالي:

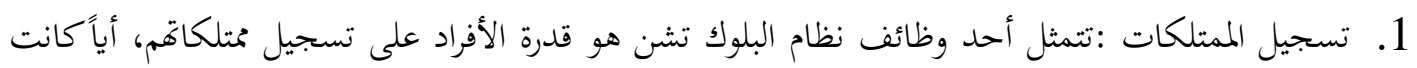

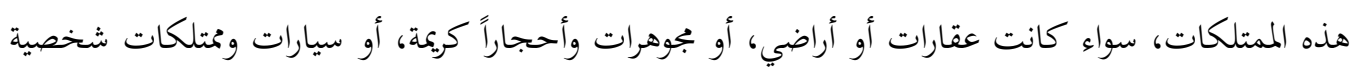

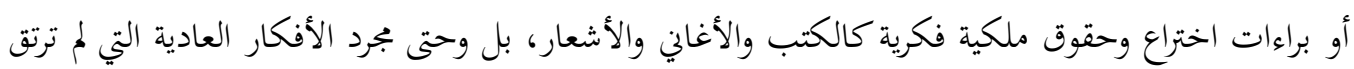

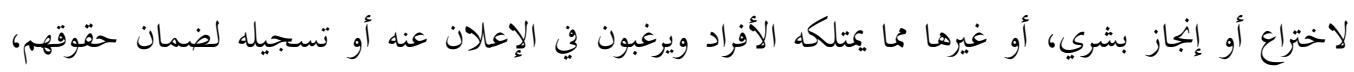

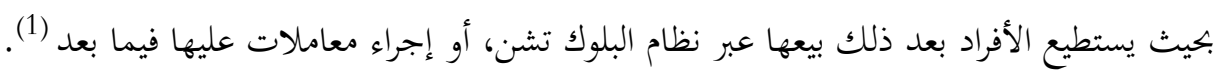

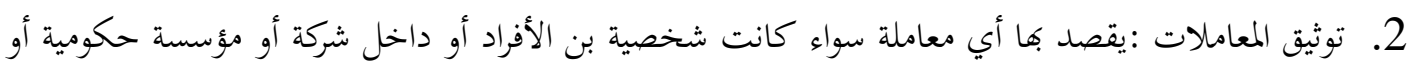
غير حكومية، فالبلوك تشن بمنزلة سجل رقمي مفتوح وموزع، يسمح للجميع بإدخال البيانات كافة عليه، سواء كانت هذه البيانات إجراءات حكومية أو متابعة خطوط الإنتاج في مصنع، أو خط سر طائرات أو

1. EYAL MALINGER, Blockchain could 'Change Everything' for Real Estate, Venture Beat, November 18, 2017, accessible at: https://venturebeat.com/2017/11/18/blockchain-could-change-everything-forreal-estate/ 


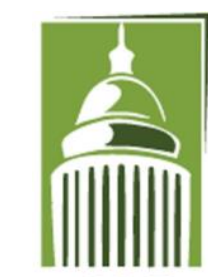

AR F

\section{Global Proceedings Repository}

American Research Foundation

ISSN 2476-017X

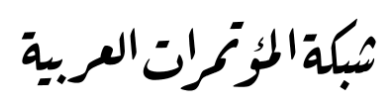

http://arab.kmshare.net/

Available online at http://proceedings.sriweb.org

المبحث الثاني/ المجالات التي يمكن فيها استخدام تقنية البلوكتشين لحفظ حقوق الملكية الفكرية.

الججالات الرئيسية التي من المختمل ان تأثر في حقوق الطبع والنشر وهي كالاتي:

1. انشاء أنظمة قائمة على تقنية البلوكتشين لإدارة الحقوق الرقمية DRM.

2. انشاء أنظمة تسجيل حقوق الطبع والنشر قائمة على تقنية البلوكتشين.

3. الترخيص الالية باستخدام تقنية البلوكتشين.

4. التقليل من الحاجة الوسطاء التقليدين او الإدارة الجماعية باستخدام تقنية البلوكتشين.

1. أنظمة إدارة حقوق الملكية الفكرية الرقمية (DRM):

أدى التدفق الهائل من المعلومات المؤتمتة التي حولها بجتمع المعلومات من الأصل الملموس التي تحميها حقوق الطبع

والنشر الى الشكل الرقمي لخلق تحديات كبيرة لإطار قانوني خاص كان يستند في السابق الى الأصول الملموسة، من حيث

المبدأ يمكن نسخ الأصول الرقمية بسهوله وخلطها ودبجها مع أصول أخرى ومشاركتها مع ملايين الأشخاص لو سلطنا

2. An Analysis of the Opportunities and Threats in Blockchain Technology, Medium, February 13, 2017, accessible at:https://medium.com/the-mission/ananalysis-of-the-opportunities-and-threats-in-blockchaintechnology

6f55d647be3e ( last accessed: February 15, 2018). 


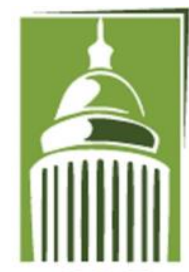

AR F
Global Proceedings Repository

American Research Foundation

ISSN 2476-017X

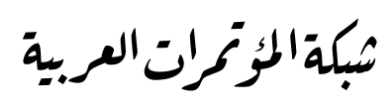

http://arab.kmshare.net/

Available online at http://proceedings.sriweb.org

الضواء على القانون فهو يجيز لك اهداء او التصرف في الكتاب او أي اصل اخر محمي بحقوق الطبع والنشر الى من تريد في هذه الحالة قانون حقوق الطبع والنشر جعلها متاحة بشكل أوسع ولم يحقق التوازن بين الحق العام والخاص. لقد أدى هذا الى خلق قانون خاص يعرف ب الألفية يستند الى اتفاقيه بيرن يمنح القطاع الخاص صلاحيات أكبر في التحكم بجقوق الملكية الفكرية على حساب أهداف السياسة العامة مثل القيود وحق الوصول المى المعلومات والتعلم. يجادل أنصار إدارة الحقوق الرقمية بان ذلك يضمن استمرار تدفق الإيرادات المالية لأصحاب الحقوق في العصر الرقمي ويعد هذا اقل محفز لإبداعهم. لقد تم تصميم أنظمة إدارة الحقوق الرقمية (DRM) لمساعدة مالكي حقوق الطبع والنشر لحماية اصولمم الرقمية عن طريق تقييد الازدواج والتوزيع والاستخدام المتمل من مجموعة من الأشخاص غير المصرح لهم من قبل مالك الحقوق الرقمية.

لقد استخدمت بعض الشركات القانون الملزم في معاهدات الويبو لمصالحها الخاصة وأساءت استخدامه مما رسخ صورة سائدة عند المستخدمين ان أنظمة إدارة الحقوق الرقمية سيئة وعديمة الجلدوى مما شجع على الاستخدامات السيئة للأعمال المحمية بحقوق الطبع والنشر. لقد كرس قانون حقوق النشر في الألفية المركزية لأنظمة إدارة الحقوق الرقمية (1). بنية أنظمة إدارة الحقوق الرقمية:

هي بجموعة من البرامج والأجهزة التي تحدد وتحمي وتدير القواعد للوصول الى المتوى الرقمي واستخدامه سواء كان على شكل (نص، صوت، مقطع فيديو) لقد طرح النموذج الأول من (DRM) في أواخر التسعينات في شكل نظام يتحكم قواعد وشروط الاستخدام في شكل مقروء آلياً. لقد تم تصميمها لإعطاء أصحاب الحقوق أكبر قدر مككن من السيطرة على المحتوى الرقمي محددة بذلك شروط وظروف الوصول والانتفاع من المحتوى. على سبيل المثال، تم تصميم لدعم نشر وبيع الكتب الالكترونية والأفلام الرقمية والموسيقى والألعاب التفاعلية وبرامج الكمبيوتر وغيرها من الأشياء الموزعة في شكل رقمي، يتم التعبير عن سياسات ونماذج اعمال أصحاب الحقوق في اتفاقيات الترخيص التي تعزز الحقوق الحصرية المعترف بها بموجب حقوق الطبع والنشر لتحديد قواعد استخدام المواد الرقمية. تترجم البنود والشروط التعاقدية الى تحديد كيف يمكن استخدام المحتوى من قبل أطراف ثالثة وتقييد إمكانيات الاستخدام وفقا لذلك. مكونات أنظمة إدارة الحقوق الرقمية .

1. Miche`leFinck . Valentina Moscon, Copyright Law on Blockchains: Between New Forms of Rights Administration and Digital Rights Management 2.0.(2018). SpringerIIC - International Review of Intellectual Property and Competition Law January 2019, Volume 50, Issue 1, pp 77-108 
Global Proceedings Repository

American Research Foundation

ISSN 2476-017X

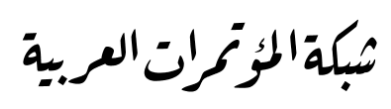

http://arab.kmshare.net/

Available online at http://proceedings.sriweb.org

هناك مكونات ذات صله بأنظمة إدارة الحقوق الرقمية وهي كالتالي (1): - - تدابير الحماية التكنولوجية (TPM): تشتمل على الأجهزة والبربجيات لحماية القواعد وتحديد المحتوى ونظام تكنولوجيا المعلومات المستخدم. وتسعى الى توفير آليه حماية فعالة يستطيع من خلالها مالكو المحتوى من إدارة موضوعهم وتمكين الوصول اليه من قبل أطراف ثالثة، ان برجيات (TPMs) المستخدمة على نطاق واسع هي التشفير، والعلامات المائية، والتحكم في النسخ، وبصمات الاصبع، والتحكم في الوصول، وإدارة مفاتيح الاستيقان وغيرها من القيود التي تفرض جميع الشروط على مستخدمي المواد الرقمية. - معلومات إدارة الحقوق (RMI): هي المعلومات التي تحدد المحتوى المحمي بحقوق الطبع والنشر او الحقوق المجاورة وأصحاب الحقوق في هذا المحتوى وشروط الاستخدام المرتبطة به. وتحمي معاهدة الويبو جميع هذه المعلومات. - - لغات التعبير عن الحقوق (RELs): تشمل معظم أنظمة (DRM)على لغات التعبير وهي لغات تقنية لما قواعد تركيب وقواعد مفردات خاصة للتعبير عن نوع الاستخدامات المسموح بها او الممنوعة او الإلزامية مثل التعبير عن عدد الأذونات في تدفق المعلومات والنسخ، والحذف والتعديل.

عيوب أنظمة إدارة الحقوق الرقمية (DRM):

لأنظمة الحقوق الرقمية بعض العيوب يماول الباحث ايضاحها هنا وهي كما يلي (2): 1. التشغيل البيني: تتنوع أنظمة إدارة الحقوق الرقمية وتتكون بنيتها من مكونات مادية وبربجية التي هي في معظمها مملوكة 2. يحتاج كسرغير قابلة للتشغيل البيني، ان التشغيل البيني بين الأجهزة والبرجيات امر ضروري للغاية. مرة واحدة فقط وبعد ذلك يمكن اجراء ملاين النسخ من العمل المحمي. 3. تمنع العديد من الاعمال المشروعة مثل عمل نسخة احتياطية او تشغيل المحتوى من اجهزه متعلدة وهذا أنشطة مشروعة قانونيا وتم حضرها بواسطة أنظمة إدارة الحقوق الرقمية. 4. مكلفة جدا حيث يصعب على مالك الحق دفع تكاليفها

1. Miche`leFinck .op.cit, pp 77-108

1. Annabel Tresise, Jake Goldenfein and Dan Hunter,(2018)." What Blockchain Can and Can't Do for Copyright,Australian Intellectual Property Journal 144 Pages 14 .Electronic copy available at: https://ssrn.com/abstract=322738. 


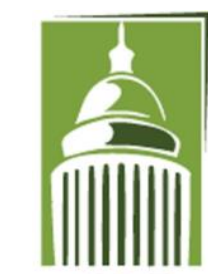

A R F
Global Proceedings Repository

American Research Foundation

ISSN 2476-017X

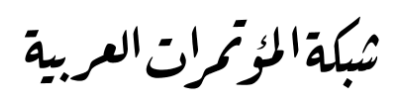

http://arab.kmshare.net/

Available online at http://proceedings.sriweb.org

5. سهولة اختراقه وقرصنته، لقد اثتت اها لا تمنع القرصنة ولكن الأسواء من ذلك انها تحبط المستهلكين الشرعيين من خلال منعهم من التشغيل البيني لعدة أجهزة غالبا ما ينظر المستخدمون الى DRM على اها أنظمة خبيثة وتمثل مشكلة بالنسبة لمه، كما اهما في كثير من الأحيان للتعامل كما هو مقصود لها، اها مكلفة وتستغرق وقتا طويلا للتطوير والنشر لذلك غالبا ما تفشل أنظمة إدارة الحقوق الرقمية في الحفاظ والسيطرة على الأصول الرقمية. وفي معظمها تكون عرضة للتلاعب العدائي. وعلى الرغم من ذلك فان قانون حقوق الطبع والنشر يكرس مركزية أنظمة إدارة الحقوق الرقمية في حماية الأصول الرقمية.

تأثير استخدام تقنية تقنية البلوكتشين في إدارة الحقوق الرقمية وكيف يمكن الاستفادة منة: توفر تقنية تقنية البلوكتشين آلية بسيطة نسبيا للتحكم في حقوق الاستخدام والحفاظ على أذونات حقوق الطبع والنشر كبديل عن الاعتماد على أنظمة إدارة الحقوق الرقمية المسجلة، على سبيل المثال يمكن ان توفر منصات تقنية البلوكتشين استخداما غير محدود وغير خاضع للأصول الرقمية للمستخدم ومع ضمان عدم إمكانية نسخ المادة، لن تحتفظ تقنية البلوكتشين نفسها بالأصل الرقمي وذلك بسبب الحجم وعدم النضج الحالي في إمكانات المعالجة ولكنها بدل من ذلك ستسهل عقدا ذكيا مشفرا بالمعلومات المتعلقة بحقوق الأصل الرقمي، ان العقد الذكي ليس عقدا قانونيا في هذه الحالة ولكنة جزء من التعليمات البرجية التي يمكنها تنفيذ البنود والأذونات التعاقدية المشفرة تلقائيا. حيث يمكن للعقد الذكي تنفيذ تخصيص استخدام الأصول الرقمية عبر "الرموز" للعملة المشفرة بين المستخدمين ومالكي الحقوق بطريقة شفافة ومحايدة هذه الوظيفة هي مفتاح الأجر والمدفوعات. مثال على ذلك، لنفترض أنك اشتريت كتابا إلكترونياً من بائع تجزئة عبر الانترنت يستخدم نظام إدارة الحقوق الرقمية المستندة على تقنية البلوكتشين، سيتم تسجيل معاملة الشراء الخاصة بك على شبكة تقنية البلوكتشين في سجل يحتوي على كافة المعلومات حول عمليه الشراء وحق الوصول الخاصة بك، عندما ترغب في قراءة الكتاب الالكتروني فان فتحة على جهازك يؤدي الى اتصال مع دفتر الأستاذ الموزع الذي يمثل تقنية البلوكتشين ويقوم نظام بفحص السجل للحصول على الإذن اللازم ويمنحك إمكانية الوصول الى الكتاب. 1 (DRM) اما إذا كنت قد اشتريت ترخيصا محدود المدة فبإمان النظام استشارة خادم التوقيت الموثوق ومقارنة الوقت / التاريخ الحالي بموجز شروط العقد الذي تم الاتفاق علية بشكل منتظم وبمجرد انتهى المدة يقيدك من الوصول الى الكتاب. وبالتالي

1

G. Ishmaev ,(2017)." Blockchain Technology as an Institution of Property", Metaphilosophy / Volume 48, Issue 5. Cited by: 3 .Avialble At: https://doi.org/10.1111/meta.12277. 


\section{Global Proceedings Repository \\ American Research Foundation}

ISSN 2476-017X

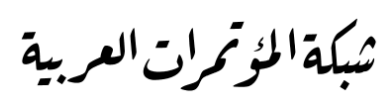

http://arab.kmshare.net/

Available online at http://proceedings.sriweb.org

يككن ان يتغلب استخدام النظام الأساسي لتقنية تقنية البلوكتشين على العديد من المشكلات المرتبطة بأنظمة (DRM)

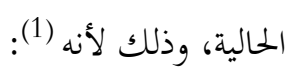

1. أنه يتجنب منح الملكية المطلقة لمعظم أنظمة إدارة الحقوق الرقمية حيث لا يسمح شراء ترخيص للاستماع على كلى الماء

اغنية في Spotify للمستخدم بالاستماع اليها على (iTunes) وذلك بسبب مشكلة التشغيل البيني، حيث

$$
\text { يمكن لنظام (DRM) المعتمد على منصة تقنية البلوكتشين تجنب هذه المشكلة. }
$$

2. يتيح العقد الذكي لأصحاب الحقوق السيطرة على من يمكنه الوصول الى منتجاتم.

3. يوفر لكل من المستخدم وصاحب الحق قدرا أكبر من الأمن ويعزز نظام اللامركزية ويحقق الشفافية ويزيد من الأمن

$$
\text { ضد أي هجوم معادي. }
$$

4. يتم تسجيل العقد على دفتر الأستاذ العام وهذا يمنحه خاصية الثبات مما يعني انه غير قابل للتغير.

5. ت تتيح اللامركزية الى إمكانية خفض محتمل في رسوم الخدمة، ان أنظمة إدارة الحقوق الرقمية مكلفة بالنسبة لأصحاب

الحقوق حيث يتطلب حماية ضد الهجمات وكذلك رسوم خدمة وصيانة من خلاص تقنية تقنية البلوكتشين سيتم

توفير الجهد والتكلفة لصاحب الحقوق وذلك لأنه لن يتحمل مسؤولية الحفاظ على تقنية البلوكتشين.

وبمجرد شراء المستخدم الأصل الرقمي من موقع الويب، يتم تنفيذ العقد الذكي على الفور ويتم تنفيذ جميع الإجراءات

الأخرى من توزيع الإتاوات تلقائيا.

وبالتالي فان استخدام تقنية البلوكتشين كبديل لأنظمة إدارة الحقوق الرقمية (DRM) تبدو ناجحة حيث لدية القدرة للتغلب على العديد من المشكلات التقنية والأمنية التي يوجهها أصحاب الحقوق، وتزيد من الأمن ضد المتسللين، وتوفر قدرا أكبر من الأذونات والاستخدام وكذلك تضمن للمستخدمين عدم تثبيت تقنيات مخفية على اجهزعم من علامات مائية وغيرها (2).

2. أنظمة تسجيل حقوق الطبع والنشر القائمة على تقنية البلوكتشين:

2. Annabel Tresise, Jake Goldenfein and Dan Hunter,(2018),op.cit. Pages14 .

1. Annabel Tresise, Jake Goldenfein and Dan Hunter,(2018). Op.cit.Pages15. 


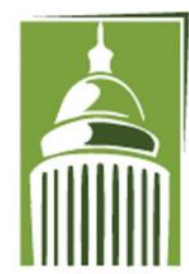

AR F
Global Proceedings Repository

American Research Foundation

ISSN 2476-017X

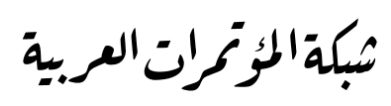

http://arab.kmshare.net/

Available online at http://proceedings.sriweb.org

ان أنظمة تسجيل حقوق الطبع والنشر القائمة على منصات البلكتشين مناسبة للتغلب على العديد من المشكلات المرتبطة بملكية حقوق النشر واثبات الوجود او الأبوة وإمكانية وصول المستخدم الى مجموعة من الاعمال الرقمية التي تم إنشاؤها حيث تثبت أنظمة التسجيل وجود عمل وملكية الشخص الذي قام بإنشائه من خلال تحديد المعلومات في سجل متاح للجمهور، من الناحية القانونية في مجالات الملكية الفكرية مثل براءات الاختراع والعلامات التجارية وأنظمة التصميم الصناعي يعد التسجيل مطلبا رمميا حيث انه بدون تسجيل يسقط عنك حق الحماية القانونية وطلب التمتع في الملكية التي ابتكرتا.

اما في قانون حقوق الطبع والنشر، تتمتع الاعمال بالحماية من تاريخ تثبيتها دون أي إجراءات رسمية، كما تحظر الإجراءات الإلزامية من قبل السلطة المحلية للتسجيل الإجباري بموجب المادة الخامسة من اتفاقية برن لحماية المصنفات الأدبية والفنية وتلزم جميع الدول الموقعة بهذا البند. وتعتبر محمية من تاريخ تثبيتها على أي وسيط سواء قد تم اتخاذ خطوات لتسجيل العمل في نظام تسجيل رسمي او أي وسيط يثبت وجودها. على الرغم من حظر الإجراءات الإلزامية، لاتزال بعض السلطات القضائية تتطلب التسجيل لإتاحة بعض الحقوق، ان أنظمة التسجيل الرسمية توفر فائدة في مجموعة متنوعة من المجالات لذلك تعتبر الأنظمة آليات مفيدة للتنسيق الاقتصادي لكل من صاحب الحق والمستخدم، حيث يمكن لصاحب الحق إثبات وجود العمل والحقوق المجاورة له، بينما يمكن للمستخدم الوصول الى المعلومات والحقوق ذات الصلة المرتبطة بالعمل (1). مزايا أنظمة التسجيل القائمة على تقنية البلوكتشين. يمكن ان تتغلب أنظمة التسجيل القائمة على منصات تقنية البلوكتشين على العديد من الصعوبات، حيث باستخدامها سيكون التسجيل بسيطا واستنادا الى نموذج إثبات الوجود كل ما يحتاج صاحب الحقوق هو تشفير الأصل الرقمي بحيث يصبح علامة بجزئة على تقنية البلوكتشين ويمكن ان يتضمن السجل تفاصيل عن أصحاب الحقوق والنسب في توزيع الإتاوات بين أصحاب الملكية. في حال ظهور أي مشكلات في المستقبل ويحتاج فيها الى إثبات وقت ومكان عمله، فستكون المعلومات متاحة على دفتر الأستاذ العام (2).

1. Miche`leFinck . Valentina Moscon, Copyright Law on Blockchains: Between New Forms of Rights Administration and Digital Rights Management 2.0.(2018).SpringerIIC - International Review of Intellectual Property and Competition Law January 2019, Volume 50, Issue 1, pp 77-108

2. Miche`leFinck . Valentina Moscon, op.cit. pp 77-108 


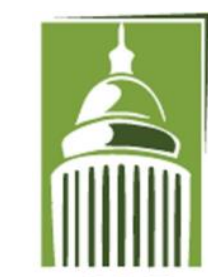

A R F
Global Proceedings Repository

American Research Foundation

ISSN 2476-017X

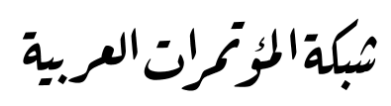

http://arab.kmshare.net/

Available online at http://proceedings.sriweb.org

من المعلوم عدم وجود حواجز جغرافية في فضاء الانترنت مما يوضح وجود فجوة واقعية على عدم وائمة القانون الحالي مع التقدم المتسارع في التقنية، تقدم تقنية تقنية البلوكتشين العامة حلول من حيث القضاء على الوسطاء والشفافية ولكن هناك تحديات مثل السرعة في تنفيذ المعاملة وكذلك الحوافز المقدمة للمنقبين الذين يفحصون ويتحققون من صحة المعاملة. كما تقدم تقنية البلوكتشين الخاصة حلول من حيث تحديد من يمكنهم المشاركة في التحقق من صحة المعاملة ومن ثم تشفيرها ولكن لن توفر الدرجة المرجوة من حيث الأمن مقارنة ب العام. من الممكن أيضا الحصول على مجموعات من الأنظمة 1 الخاصة والعامة. 1

على الرغم من المزايا التي تقدمها تقنية البلوكتشين الا ان بناء مثل هذا النظام لايزال يتطلب جهود متظافرة من قبل الأطراف المعنية على المستوى الدولي، (في بادرة هي الأولى من نوعها أوصت اللجنة المعنية بمعايير الوييو في الدورة السادسة المنعقدة في جنيف من 1 الم 9 أكتوبر (2019م) انشاء مهمة لإعداد توصيات بشأن تقنية تقنية البلوكتشين وكانت التوصية رقم rا تتعلق بإنشاء سجل ملكية فكرية موزع؛ وهذا نص البيان " التوصية رقم rا إ بتعاون مع الدول الأعضاء المهتمة، ينبغي ان يطور المكتب الدولي نموذجا لسجل ملكية فكرية موزع. ويمكن استخدام النموذج في تطبيقات الملكية الفكرية لاستحداث سجل أصلي لعديد من تطبيقات الملكية الفكرية، على سبيل المثال من اجل التحقق من صحة المطالبات بالأولوية. ودراسة امكانية استخدام سجل ملكية فكرية موزع يربط بقاعدة البيانات (WIPO CASE) أو بالسجل الدولي. وينبغي أيضا استكشاف امكانات تكنولوجيات تقنية البلوكتشين لربط هذه السجلات الموزعة. واستلمت اللجنة اقتراحين بشان تقنية البلوكتشين من استراليا والاتحاد الروسي كلهما يقترحان وضع نموذج لتوحيد معايير استخدام تقنية البلوكتشين في مجال الملكية الفكرية، بما في ذلك مبادئ توجيهية وممارسات مشتركة واستخدام مصطلحات كإطار يدعم التعاون ويثبت صحة المفهوم، وكذلك اقتراح وضع معيار جديد للويبو ينطبق على تكنولوجيا تقنية البلوكتشين في عميات منح حماية حقوق الملكية الفكرية، ومعالجة المعلومات واستخدامها، ويقترح أيضا انشاء فرقة عمل جديدة باسم فرقة العمل المعنية بسلاسل الكتل، تتولى هذه المهمة الجديدة، في الوقت الحالي من تاريخ ـّ ابريل (2019م) يتم مناقشة الموضوع في برنامج عمل لجة المعايير باسم (تقنية البلوكتشين للملكية الفكرية المهمة رقم 9ه) على ان يتم استعراض تقرير عن التقدم المحرز في تنفيذ المهمة لي تطلع علية اللجنة في دورةا السابعة. نود الإشارة هنا الى ان المنظمة

1

G. Ishmaev ,(2017)." Blockchain Technology as an Institution of Property", Metaphilosophy / Volume 48, Issue 5. Cited by: 3 .Available At: https://doi.org/10.1111/meta.12277. 


\section{Global Proceedings Repository \\ American Research Foundation}

ISSN 2476-017X

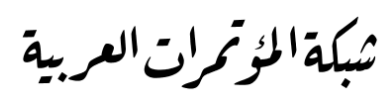

http://arab.kmshare.net/

Available online at http://proceedings.sriweb.org

العالمية للملكية الفكرية (الويبو) معنية فقط بتسجيل براءات الاختراع والعلامات التجارية والتصاميم الصناعية وتسميات المنشاء وكذلك أسماء الحقول على الانترنت ولا تشمل حقوق الطبع والنشر (1). يمكن ان يكون سجل الوييو الخاضع للرقابة حلا سهلا لأنظمة التسجيل المحلية مما يسمح للمستخدمين بالوصول الفوري الى معلومات الحقوق المتعلقة بالأصول الرقمية. ومع ذلك مالم يكون للويبو القدرة على حل النزاعات على سلسة الكتل على غرار التحكيم سيكون دورها فقط في توفير السجل وإثبات الوجود ويتعين على أصحاب الحقوق التقاضي في المحاكم المحلية وسوف تتحمل الويبو عبئ تكلفة إدارة السجلات، وعلى المستوى المحلي يجب ان يكون نظام التسجيل طوعيا حتى لا يتعارض مع اتفاقية برن، في كلتا الحاليتين قد لا يكون نظام التسجيل عمليا. ما فائدة الويبو لتمويل وتشغيل السجل إذا لم يكون شرط في قانون حقوق التأليف والنشر: بدون تغيير في المادة (5) من اتفاقية برن او الهيكل القانوني المحيط بها يبدو اتباع فج حكومي او الويبو مستحيلا في المستقبل المنظور . ومن ناحية أخرى بداء اللاعبون من القطاع الخاص في استكشاف منصة تقنية البلوكتشين لتسجيل حقوق الطبع والنشر وإدارة الحقوق. ومن المزايا الرئيسية له أنه يمكن للشركة انشاء نظام تسجيل دولي والمحافظة علية. هذا يعني أنه يمكن للمستخدم ان يتحقق بسرعة وسهوله من الأصل وتفاصيل صاحب الحقوق والاستخدام المتاح للعمل قبل استخدامه (أي الحصول على المعلومات الببليوغرافية عن العمل) ومع ذلك من المرجح الا يهتم مواطن دولة معينة بمعرفة الأصل والتفاصيل لصاحب عمل في دولة أخرى إذا لم يتمكن من استخدامها لأغراضه الخاصة. علاوة على ذلك ليس من المجدي بتحاريا تشغيل نظام على منصة تقنية البلوكتشين إذا كان كل ما يمكن فعله هو تقديم معلومات تتعلق بالعمل سواء كانت اغنية او كتاب او فلم، لذلك يكون سجل تقنية البلوكتشين محدود إذا لم يمكن المستخدم من الوصول المى المحتوى. في ضواء هذه الاعتبارات سيحتاج اللاعبون في القطاع الخاص ليس فقط إدارة السجل ولاكن أيضا توفير الوصول الى المحتوى او الترخيص للمستفيدين. ان إثبات السجل فقط يعتبر منهك ومكلف وبلا جدوى ان لم يوفر معه إمكانية الوصول الى المختوى وهذا لأيتم الا بترخيص استخدام العمل (2). 3. أنظمة الترخيص الآلي باستخدام تقنية البلوكتشين. على الرغم من عدم نضج العقود الذكية الا اها تشير في حال لو تطورت كحل واسع الانتشار لمشاكل أنظمة إدارة الحقوق الرقمية فمن المتوقع ان تتغير الوسائل التقليدية لترخيص حقوق النشر. في الواقع يعد الترخيص على منصات تقنية

1. Miche`leFinck . Valentina Moscon, 1,op.cit. pp 77-108

1. Annabel Tresise, Jake Goldenfein and Dan Hunter,(2018).op.cit. Pages 26 


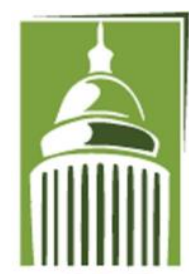

AR F
Global Proceedings Repository

American Research Foundation

ISSN 2476-017X

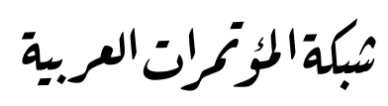

http://arab.kmshare.net/

Available online at http://proceedings.sriweb.org

البلوكتشين بأحدث ثورة في الصناعات الإبداعية لأنه يمكن ان يوفر تحما أكبر في محتوى حقوق الطبع والنشر، وتخفيض تكاليف المعاملات للمؤلفين، وإزالة الوسطاء، وتوليد مكافأة فورية لمنشئ العمل. حيث يمكن تنفيذ العقود الذكية كوسيلة لتوفير مكافأة عادلة وسريعة لأصحاب حقوق الطبع والنشر والتفاعل المباشر مع جمهورهم. بينما تتعامل أنظمة إدارة الحقوق الرقمية DRM مع الوصول الى الأذونات والتحكم فيها، فان ترخيص حقوق الطبع والنشر يتعلق بتبادل الأذونات والكفاءات، بمجرد اكتمال شراء الأصل الرقمي، يتم تشفير المعلومات المتعلقة بالشراء في بتزئة مضمنة بشكل دائم في تقنية البلوكتشين، مما يتيح الاستخدام التلقائي سيكون تبادل الدفع هو ترخيص للاستخدام وفقا لشروط العقد. كما يمكن الدفع المباشر والمكافأة للمؤلف، ستكون المعاملة بسيطة حيث يتم تسجيل المعلومات المتعلقة بالمالك سواء كان المالك يريد ان يتقاضى الأجر عن طريق البيع او التأجير على كل مرة يتم استخدام الأصل الرقمي، كما تستطيع العقود الذكية التكيف مع أي شروط أخرى مثل حقوق إعادة الاستخدام. كما ان العقود الذكية قادرة على تسهيل المعاملات الأكثر تعقيدا والتي تشمل على عدد من المؤلفين او اعمال متعددة وكذلك الحقوق المجاورة لحق المؤلف او عن طريق التعاون، على سبيل المثال تم انتاج فيلم، أصحاب الحقوق هنا هم المخرج والمنتج وبمموعة من الممثلين والمصورين وطاقم فني وعدد كبير من المشاركين يستطيع العقد الذكي تأدية تلقائية لمكافئة وتوزيع الإتاوات على جميع المدرجين في العقد بناء على النسبة المئوية المحددة في الاتفاق الخاص كمم في كل مرة يتم فيها شراء العمل او استخدامه. 1 أحد الفوائد المحتملة من استخدام وظيفة العقد الذكي في الترخيص هي الطبيعة الثابتة لسلة الكتل، بمجرد ان يتفق الطرفان على التوزيع الخاص لنسب الملكية سيتم تشفيرها على تقنية البلوكتشين وبعد ذلك لا يمكن تغيرها او العبث بها. وبالتالي يعتبر سجل ثابت يمكن الرجوع الية في حل النزاع او خلافات محتملة بشأن مدفوعات الإتاوات وتطبيقها وفقا للاتفاق على الرغم من ذلك فان الخاصية الرئيسية التي تتميز بها تقنية البلوكتشين وهي الثبات من أي تغير او عبث تخلق مجموعة من التحديات حيث من الممكن ان يرغب صاحب الحق في مزيد من المرونة للسماح بإجراء تغييرات منتظمة على تلى ني شروط الترخيص.

G. Ishmaev ,(2017)." Blockchain Technology as an Institution of Property", Metaphilosophy / Volume 48, Issue 5. Cited by: 3 .Avialble At: https://doi.org/10.1111/meta.12277. 


\section{Global Proceedings Repository \\ American Research Foundation}

ISSN 2476-017X

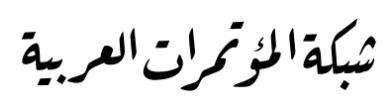

http://arab.kmshare.net/

Available online at http://proceedings.sriweb.org

ان من النتائج الأكثر فائدة للترخيص الآلي هي زيادة تمكين أصحاب الحقوق بسلطة أكبر على الترخيص. أنظمة الترخيص الحالية غالية الثمن وبطيئة من حيث الاجراء وينقصها الشفافية في توزيع مدفوعات الإتاوات، في الوقت الحالي لدينا بالفعل مؤشرات مبكرة على التغيرات التي يمكن تنفيذها خاصة في قطاع الموسيقى (1).

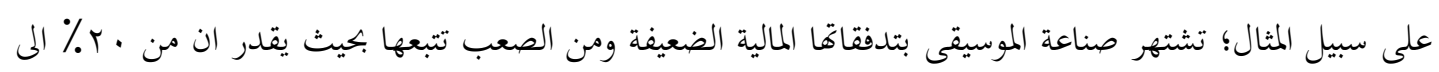

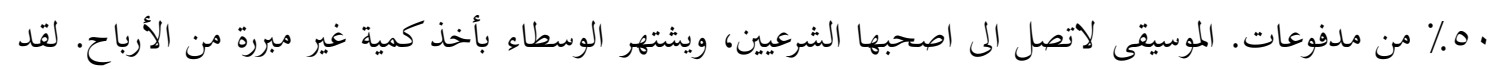
ظهر ت العديد من الشركات الناشئة التي سعت الى استخدام تقنية البلوكتشين لحل هذه المشكلات، على سبيل المثال Ugo Music تستخدم العقود الذكية على نظام Ethereum حيث يقوم الموسيقي الذي يستخدم المنصة بإنشاء ملف تعريف المستخدم يشبه الملفات التي يتم عرضها على Spotify ثم يقوم بتحميل الموسيقى الخاصة به، مما يتيح له التحكم فيها وتوزيعها. تصف الشركة عملها كما يلي: تستخدم العقود الذكية في بناء أنظمة ترخيص مرنة وقياسية، تمكن الدفع التلقائي لأصحاب الحقوق استنادا اللى التراخيص التي يصمموها في واجهه سهله الاستخدام.

يمكن تمديد العقد ليشمل مجموعة واسعة من الوظائف الإضافية، وكذلك تغير التسعير وتوجيه الدفع. لقد حصلت الشركة على تسويق إعلامي ضخم وأصدر بعض المشاهير في الوسط الفني البومات على منصتهم، وتستخدم شركة ناشئة أخرى تقنية تقنية البلوكتشين مثل Mycelia Bit tunes،Ascribe بطرق مختلفة سعين منهم الى تعطيل الوسطاء الموسيقيين كما يقولون او يزعمون لمالكي أصحاب الحقوق. الا أنه في الجانب العملي هناك اعتبارات للترخيص الفردي الآلي يتطلب إجابات على سبيل المثال، هل من العملي او المحتمل ان يتجاهل المستخدمون منصات عالمية مثل YouTube Spotify التي تحريا يوميا مئات الملاين من الأغاني من اجل التعاقد بشكل فردي مع الفنانين على منصة تستند على سلسة الكتل؟ من اجل المنافسة ستحتاج هذه المنصات الى تخزين وتشغيل ملاين العقود، ان لم يكن مليارات وستحتاج الى معالجتها بسرعة ترضي المستخدمين وهذه الخصائص تعد من التحديات والمعوقات في تقنية البلوكتشين " سناقشها فيما بعد ". وستحتاج

1. Annabel Tresise, Jake Goldenfein and Dan Hunter,(2018) .op.cit, Pages 26 2

Stuart Dredge, "Ujo Music on Blockchain: It's Such an Uphill Battle with Existing Companies", Music Ally (4 August 2017) http://musically.com/2017/08/04/ujo-music-blockchain-uphill-battle-existing/companies 


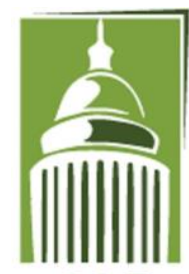

AR F
Global Proceedings Repository

American Research Foundation

ISSN 2476-017X

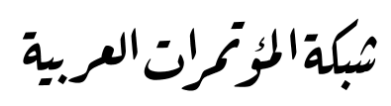

http://arab.kmshare.net/

Available online at http://proceedings.sriweb.org

أيضا الى إجابات على الإسالة المتعلقة بالأمن خاصة وان العقود الذكية مرتبطة بالعملات المشفرة لإلغاء المعاملة في حالة

$$
\text { حدوث خرق لأي سبب فما هي العملية القضائية او الإدارية لإرجاع هذه الأموال او تتبعها؟ }
$$

وهناك اعتبار اخر هو ما إذا كان المستخدمون سيرغبون في الحصول على عملة مشفرة من اجل شراء الاغنية او الألبوم؟ سيكون من المثير للاهتمام مراقبة نجاح او فشل هذه الشركات الناشئة على مدى السنوات القليلة المقبلة، ولكن إذا نجحت

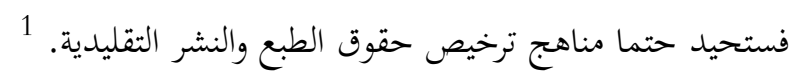

4. التقليل من الحاجة المى الوسيط أو منظمات الإدارة الجماعية:

ان الأطر القانونية والاقتصادية والتكنولوجية الحالية لا تسهل من وجود سوق عملية او قابلة للحياة او التنفيذ لأصحاب

الحقوق الفردية لترخيص أعمالم او مراقبة وإنفاذ حقوقهم، دون اشراك الوسطاء، توفر الإدارة الجماعية للحقوق فوائد اقتصادية لكل من المؤلفين والمستخدمين لاسيما عن طريق خفض تكاليف المعاملات. ونتيجة لذلك يتم تشجيع أصحاب CMOs الحقوق بالانضمام الم منظمات الإدارة الجماعية ذات الصلة بمجالهم. بتعل هذه الترتيبات في بعض الأحيان وكيلا للمؤلف، ولكنها غالبا ما تتطلب تعيينا كليا للحقوق، مما يجعلها المالك لحقوق التأليف والنشر . حيث تقوم بتجميع الكتالوجات الكبيرة للأعمال التي تحت رعايتها، ومن ثم تقوم بتنظيم التراخيص ومنحها وفرضها نيابة عن أصحاب الحق. يعد استخدام الإذاعة الموسيقية مثال شائع على استخدام مرخص به جماعيا، حيث التفاوض مع أصحاب الحقوق الفردية غير عملي، تتمتع منظمات الإدارة الجماعية بقدرة أكبر على المساومة كما يمكنهم تحديد مجموعة المستخدمين بسهوله أكبر، ولديهم موارد أكبر من اجل إنفاذ الحقوق. لقد ظهرت هذه المنظمات في البداية على اها تقدم حلول عندما كانت التكنولوجيا في بدايتها ظهرت أدوات التصوير والاستنساخ الغير مرخص على نطاق واسع مما أدى الى فقدان السيطرة من جانب أصحاب الحقوق الفردية، ومع ذلك فقد تعرضت للنقد على مر السنين بسبب الافتقار الى الشفافية وتأخير وقت دفع الإتاوات وإساءة الاستخدام والاحتكار. واستغلال الاعمال اليتيمة، وكذلك عدم المرونة في التبادل البيني حيث لـ تستخدمه ضد المستخدمين الذين لديهم مورد واحد (2). في الوقت الحالي توجد مجموعة كبيرة من الدعاوى القضائية والتعليقات العلمية التي تتناول قانون المنافسة حول ممارسات معينة من منظمات الإدارة الجماعية، لقد أصبحت المشكلات المتعلقة ب CMOs كثيرة بشكل كاف حيث تناقش 1 Annabel Tresise, Jake Goldenfein and Dan Hunter,(2018)." What Blockchain Can and Can't Do for Australian Intellectual Property Journal 144 Copyright, Pages14 Electronic copy available at: https://ssrn.com/abstract $=322738$

1. Annabel Tresise, Jake Goldenfein and Dan Hunter,(2018), op.cit. Pages 34 . 


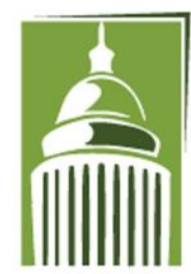

AR F
Global Proceedings Repository

American Research Foundation

ISSN 2476-017X

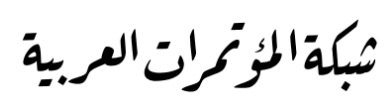

http://arab.kmshare.net/

Available online at http://proceedings.sriweb.org

الهيئات في جميع أنحاء العالم كيف يمكن للتكنولوجيا، الجديدة ان تتيح أنظمة أكثر عدلا وأكثر شفافية في تقسيم الأجور. توفر منصات تقنية البلوكتشين طريقا تقنيا واحد لتحديد وظيفة الوسيط الخاصة ب (CMOs) (1) كوغا تقنيات شبكات وقواعد بيانات الحافية في نفس الوقت، باستطاعتها عمل اغلب وظائف CMOs التي تجمع بين المستخدمين مع الاعمال، ولكن تتميز بتخفيض تكاليف المعاملات بشكل كبير، هذا يعد بتوفير سلسلة قيمة شفافة للأعمال ومن الممكن ان تساعد أيضا في مشكلة الاعمال اليتيمة. علاوة على ذلك في ظل الظروف الحالية، تتقاضى منضمات الإدارة الجماعية باستمرار ضد بعضها البعض لمنع التراخيص متعددة الولايات، من الممكن ان تلغي منصات تقنية البلوكتشين الحاجة لموفري المختوى عبر الانترنت للحصول على ترخيص من مديري التسويق المعنين في كل ولاية.

يمكن للنظام الايكولوجي او البيئة التقني القائم على تقنية البلوكتشين تنسيق وظائف التسجيل والترخيص وإدارة الحقوق

الرقمية بطريقة تكفي لإلغاء مراكز الاحتكار في منظمات الإدارة الجماعية، ان وظيفة الشباك الواحد للترخيص الآلي تعتبر ضرورية من الناحية الاقتصادية من قبل الميئات مثل المفوضية الأوربية يمكن ان تؤديها بنية تقنية بدلا من ذلك. لقد اطلعنا على الجانب النظري وما تتميز به تقنية تقنية البلوكتشين من إمكانات، بينما في التطبيق العملي ستثير عدة تحديات وبعض بن الإسالة المتعلقة بها (سيتم الحديث بشكل موسع فيما بعد في قسم التحديات). على الرغم من الخصائص التي توفرها العقود الذكية الا اها تعد عقود تنفيذ اتفاق او إبرام مأتم الاتفاق علية بين الأطراف المشاركة ولا تعرف على اها عقد قانوني. من الممكن كذلك تسجل اعمال منتهكة من قبل شخص ما على منصة من منصات تقنية البلوكتشين ومن الممكن أيضا ظهور منصات لتقنية تقنية البلوكتشين متخصصه في الاعمال المنتهكة، صحيح اها تقنية ثورية وتعد بتحول جديد واهما سوف تخلق أسواق جديدة ولاكن لا يمكن إلغاء بشكل كلي منظمات الإدارة الجماعية او أي وسيط لان أدوار المنظمات الثمل من التسجيل وإصدار التراخيص وتوزيع الإتاوات(2)، ومن هنا نورد إجابة المدير العام لمنظمة الويبيو فرانسيس غري حينما سؤل عن دور تقنية تقنية البلوكتشين في استبدال أنظمة إدارة حقوق الملكية الفكرية؟ أجاب حينها "انه من غير الممكن ان تحل محل الوظيفة الأساسية لمنح حق الملكية من قبل الدولة او سلطة عامة، المكية الفكرية هي انشاء الدولة، وخلافا للممتلكات المادية، ليس لها وجود الا من خلال انشاء حق من قبل الدولة، لا أرى نظاما موزعا خاصا مثل تقنية البلوكتشين يحل محل الوظيفة الأساسية لمكاتب البراءات في تحديد منح حق الملكية ام لا، ارى اها شكل متفوق محتمل في تسجيل المعاملات فيما يتعلق بحقوق الملكية الفكرية الحالية، هناك على سبيل المثال، العديد من التطبيقات المتملة لتقنية

2. Annabel Tresise, Jake Goldenfein and Dan Hunter,(2018). Op.cit. Pages 34 .

1. Annabel Tresise, Jake Goldenfein and Dan Hunter,(2018), op.cit. Pages 46 . 


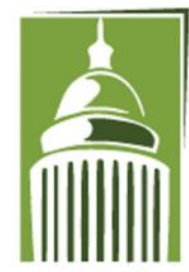

AR F
Global Proceedings Repository

American Research Foundation

ISSN 2476-017X

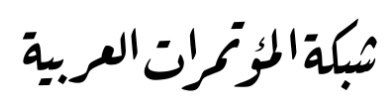

http://arab.kmshare.net/

Available online at http://proceedings.sriweb.org

تقنية البلوكتشين في استخدام حقوق الملكية الفكرية والتداول بها مثل التراخيص، بتحدر الإشارة هنا الى توضيح ان أنظمة الإدارة الجماعية هي مؤسسات خاصة ربحية تختلف عن مكاتب البراءات التي تحدث عنها، يرى الباحث (ان فكرة التخلي عن الوسيط بشكل كليا من خلال رمز الكمبيوتر في تقنية تقنية البلوكتشين يثير الكثير من الشكوك ومن الصعب التنباء به في الوقت الحلالي وذلك لان العقود الذكية تعد تقنية فتية وهناك تساؤلات عديدة من الجانب العملي لم تثبت بعد نجد ان جميع المهتمين والمطورين يربطون وصف خصائص التقنية بكلمة من الممكن على الرغم من الإمكانات الهائلة التي تقدمها تقنية تقنية البلوكتشين الا اها تعالج جوانب محدودة من الدور الإداري للوسطاء ولا يمكنها في الوقت الحالي ان تقوم بالدور الإداري والقانوين والاستشاري وغيرها من اعمال تقوم بها المنظمات الإدارية/الوسطاء، (1).

المبحث الثالث: التحديات والمعوقات التي تواجه تقنية البلوكتشين:

كغيرها من التقنيات تواجه العديد من التحديات والمعوقات في المراحل المختلفة لتطبيقها، خاصة فيما يخص الملكية الفكرية وكيفية الحفاظ على حقوق المخترعين والمؤلفين للأفراد والكيانات المختلفة وستحاول الدراسة في هذات المبحت المبحث التطرق لبعض من التحديات والمعوقات بحسب ما اورده الخبراء في هذا المجال. العيوب المصاحبة للعملات المشفرة:

هناك بعض العيوب في التكنولوجيا التي يجب معالجتها قبل استخدامها على نطاق واسع في المعاملات اليومية لتقنية البلوكتشين ومن هذه العيوب ما يلي (2): 1. قابلية التوسع يعد بتكوين ذو شعبية كبيرة. ومع ذلك، لا يمكنها معالجة سوى سبع معاملات في الثانية حيث يمكن ل (Hyperledger) التعامل مع (24,000 Visa 10،000) يصبح من الصعب تخيل الاستخدام العملي لتقنية البلوكتشين مع مسألة قابلية التوسع في العرض، تحتاج كل عقدة مشارك إلى التحقق من الصفقة والموافقة عليها، وبالتالي يمكن أن يستغرق تبادل بتكوين واحد ما يصل إلى عدة ساعات.

1. Annabel Tresise, Jake Goldenfein and Dan Hunter,(2018).op.cit. Pages 34 .

1. Maruti Techlabs,(2016.), Blockchain-benefits drawbacks and everything you need to know. AVIALBLE AT:https://www.marutitech.com/blockchain-benefits published on 18/11/2016 and has been updated on 20/11/2018. 


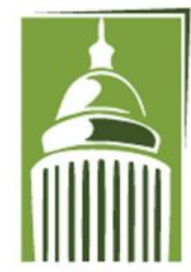

AR F
Global Proceedings Repository

American Research Foundation

ISSN 2476-017X

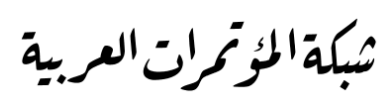

http://arab.kmshare.net/

Available online at http://proceedings.sriweb.org

2. التخزين نظرًا لأنه يتم تخزين قواعد بيانات البلوكتشين إلى أجل غير مسمى على جميع عقد الشبكة، فإن مسألة تخزين الأسطح، مع ازدياد عدد المعاملات، فإن حجم قاعدة البيانات سوف يتوسع، وليس هناك طريقة لتخزين بيانات غير محدودة يتم إلحاقها على أجهزة الكمبيوتر الشخصي. 3. الخصوصية - البيانات الموجودة على البلوكتشين العمومي مشفرة وبجهولة الهوية، ولكنها تقع في أيدي جميع العقد في الشبكة. لذلك، كل شخص في الشبكة لديه حق الوصول إلى هذه البيانات، هناك احتمال أن يقوم شخص ما بتتبع هوية شخص ما في الشبكة من خلال بيانات المعاملات، تمامًا كما تستخدم الشركات في العادة أجهزة تتبع الويب وملفات تعريف الارتباط، هذا يثبت أن تقنية البلوكتشين ليست آمنة 100 في المئة، لسوء الحظ. 4. اللوائح - تشكل الأنظمة التنيمية في المجال المالي تحديًا لتطبيقها. سيتعين على تطبيقات تقنية البلوكتشين وضع عملية تحديد الجاني في حالة حدوث عملية احتيال، وهو ما يمثل تحديًا. يجب وضع الجوانب التنظيمية الأخرى لتكنولوجيا

$$
\text { البلوكتشين أولاً لتسهيل اعتمادها على نطاق واسع. }
$$

5. الأمن - سأتوشى ناكاموتو سلط الضوء على هجوم 51 \% عندما أطلق بتكوين، يمكن توضيح الهجوم ببساطة على هذا النحو إذا كانت 51٪ من العقد في الشبكة كاذبة، فيجب قبول الكذبة كحقيقة، لذلك سيتعين على كل فرد في

$$
\text { الشبكة مراقبة ذلك باستمرار لإدراك أي تأثير غير مرغوب فيه. }
$$

ونظرًا لأن تقنية تقترب من اعتمادها على نطاق واسع، فقد يتم حل هذه التحديات بمرور الوقت. لمزاياها الهائلة. التحديات التي تواجه تقنية البلوكتثين في حفظ حقوق الملكية الفكرية: يحددها (Savelyev) في أربع محاور كالتالي (1): 1. التخزين وقابلية التوسع في البلوكتشين: ان الإسالة التي تحتاج الى إجابات هي ما المكان الذي سيتم فيه تخزين

$$
\text { اعمال حقوق الطبع والنشر هل سيكون على نفس تقنية البلوكتشين او في مكان اخر. }
$$

- - تفرض الحالة الحالية لتكنولوجيا البلوكتشين قيودا كبيرة في وضع المحتوى الإبداعي مباشرة على البلوكتشين، على

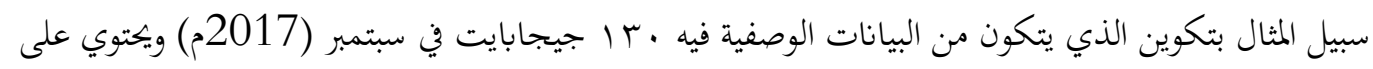
بينات وصفية فقط ولا توجد ملفات ثقيلة منذ يناير (2013م) ازداد حجم كتلة تقنية البلوكتشين ويتضاعف الحجم كل عام، وبغض النظر ان حجم كتلة البتكوين في الوقت الحالي محدود بالشفرة المى (1) ميغابايت لكل

1. Alexander Savelyev,2018. Copyright in the blockchain era: Promises, challenges, Computer Law \&Security Review Volume 34, Issue 3, June 2018, Pages 550-561. Available AT: https://doi.org/10.1016/j.clsr.2017.11.008 


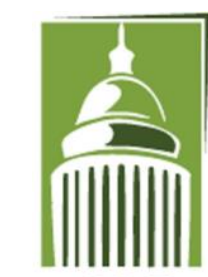

AR F
Global Proceedings Repository

American Research Foundation

ISSN 2476-017X

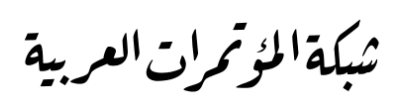

http://arab.kmshare.net/

Available online at http://proceedings.sriweb.org

كتلة لذا فان تخزين المحتوى على تقنية البلوكتشين يمثل مشكلة، خاصة اذاكنّا نتحدث عن شبكة كبيرة من المستخدمين مع زيادة كميات المعلومات والتي يجب ان تنعكس على تقنية البلوكتشين، سيشكل العثور على حوافز صحيحة للمستخدمين والتي تكون جاهزة لتخزين البيانات ذات الصلة مهمه صعبة للغاية وحيث قد تكون التكاليف المرتبطة بالتخزين كبيرة. - - اما إذا تقرر ان الملفات الرقمية ذات الاعمال المحمية بحقوق الطبع والنشر سوف تكون موجودة خارج البلوكتشين، فأها تثير التساؤل التالي. كيف يمكن ضمان ان تظل بيانات البلوكتشين مرتبطة بالعمل ذي النسخ المتماثلة ذات الصلة بالعمل نفسه، بمعنى ان بيانات البلوكتشين تبقى فعلية في جميع الأوقات، قد يصبح هذا المحتوى غير متاح بسبب الأعطال الفنية للبنية التحتية للشخص المسؤول عن تخزينية او بسبب الإجراءات المتعمدة من قبل هذا الشخص مثل الإهمال او تعمد العبث بها وبالتالي فان تخزين الخمتوى الرقمي خارج السلسلة يخلق مشكلة تتعلق بإمكانية الوصول الى مثل هذا المختوى وتتحدى مدى فاعلية حل تقنية البلوكتشين الشاملة. بالإضافة الى ذلك، على الرغم من أنه يبدو للوهلة الأولى اها في الغالب مسالة تقنية، الا ان الخيارات المعمارية المتعلقة بتخزين البيانات في البلوكتشين سيكون لها اثار قانونية أيضا. إذا كان هناك نوع من الصومعة المركزية لتخزين المحتوى الرقمي المرتبط بقاعدة بيانات إدارة الحقوق على البلوكتشين، فسيقوم المشرف على هذه الصوامع باستخدام المصنفات المحمية بحقوق النشر ذات الصلة على الأقل في شكل من أشكال إعادة إنتاجها، من المتمل ان يجعله هدفا لادعاءات الانتهاك، سوف يستوفي هذا السؤال معيار الوسيط عبر الانترنت لمنصات استضافة المعاملات، وهي حالة تمنح الإعفاءات من المسؤولية عن انتهاك حقوق النشر. 2. الثبات: ان الطبقة الثابتة للمعلومات على البلوكتشين تخلق بعض المشاكل مع تطبيق الإعفاءات او انفاذ امر صادر من المحكمة بإزالة المحتوى ذي الصلة او منع الوصول الية (آلية الإزالة)، كما هو الحال في المملكة العربية السعودية اذا ثبت ان المحتوى خخالف فيتم توجيه وزارة الاتصالات وتقنية المعلومات بإزالة المحتوى، اذا تم تخزين المحتوى الرقمي على البلوكتشين فقد يكون من المشكوك فيه حذفة او منع الوصول الية وبالتالي يصبح البلوكتشين عدوة للدولة والسلطات القضائية، لأنه سيكون مخالف لمبادئ نظام البلوكتشين، في هذه الحالة، لن يتمكن مدير النظام الأساسي في البلوكتشين الاستفادة من الإعفاء من المسؤولية للوسيط عبر الانترنت، اما اذا تم تخزين المحتوى الرقمي خارج البلوكتشين ويوفر رابطا له فقط. فسيكون من الممكن تقنيا إزالة/حظر الوصول الى هذا المحتوى. ولكن في هذه الحالة ستصبح البيانات الوصفية المخزنة على البلوكتشين ذات الروابط التي تربط العمل الخارجي مؤرخة وتعتمد بشكل عام على تصرف طرف ثالث. 


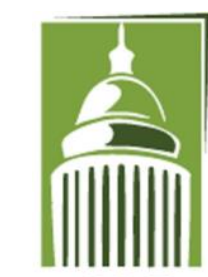

A R F
Global Proceedings Repository

American Research Foundation

ISSN 2476-017X

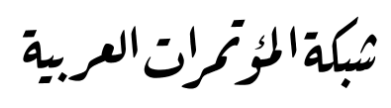

http://arab.kmshare.net/

Available online at http://proceedings.sriweb.org

3. قضايا تأثير الشبكة او التبني لتقنية البلوكتشين: من اجل إطلاق العنان للإمكانات الكامنة لنظام جديد لإدارة حقوق التأليف والنشر القائم على البلوكتشين. يجب استخدامه من قبل عدد كبير من أصحاب الحقوق والمستخدمين وتغطية الإعداد الكافية من الاعمال المشهورة المحمية بحقوق النشر، وكذلك فان مثل هذا النظام سيعتمد بشكل كبير على ما يسمى " تأثير الشبكة" حيث تعتمد قيمة المنتج على عدد المستخدمين له، وكلما زاد عدد المستخدمين يصبح النظام أكثر قيمة وفعالية وقدرة على جذب قاعدة اوسع من المستخدمين. من الأمثلة الشائعة هي شبكة الهاتف؛ حيث يتفق الجميع ان قيمة خدمة الهاتف تعتمد بشكل كبير على عدد الأشخاص الذين يستخدموها وينطبق الشيء نفسه على أنظمة إدارة حقوق الطبع والنشر المعتمد على البلوكتشين: كلما زاد عدد قاعدة المستخدمين والمستفيدين لديهم زادت القيمة والفائدة لدى كل من المؤلفين (أصحاب الحقوق) والمستخدمين كذلك. ان أحد التحديات الرئيسية في تنفيذ نظام إدارة حقوق الطبع والنشر الفعال القائم على البلوكتشين هو جلب عدد كاف من الناس الية. ومن أكبر العقبات التي تحول دون انشاء حلول إدارة حقوق الطبع المستندة على البلوكتشين مع قاعدة بيانات كبيرة بما يكفي من الاعمال المحمية بقواعد حقوق الطبع وقاعدة المستخدمين هي إعادة الثقة بالإدارة الجماعية والوسطاء الآخرين سيصبح الامر غير محبب، إذا بداء الناشرون بترخيص أعمالمم مباشرة دون أطراف ثالثة / وسطاء.

4. القضايا القانونية لسلسة الكتل: ان القضايا القانونية لسلسة الكتل والعقود الذكية والعملات المشفرة هي حاليا موضوع مناقشات ساخنة بين المحامين والساسة والأكاديميين والمنظمين في جميع أنحاء العالم، في حين ان العديد من الناس يفتنون بالإمكانات التي يتيحها البلوكتشين، الا ان هناك الكثير من البيانات المتناقضة والتحذيرية الصادرة من المنظمين حول التعمية السرية والمخاطر المرتبطة بها، حيث تمنع بعض الدول حالات معينة من العملات المشفرة، وأخرى تحظرهم تماما، ان إضفاء الشرعية على العملة الشفرة المجهولة والعمليات المصاحبة معها هو واحد بلد من الشروط الأساسية لتيسير تبني تقنيات البلوكتشين بشكل واسع. يتطلب التحقق من المعاملات في البلوكتشين استثمارات كبيرة من الطاقة الحاسوبية ويجب تعويض هذه الاستثمارات بطريقة ما لتكون قابلة للتنفيذ. المعوقات والتحديات التي تحول دون تبني تقنية البلوكتشين بشكل عام. 1. تسجيل كم هائل من المعلومات مما يحتاج الى معالجة البينات الوصفية بشكل كفاء وطريقة استدعاء هذه البيانات. 2. 2 التخزين وإمكانية التوسع.

3. البطيء في تنفيذ ومعالجة المعاملات مقارنة بالأطراف الثالثة الموثوقة. الا اها أسرع من الأطراف الثالثة في التسوية. 


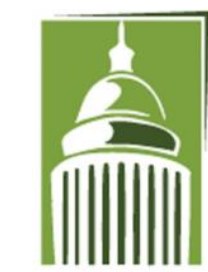

AR F
Global Proceedings Repository

American Research Foundation

ISSN 2476-017X
شبكة المؤمرات العر.ية

http://arab.kmshare.net/

Available online at http://proceedings.sriweb.org

4. أسعار العملات المشفرة متذبذبة - إذا استخدمت في حقوق الطبع والنشر من الممكن ان تزيد بشكل كبير من سعر

العمل او تنقصه.

5. تقنية البلوكتشين تعمل على إلغاء دور بعض الوسطاء وإدخال وسطاء جدد في السوق. الهيكل البنائي يتطلب لاعبين

$$
\text { جدد في الوسط. }
$$

6. لا يكاد متوافق مع الأطر القانونية في كثير من أشكاله.

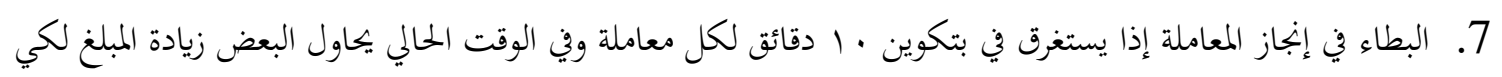

$$
\text { يتم إنماء معاملته. }
$$

8. في كثير من الأوقات تكون عدوة للسلطة والقرارات الإلزامية من المحاكم؛ إذا أصدر حكم نافذ بحجب او منع الوصول

$$
\text { الى محتوى معين. }
$$

9. عندما يتم تنغيذ البرنامج تلقائيا لم يعد بالإمكان التراجع عن المعاملات غير المرغوبة فيه وذلك لعدم أهلية أحد الأطراف

$$
\text { او التخلف عن الوفاء بالالتزامات. }
$$

مزايا تقنية البلوكتشين في حفظ حقوق الملكية الفكرية:

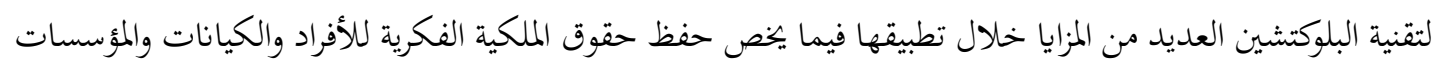

$$
\text { اضافة للدول ومن هذه المزايا ما يلي: }
$$

1. تختفظ تقنية البلوكتشين بالأصل الرقمي حيث توفر للمستخدم ضمان استخدام غير محدود للمحتوى الخاص للأصول

$$
\text { الرقمية مع ضمان عدم إمكانية نسخ المادة بسبب الحجم وعدم النضج الحالي في إمكانية المعالجة. }
$$$$
\text { 2. سجل ثابت؛ ما يعني إثبات أبوة لصاحب العمل وكذلك اثبات وجود للعمل. }
$$

3. عدم وجود نقطة واحدة للفشل؛ ما يعني لا يمكن تعطيل البلوكتشين بتعطل عقدة او عقدتين.

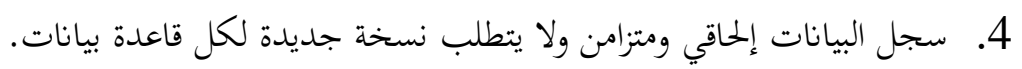

$$
\begin{aligned}
& \text { 5. 5. إمكانية التتبع التبات } \\
& \text { 6. تقليل التكاليف } \\
& \text { 7. الشفافية. } \\
& \text { 8. توفر الثقة }
\end{aligned}
$$

9. عقد ذكي قابل للأنفاذ إذا ما توفرت الشروط المحددة مسبقا بواسطة رمز الكمبيوتر.

10.توزيع الإتاوات بواسطة العقود الذكية بشكل مؤتمت حسب النسبة الخحددة في العقد. 


\section{Global Proceedings Repository \\ American Research Foundation}

ISSN 2476-017X

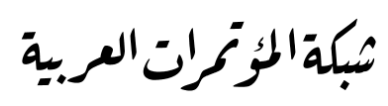

http://arab.kmshare.net/

Available online at http://proceedings.sriweb.org

11. 11 إصدار التراخيص الالية للمكية الفكرية.

12.دفاتر الأستاذ الإلكترونية هي أرخص بكثير للحفاظ على أنظمة المحاسبة التقليدية؛ ويمكن تخفيض عدد الموظفين في المكاتب الخلفية بشكل كبير.

13.أنظمة DLT المؤتمتة بالكامل تقريباً تؤدي إلى أخطاء أقل بكثير وإلغاء خطوات التأكيد المتكررة. 14. يعني تقليل تأخير المعالجة أيضًا تقليل رأس المال مقابل مخاطر المعاملات المعلقة.

تناولنا فيما سبق إثر استخدام تقنية البلوكتشين في حفظ حقوق الملكية الفكرية من خلال دراسة تم الاعتماد فيها على المنهج الوثائقي النظري، وقد هدفت الدراسة إلى التعرف على مقومات وأبعاد هذه التقنية التي تساعدها في حفظ حقوق الملكية الفكرية، وكذلك معرفة مدى تأثيرها في بعض المجالات الرئيسية المستخدمة في حفظ حقوق الملكية الفكرية، ومن ثم معرفة القيود والمعوقات الهيكلية لمذه التقنية في مجال حقوق الطبع والنشر للملكية الفكرية، ومناقشة الفرص والتحديات التي تواجه المؤسسات عند تطبيق هذه التقنية.

وتناول الباحث من خلال الفصل الأول الإطار العام وتساؤلات الدراسة وفي فصولها التأليه تناول الأدبيات النظرية

المتعلقة بتقنية البلوكتشين مفهومها واستخداماقا، ومن ثم تناول استخدام البلوكتشين في مجال الملكية الفكرية مفهومها وانظمتها ثم اختتم الباحث بالتحديات التي تواجه تطبيقات تقنية سلسلة.

ومن أهم ما خلصت إليه من نتائج اجماع نسبة كبيرة من الدراسات ان تقنية البلوكتشين تعتبر من احدث التقنيات واهمها والتي بدا استخدامها في مجال الملكية الفكرية وحفظ الحقوق الفكرية، حيث بدأت العديد من القطاعات تستكشف إمكانيات تلك التقنيات مع ظهور استخدامات ذكية جديدة، وخلصت الدراسة الى ان تقنية البلوكتشين لها امكانيات كبيرة يمكن تطبيقها لإدارة حقوق الملكية الفكرية وحفظها لأصحاها، وبالتالي ظهرت أنظمة ولوائح وقوانين الملكية الفكرية من خلال البرامج والأنظمة الذكية بدلاً من إدارتا بالطريقة التقليدية وهذه تعتبر بمثابة ميزه جديدة اكتسبتها الملكية الفكرية بتطبيقها للبلكتشين، ومن المتوقع ان يؤدي ذلك الى تسجيل حقوق الملكية الفكرية في سجل موزع عوضاً عن قاعدة بيانات تقليدية إلى تويلها إلى حقوق ملكية فكرية ذكية. 


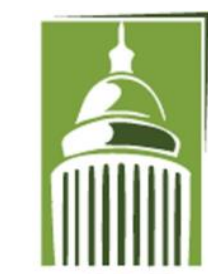

AR F
Global Proceedings Repository

American Research Foundation

ISSN 2476-017X

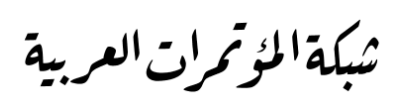

http://arab.kmshare.net/

Available online at http://proceedings.sriweb.org

كما ان تطبيق البلوكتشين في حفظ حقوق الملكية الفكرية من شانه ابراز استخدام نظام مكاتب الملكية الفكرية تكنولوجيا والبحث عن السجلات الموزعة في إنشاء سجلات ذكية للملكية الفكرية مثل تسجيل براءة الاختراع او الاسم التجاري او العلامة التجارية المحددة وهي عملياً افضل من ادارة هذه السجلات تقليدياً، ايضا وباستخدام تقنية البلوكتشين وتطبيقها في مجال حفظ حقوق الملكية الفكرية قد يؤدى ذلك لتقليل الوقت والتكلفة المالية مقارنة بتطبيقات الطريقة التقليدية في حفظ حقوق الملكية الفكرية من الناحية النظرية الا انه من المبكر الحديث عن فوائدها في تقليل التكلفة والغاء دور الوسيط في حفظ حقوق الملكية الفكرية من الجانب العملي.

أيضا من ميزات استخدام تطبيقات البلوكتشين في حفظ حقوق الملكية الفكرية إن دفاتر الأستاذ الإلكترونية هي أرخص بكثير للحفاظ مقارنة بأنظمة المحاسبة التقليدية، ويمكن تخفيض عدد الموظفين العاملين في هذا المجال من خلال الاستعاضة عنهم بالأجهزة والتقنيات الحديثة، وكما خلصت الدراسة الى أن استخدام البلوكتشين في حفظ الحقوق الفكرية يتيح الفرصة لأبرام العقود إلكترونياً وهي ما تسمي بالعقود الذكية والتي لها القدرة على حفظ الحقوق الفكرية لأصحابها بشكل احترافي وغير قابل للاختراق والتعديل، ومن مميزات استخدام البلوكتشين في حفظ الحقوق الفكرية امكانية تتبع عقود التوريد الذكية إلكترونيا من قبل المستفيدين وذلك دون الرجوع للمستندات الورقية التي تم التوقيع عليها.

وفي سياق اخر هناك العديد من المعوقات والتحديات التي تواجه تطبيق تقنية البلوكتشين في حفظ الحقوق الفكرية ومنها تسجيل كم هائل من المعلومات مما يحتاج الى معالجة البينات الوصفية بشكل كفئ وطريقة استدعاء هذه البيانات حيث يتعذر احيانا معالجة المشكلات التقنية بالسرعة المطلوبة وقد يستدعى ايضا استدعاء الشركات المنفذة لهذه البرامج بغرض اصلاحها اذا كانت الاعطال والمشكلات كبيرة، ايضا خلصت الدراسة الى امكانية تعرض نظام البلوكتشين الى الاختراق اذا تم تخزين البيانات خارج السلسلة وبالتالي يمكن تعرض العقود الذكية وحقوق الملكية الفكرية لأصحاب العلامات التجارية او براءات الاختراع الى ضرر نتيجة اختراق نظام السلسة. الباحث خلص الى ان نظام البلوكتشين مازال في بدايات تطبيقه ولم يخظى بالانتشار في المؤسسات الادارية وذلك نتيجة لعدة محددات منها عدم القبول العام نتيجة صعوبة التقنيات الالكترونية المستخدمة فيه، وعدم استخدامه في مؤسسات اخرى بحيث يمكن للراغبين في تطبيقه استعراض التجارب الاخرى للاستفادة من الايجابيات وبحاوز السلبيات في تلك المؤسسات المنفذة لتقنية البلوكتشين، ايضا توجد قطاعات يصعب تطبيق نظام البلوكتشين فيها نتيجة استخدامها انظمة الكترونية منذ اوقات طويلة مثل المصارف وشركات التامين وغيرها وبالتالي هنالك صعوبة في التخلص من انظمتها واحلالها بنظام جديد لا يعرفون مخاطر تطبيقه ولا توجد معايير موحدة. 


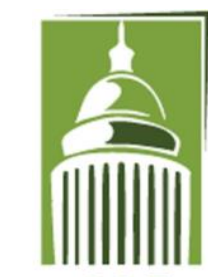

AR F
Global Proceedings Repository

American Research Foundation

ISSN 2476-017X

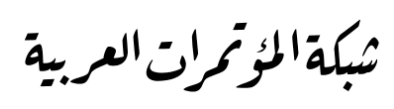

http://arab.kmshare.net/

Available online at http://proceedings.sriweb.org

اذن يعتقد الباحث ان نظام البلوكتشين يمكنه ابراز ثورة فنيه وتكنلوجية إذا ما تم تطبيقه بشكل اوسع في المؤسسات الادارية خاصه الكبرى حول العالم، ويخلص على ان حداثة البلوكتشين هي سبب في ضعف انتشاره، وقد يكون التردد والخوف في تطبيق البلوكتشين أحد اهم اسباب عدم انتشاره عالمياً.

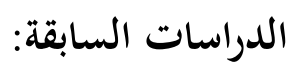

تعتبر الدراسات السابقة ركيزة هامة لتحقيق أهداف الدراسة ونقطة انطلاق هامة لمعظم الدراسات حيث البدء من حيث انتهى الآخرون, لذلك فقد سعى الباحث إلى جمع الدراسات المتصلة بموضوع الدراسة الحالية في حدود علم وإمكانيات الباحث حيث استطاع أن يجمع بعض الدراسات التي لها علاقة غير مباشرة بالدراسة الحالية نسبة لندرة الدراسات التي تناولت الموضوع بالضبط اي تقنية البلوكتشين واثرها على الملكية الفكرية، أما ما وجده الباحث من دراسات فقد تناولت اما تقنية البلوكتشين أو الملكية الفكرية وحقوقها بشكل منفصل عن بعضهما البعض وقد وقع اختيار الباحث على بعض الدراسات التي تناولت كلا المحورين على النحو التالي: دراسة(1) (الشاطر، 2018م)، بعنوان: تقنية تقنية البلوكتشين و تأثيراتما في قطاع التمويل الإسلامي، دراسة وصفيه، اوضحت بانه تعتبر تقنية البلوكشين وافدا جديدا يحمل معه العديد من المفاجآت لكثير من القطاعات تماما كما حملها الانترنت من قبل، وهو ما دعا مجتمع خبراء التقنية بوصفها أها الجيل الثاني من الانترنت، وهذه المعلومة تستوجب قيام خبراء كل قطاع معني بتأثيراتا بالمسارعة التقييمية لما بحلبه هذه التقنية من فرص وتحمله معها من تحديات ومخاطر، وذلك لاتخاذ قرارات رشيدة وواعية بحاهها في القريب العاجل، ومن التحولات الجذرية الخطيرة التي تطال قطاع التمويل: تغير نموذج الأعمال وطريقة أداء المهام بما يستلزمه ذلك من تغييرات في المجال التعليمي والتدريبي والقانوني أيضا، حيث أن التقنيات الجديدة في عالم اليوم، ومنها البلوكشين تزيد من الكفاءة، وتخفض من التكاليف، وتوفر الوقت بشكل كبير، وهذه المزايا هي أهداف إسلامية مطلوبة، ونحن نسعى في هذا البحث الأولي للتعريف بالتقنية من حيث الماهية والآلية والخصائص -وغير ذلك مما يهم- لرسم تصور أفضل حولها، بالإضافة لرصد التأثيرات المحتملة على نموذج الأعمال والتدليل عليها، واقتراح السبل لمواجهة الواقع المحتمل بعد توصيف الواقع العالمي ومواقفه بحاه هذه التقنية، وقد توصل البحث إلى بجموعة من النتائج والتوصيات منها: تبني التقنية في عمليات التسوية بين البنوك، واللجوء إلى الشبكات الخناصة من التقنية عوضا عن العامة،

1. الثاطر ، منير • (2018م). تقنية سلسلة الثقة (البلوك تثين) وتأثيراتها في قطاع التمويل الإسلامي: دراسة 


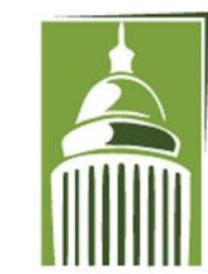

AR F
Global Proceedings Repository

American Research Foundation

ISSN 2476-017X

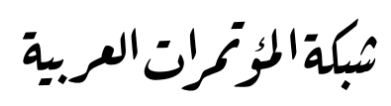

http://arab.kmshare.net/

Available online at http://proceedings.sriweb.org

واستحداث تخصصات وبجلات علمية لدراسة مفصلة حول سبل الاستفادة من التقنية، وكان ذلك باستخدام المنهج الوصفي الاستقرائي التحليلي.

دراسة(1) (خليفة،2018م) في دراسته حول البلوك تشين: الثورة التكنولوجية القادمة في عالم المال والإدارة، الى ان البلوك تشن Blockchain أو تقنية البلوكتشينة يعد أكبر سجل رقمي موزع ومفتوح يسمح بنقل أصل الملكية من طرف إلى

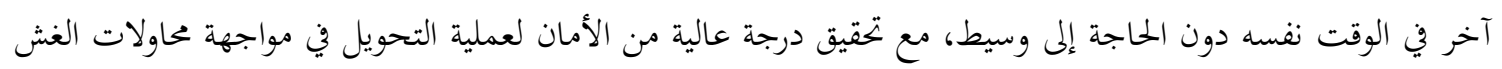
أو التلاعب، ويشرك في هذا السجل جميع الأفراد حول العالم ويمكن اعتبار البلوك تشن حالياً أكبر قاعدة بيانات موزعة عالمياً بين الأفراد، وابرزت الدراسة بعض من مميزات لنظام تقنية البلوكتشين (البلوك تشين) وهي كما يلي: 1. مواجهة الروتين: حيث يساعد هذا النظام الدوائر الحكومية على تحقيق الفاعلية، في جميع المعاملات الخاصة بالأفراد تكون واضحة داخل السلسلة.

2. ضمان: حيث يسمح نظام البلوك تشن بتتبع جميع الخطوات الخاصة بالمعاملة، وهو ما يساعد في النهاية على بلى ضمان تقديم الخدمة بأفضل جودة مككنة. 3. التصدي للفساد: لا يسمح نظام البلوك تشن بالتعديل أو الإلغاء، وجميع المعاملات التي تتم عليه مسجلة خطوة بخطوة بالتوقيت، وفي حالة التلاعب أو التزوير لا تقبل السلسلة إدخال المعاملة مرة أخرى، بما يساعد في القضاء على الفساد. 4. التوزيع العادل للثروة: يساهم هذا النظام في توزيع الثروة بن جميع الأفراد حول العالم وعدم احتكارها من قبل بعض الهيئات أو المنظمات، وذلك لأن جميع الأفراد حول العالم يمكن أن يشاركوا في إفهاء وحفظ المعاملات

$$
\text { والحصول على نسبة منها. }
$$

دراسة(2) (صونيه،2012م)، بعنوان: حماية الملكية الفكرية الأدبية والفنية في البيئة الرقمية في ظل التشريع الجزائري، هدفت الدراسة الى معرفة مدى وعي المشرع الجزائري بالتغيرات التكنولوجية الحديثة التي من شاها ايجاد حلول قانونية ومنطقية لعدم الوقوع في التهديدات والاعتداءات على حقوق الملكية الفكرية في هذا الوسط، وتمثل 1. خليفة، ايهاب. (2018م). البلوك تثين: الثورة التكنلوجية القادمة في عالم المال والادارة، ورقة علمية صادرة عن مركز المستقبل للأبحاث والدراسات المتقدمة، ابوظبي، الامارات المتحدة.

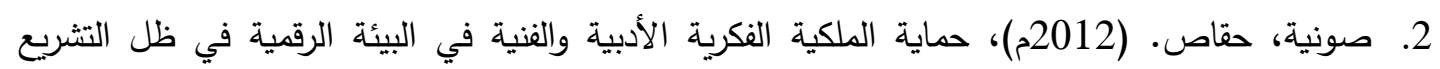

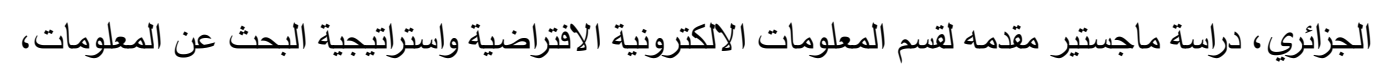

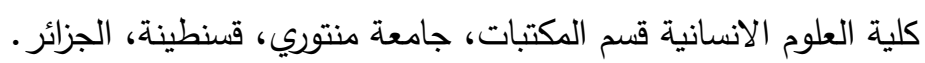




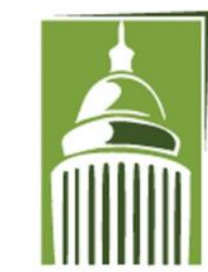

AR F
Global Proceedings Repository

American Research Foundation

ISSN 2476-017X

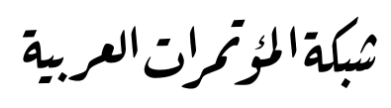

http://arab.kmshare.net/

Available online at http://proceedings.sriweb.org

تساؤل الدراسة الرئيس في ما مدى حماية النص القانوين الوطني الجزائري لحقوق المؤلف في البيئة الرقمية، واعتمدت الدراسة على المنهج الوصفي باعتباره المنهج المناسب للدراسة، ومن نتائج الدراسة ما يلي: 1. إن المشرع الجزائري ليس في معزل عن الأحداث والتطورات الحديثة التي عرفها بجتمع المعلومات. 2. التقدم التكنولوجي الذي أثر ايجاباً وسلباً على حقوق المؤلف والتغيرات المذهلة في هذا العالم الرقمي. 3. اكدت الدراسة على أهمية حماية الحقوق الفكرية.

4. إرساء نظام الادارة الجماعية لحقوق المؤلف لتسهيل تسيير هذه الحقوق في ظل بيئة متطورة تقنياً.

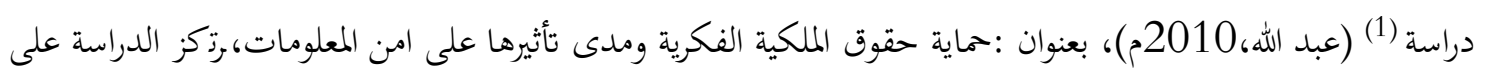
حماية حقوق الملكية الفكرية ومدى تأثيرها على امن المعلومات والتي تبين اهمية حماية حقوق الملكية الفكرية في الوقت الراهن من خلال تناول اهمية حماية الملكية الفكرية والاستراتيجية المطلوبة والآليات القانونية اللازمة لتوفير تلك الحماية والبعد التنموي لهذه الحماية وآثار حماية الملكية الفكرية على امن المعلومات وخلصت الدراسة الى مجموعة من التوصيات كما يلي:

$$
\text { 2. 1. يجب مراجعة القوانين والتشريعات العربية لكي تواكب التشريعات العالمية لحماية البيئة الرقمية. }
$$

3. العمل على ادخال بعض التعديلات على الاتفاقيات الدولية لكي تحقق امال الشعوب وتنهض بالمستوى الاقتصادي لما.

4. توفير وتطوير الحماية القانونية لحقوق الملكية الفكرية دعما لتحقيق الامن المعلوماتي ومكافحة الجريمة المعلوماتية. 5. يجب تنظيم جوانب الملكية الفكرية المرتبطة ببرامج الحاسب والانترنت، فيجب النص صراحة في القوانين العربية على حماية مواقع واسماء وعناوين الانترنت والنشر الالكتروين.

1. عبد الله، مصطفى حمد الله. (2010)، حماية حقوق الملكية الفكرية ومدى تأثيرها على امن المعلومات .

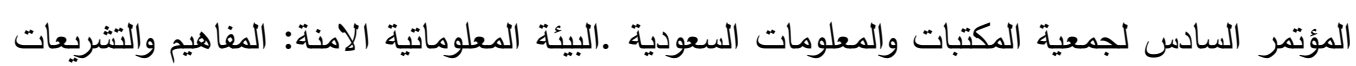
والتطبيقات 7 - 6 ابريل الرياض. 


\section{Global Proceedings Repository \\ American Research Foundation}

ISSN 2476-017X

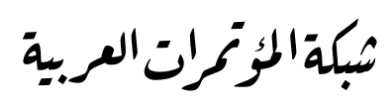

http://arab.kmshare.net/

Available online at http://proceedings.sriweb.org

المراجع العربية:

الزهراني، راشد بن سعيد. (2009-1430). التعاملات الالكترونية الحكومية في المملكة العربية السعودية، مكتبة

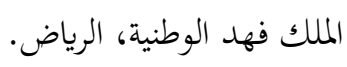

نديم، عفاف محمد، (1) • ب). حقوق الملكية الفكرية في العصر الرقمي بين الحماية القانونية والوصول العادل، الجلة

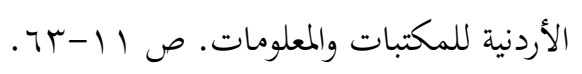

متاح على: دار المنظومة.

الشلبي، فراس سليمان والخوالدة، رياض عبد الله. (د ت). دور الحكومة الالكترونية في تعزيز الفاعلية التنظيمية دراسة حالة وزارة المالية الاردنية، دراسة مقدمة الى كلية عمان الجامعية، عمان: جامعة البلقاء التطبيقية. المبيضين، صفوان. (2011). الحكومة الإلكترونية النماذج والتطبيقات والتجارب الدولية. عمان: دار اليازوري العلمية للنشر والتوزيع.

قاسم، حشمت. (2007م). مدخل لدراسة المكتبات وعلم المعلومات، الطبعة الثانية، القاهرة: دار غريب. حمود، خضير كاظم. (2010). منظمة المعرفة، عمان: دار صفاء للنشر والتوزيع.

حجازي، عبد الفتاح بيومي. (2004). مقدمة في التجارة الالكتونية العربية، الكتاب الأول شرح قانون المبادلات والتجارة الالكتروني التونسي، الاسكندرية: دار الفكر الجامعي.

على، أممد. (2012). مفهوم المعلومات وإدارة المعرفة، مجلة جامعة دمشق-البلد 28 - العدد الأول 2012. مكليود، رإيموند وشيل، جورج. (2009). نظم المعلومات الادارية، ترجمه على سرور على ابراهيم سرور، القاهرة: دار

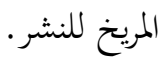

ياسين، سعد غالب والعلاق، بشير عباس. (2009). التجارة الالكترونية، عمان: دار المناهج للنشر والتوزيع. الشاطر، منير. (2018م). تقنية سلسلة الثقة (البلوك تشين) وتأثيراها في قطاع التمويل الإسلامي: دراسة وصفية. 
Global Proceedings Repository

American Research Foundation

ISSN 2476-017X

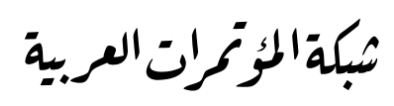

http://arab.kmshare.net/

Available online at http://proceedings.sriweb.org

صونية، حقاص. (2012م)، حماية الملكية الفكرية الأدبية والفنية في البيئة الرقمية في ظل التشريع الجزائري، دراسة ماجستير مقدمه لقسم المعلومات الالكترونية الافتراضية واستراتيجية البحث عن المعلومات، كلية العلوم الانسانية قسم المكتبات، جامعة منتوري، قسنطينة، الجزائر.

عبد الله، مصطفى حمد الله. (2010)، حماية حقوق الملكية الفكرية ومدى تاثيرها على امن المعلومات .المؤتر

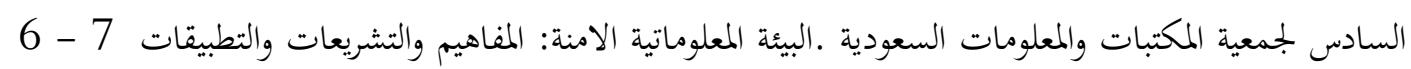

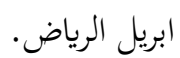
خليفة، ايهاب. (2018م). البلوك تشين: الثورة التكنلوجية القادمة في عالم المال والادارة، ورقة علمية صادرة عن مركز المستقبل للأبحاث والدراسات المتقدمة، ابوظبي، الامارات المتحدة.

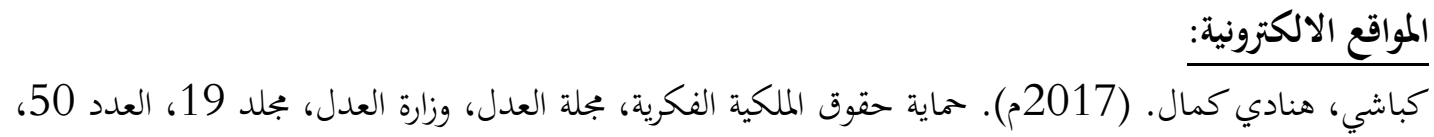

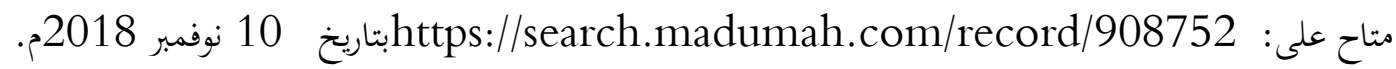

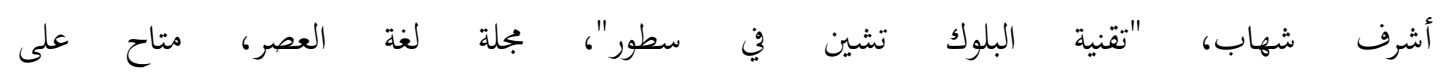
بتاريخ (2018/11/17 http://ahram.org.eg/news/87647.aspx

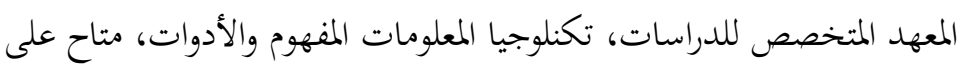
http://qu.edu.iq/el/plagingfile.php/87045/mod-resuoce-content/0

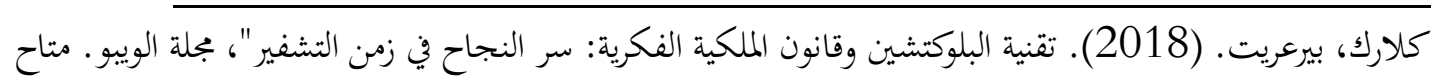

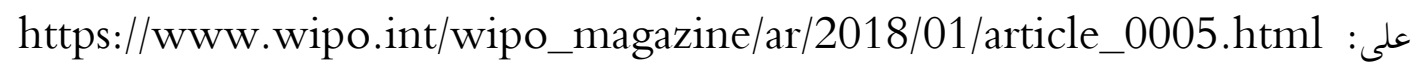

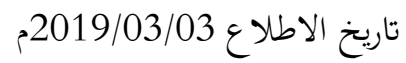

\section{المراجع الاجنبية:}

Daniel Conte de Leon, Antonius Q, and other. (2017)." Blockchain: properties and misconceptions", Asia Pacific Journal of Innovation and Entrepreneurship, Vol. 11 No. 3. pp. 286-300. APJIE 11,3. Available at: https://doi.org/10.1108/APJIE-122017-034 Permanent link to this document: https://doi.org/10.1108/APJIE-12-2017034 


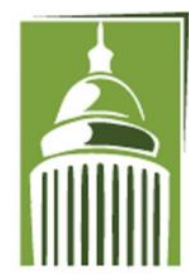

AR F
Global Proceedings Repository

American Research Foundation

ISSN 2476-017X

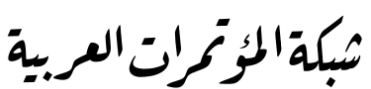

http://arab.kmshare.net/

Available online at http://proceedings.sriweb.org

Hassan, S and P De Filippi. (2017). The Expansion of Algorithmic Governance: From Code Is Law to Law Is Code, Field Actions Science Reports: The Journal of Field Actions Special, issue 17.

See Wei Dai, supra note 14; Wei Dai. (2019). BITCOINWIKI, https://perma.cc/NLE2-YM3Q (last visited Oct. 22, 2017); Wei Dai, THE BOOK OF BITCOIN,https://perma.cc/A935-B8RF (last visited APRIL. 22.

Nakamoto,S.(2008),Bitcoin:a peer-to-peer electronic cash system,available at: https://bitcoin.org/bitcoin .

Jake Goldenfein and Dan Hunter, (2017). Blockchains, Orphan Works, and the Public Domain, Columbia Journal of Law \& the Arts, Vol. 41, No. 1, 2017, Posted: 11 Dec 2017, Available At:https://ssrn.com/abstract=3083153.

Bikramaditya SinghalGautam DhamejaPriyansu Sekhar Panda,(2018).Beginning Blockchain A Beginner's Guide to Building Blockchain,, Apress Media LLC, California, Berkeley, CA,PAGE.

Bikramaditya Singhal Gautam Dhameja Priyansu Sekhar Panda .(2018).

Beginning Blockchain A Beginner's Guide to Building Blockchain,,Apress Media LLC , California, Berkeley, CA.

Debajani Mohanty, (2018). Ethereum for Architects and Developers,Apress Media LLC, California.

G. Ishmaev, (2017). Blockchain Technology as an Institution of Property, wiley online library Metaphilosophy / Volume 48, Issue 5. Cited by: 3 .AVIALBAL AT: https://doi.org/10.1111/meta.12277

Bikramaditya Singhal Gautam Dhameja Priyansu Sekhar Panda .(2018). Beginning Blockchain A Beginner's Guide to Building Blockchain,, Apress Media LLC , California , Berkeley, CA.

Daniel Drescher, (2017)."BLOCKCHAIN BASICS: A NON-TECHNICAL INTRODUCTION IN 25 STEPS, Springer Science+Business Media New York. Josep Lluis de la Rosa1, and another, (2017). A SURVEY OF BLOCKCHAIN TECHNOLOGIES FOR OPEN INNOVATION، ResearchGate. Available at:https://www.researchgate.net/profile/Lutz_Maicher/publication/321381169 A Survey of Blockchain Technologies for Open Innovation/links/5a1fccd9aca272cbfbc325cb/A-Survey-of Blockchain-Technologiesfor-Open Innovation.pdf?origin=publication detail.

Bal'azs Bodo', Daniel Gervais $\dagger$ and Jo ao Pedro Quintais, (2018). Blockchain and smart contracts: the missing link in copyright licensing, Oxford International Journal 


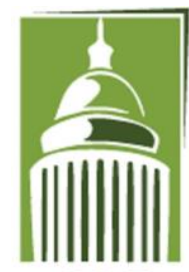

AR F
Global Proceedings Repository

American Research Foundation

ISSN 2476-017X

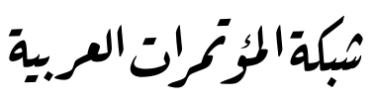

http://arab.kmshare.net/

Available online at http://proceedings.sriweb.org

of Law and Information Technology, VOLUM 26, ISSUE 4, WINTER 2018, PAGES 311-336. November,16. AVIALBE at:http://creativecom- mons.org/licenses/by/4.0. Shermin Voshmgir, And Valentin Kalinov,(2017), Blockchain A Beginners Guide .BlockchainHub. Version 1.0 Available at https://blockchainhub.net/. Miche`le Finck. Valentina Moscon, Copyright Law on Blockchains: Between New Forms of Rights Administration and Digital Rights Management 2.0.(2018).SpringerIIC - International Review of Intellectual Property and Competition Law January 2019, Volume 50, Issue 1.

Annabel Tresise, Jake Goldenfein and Dan Hunter,(2018)." What Blockchain Can and Can't Do for Copyright,Australian Intellectual Property Journal 144 .Electronic copy available at: https://ssrn.com/abstract=322738.

Maruti Techlabs,(2016.), Blockchain-benefits drawbacks and everything you need to know. AVIALBLE AT:https://www.marutitech.com/blockchain-benefits published on 18/11/2016 and has been updated on 20/11/2018

Alexander Savelyev,2018. Copyright in the blockchain era: Promises, challenges, Computer Law \&Security Review Volume 34, Issue 3, June 2018, Pages 550-561. Available AT: https://doi.org/10.1016/j.clsr.2017.11.008.

Don Tapscott.(2018). How the blockchain is changing money and Business, TED Summit, June 2016, accessible at: http:// bit.ly/2bp4XiI (Last accessed: February 5. EYAL MALINGER, Blockchain could 'Change Everything' for Real Estate, Venture Beat, November 18, 2017, accessible at:

https://venturebeat.com/2017/11/18/blockchain-could-change-everything-for-realestate/

An Analysis of the Opportunities and Threats in Blockchain Technology, Medium, February 13, 2017, accessible at:https://medium.com/the-mission/an-analysis-of-theopportunities-and-threats-in-blockchaintechnology-6f55d647be3e ( last accessed: February 15, 2018).

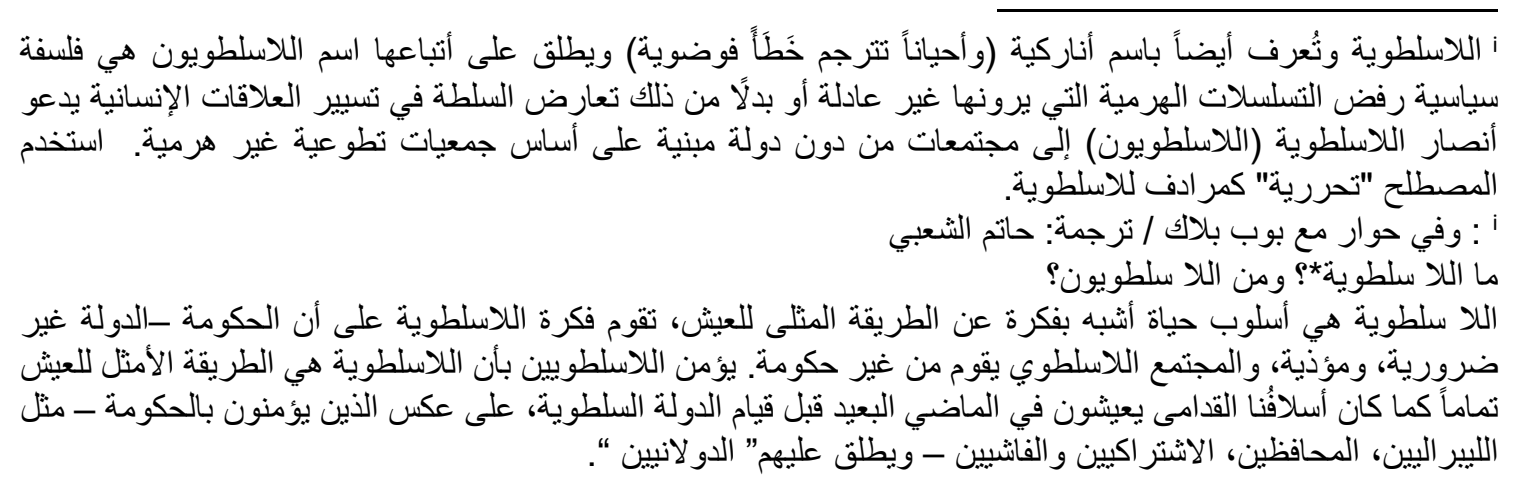




\section{Global Proceedings Repository \\ American Research Foundation}

ISSN 2476-017X

Available online at http://proceedings.sriweb.org

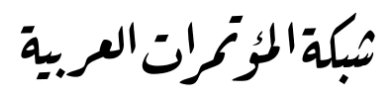

http://arab.kmshare.net/

ARF

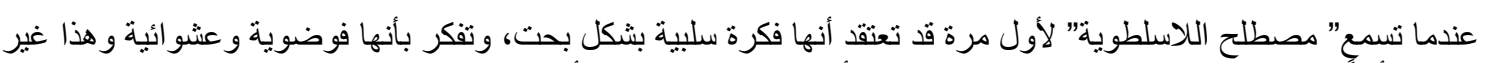

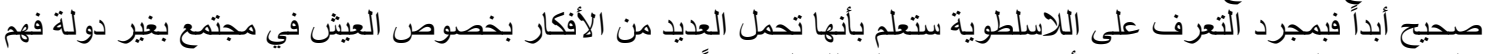

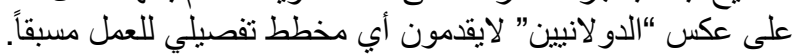

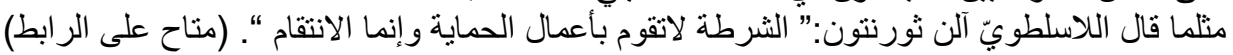
https://www.marxists.org/archive/malatesta/1930s/xx/toanarchy.htm

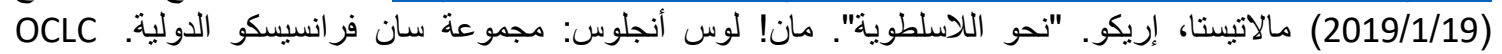

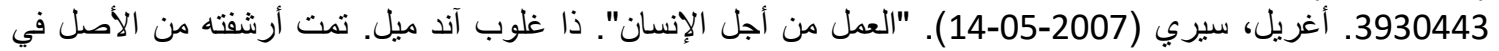

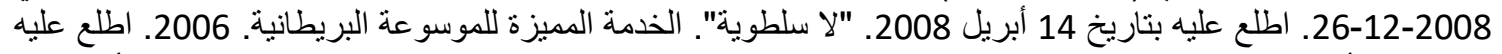

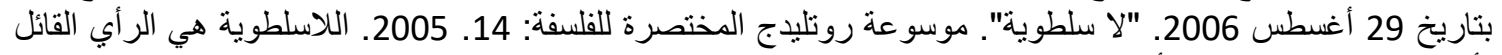

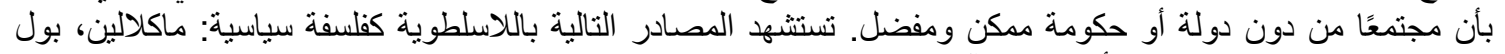

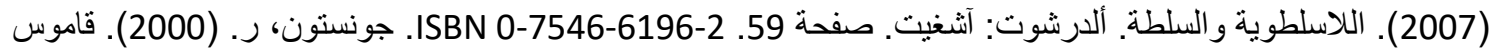

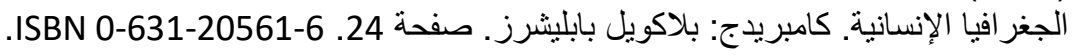

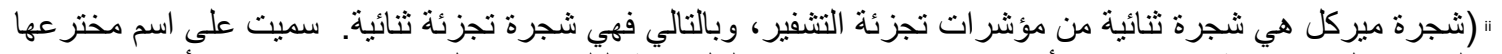

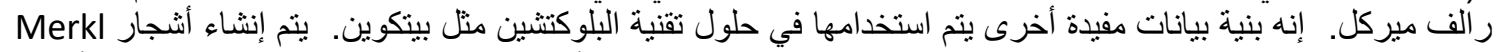

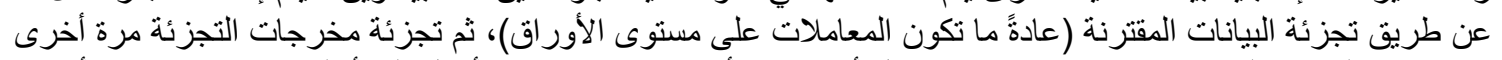

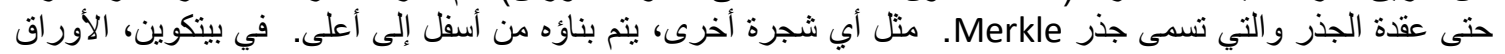

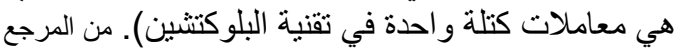

Bikramaditya SinghalGautam DhamejaPriyansu Sekhar Panda,(2018).Beginning Blockchain A Beginner's Guide to Building Blockchain,, Apress Media LLC, California , Berkeley, CA,PAGE 